\title{
Exploitation of synergistic effects between semiochemicals and Metarhizium brunneum against soil pests
}

\author{
Dissertation \\ zur Erlangung des Doktorgrades \\ der Fakultät für Agrarwissenschaften \\ der Georg-August-Universität Göttingen
}

vorgelegt von

Michael Albert Brandl

geboren in Kempten (Allgäu)

Göttingen, Mai 2016 
D7

1. Referent: Prof. Dr. Stefan Vidal

2. Referent: Prof. Dr. Anant Patel

Tag der mündlichen Prüfung: 13. Mai 2015 

Ich danke dir, Herr, mein Gott, von ganzem Herzen und ehre deinen Namen ewiglich.

Psalm 86,12 

Table of contents

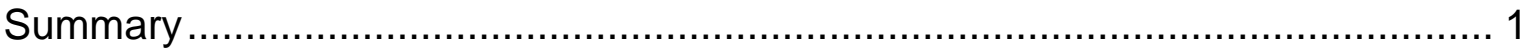

General introduction ................................................................................. 3

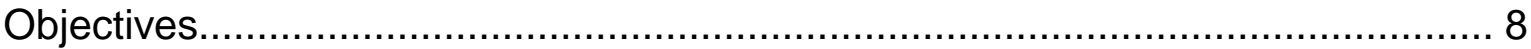

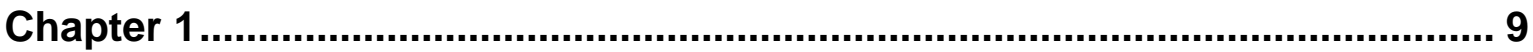

Screening of botanical extracts for repellence against western corn rootworm larvae

Chapter 2.

A stress-and-kill approach using a combination of turmeric and Metarhizium brunneum for western corn rootworm larval control

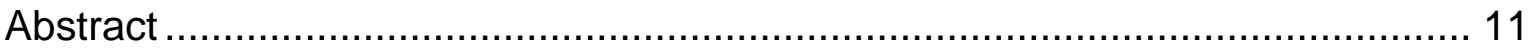

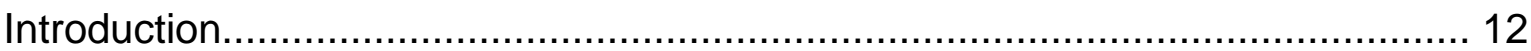

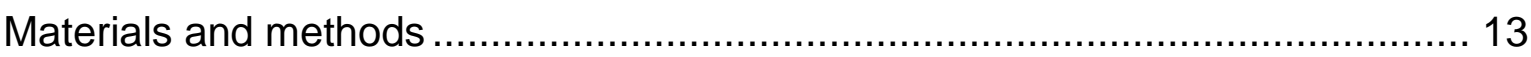

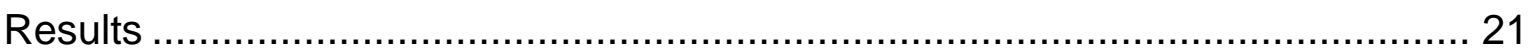

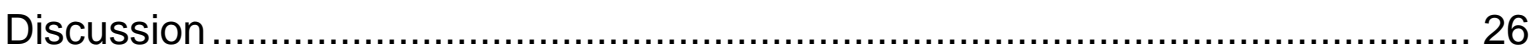

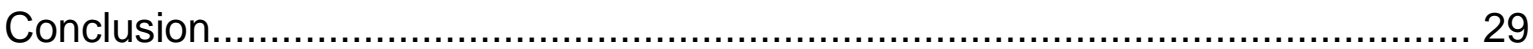

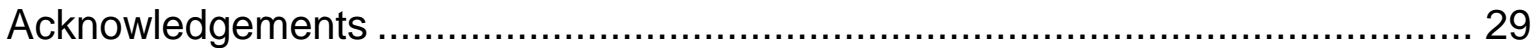

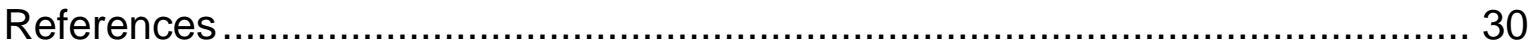

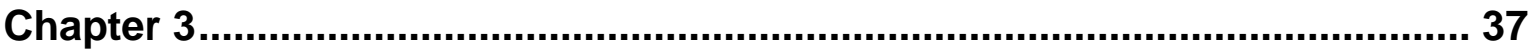

Wireworm damage reduction in potatoes with an attract-and-kill strategy using Metarhizium brunneum

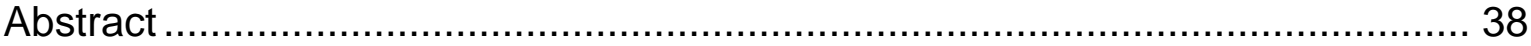

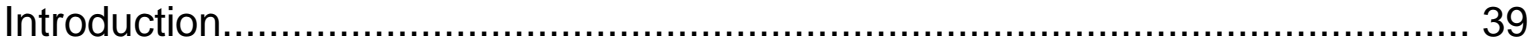

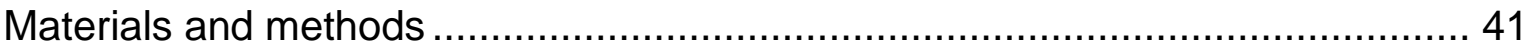


Results

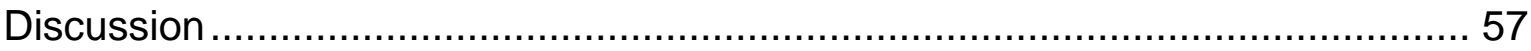

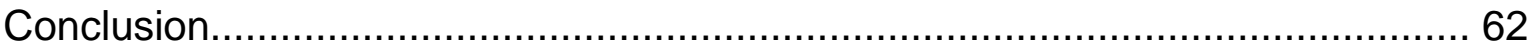

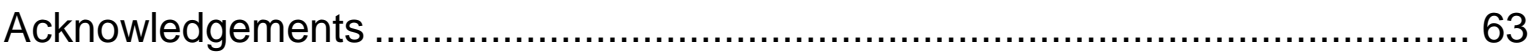

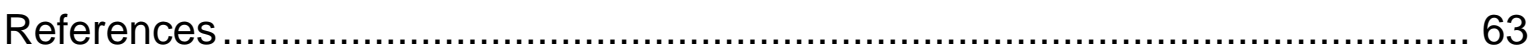

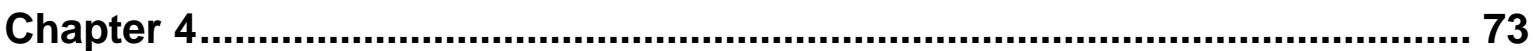

Technical attract-and-kill formulations for wireworm control with Metarhizium brunneum in potatoes

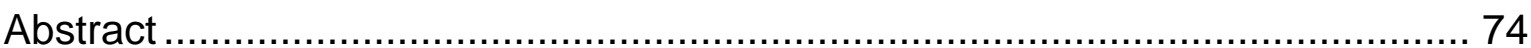

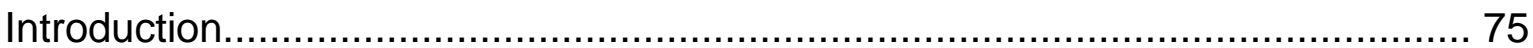

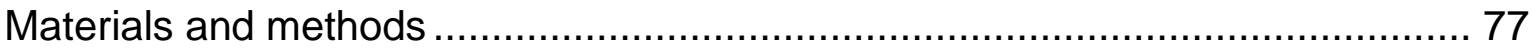

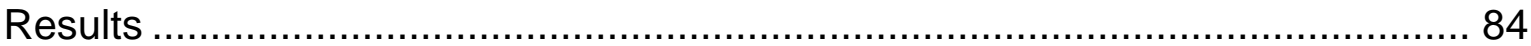

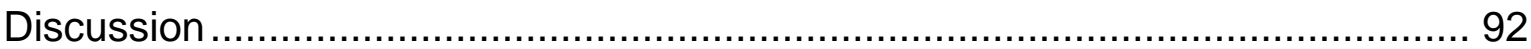

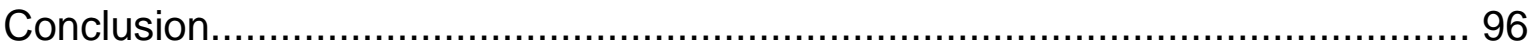

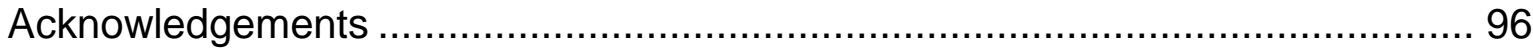

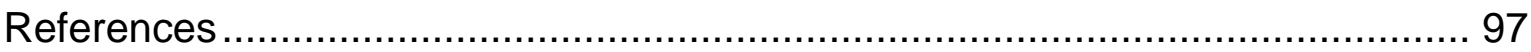

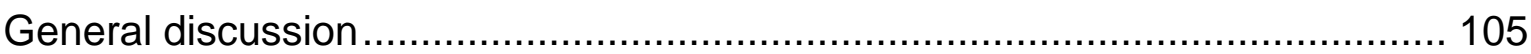

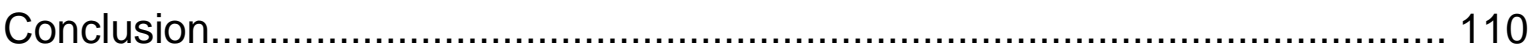

References: General introduction and general discussion .............................. 111

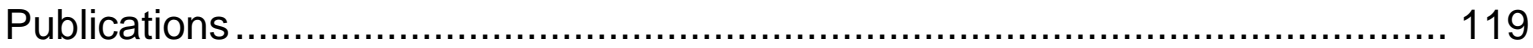

Acknowledgements / Danksagung .................................................................. 121 


\section{Summary}

Root-feeding insects, such as the larvae of the western corn rootworm (WCR), Diabrotica virgifera virgifera LeConte (Coleoptera: Chrysomelidae) and wireworms Agriotes spp. Eschscholtz (Coleoptera: Elateridae), the larvae of click beetles, are widely recognized as major soil pests, which influence agricultural productivity. Environmental concerns and a high risk of insecticide use as well as the lack of other efficient control options require new and effective strategies to target these pests. Two behavioral based control approaches, combining the use of the entomopathogenic fungus Metarhizium brunneum (Metschnikoff) Sorokin from the order Hypocreales (Ascomycota) and semiochemicals as efficacy enhancing agents, were tested to improve biological soil pest control. WCR larval control was evaluated with a "stress-and-kill" (SK) strategy in laboratory and greenhouse experiments using botanical repellents to increase the chance of contact and susceptibility with $M$. brunneum conidia. Wireworm control was tested with an "attract-and-kill" (AK) strategy in field and laboratory experiments, whereas the pest is lured towards $M$. brunneum conidia with an artificial carbon dioxide $\left(\mathrm{CO}_{2}\right)$ source as an attractant. Both strategies were conducted with different formulation techniques to improve shelf-life and practical feasibility for an application in the field.

1. The behavioral and spatial distribution changes of second instar WCR larvae were studied in no-choice tests conducted in Petri dish bioassays and rhizotron experiments to assess the most suitable botanical extract as a stressing agent.

a. Garlic and turmeric derived extracts were evaluated as the most promising extracts as WCR larvae avoided garlic / turmeric treated soil.

b. Turmeric evaluation in rhizotron experiments revealed WCR larval avoidance of turmeric soil up to $5 \mathrm{~cm}$ from its application point in the maize (Zea mays L.) root system resulting in an increased dispersal and larval movement in the soil.

c. Turmeric was therefore evaluated as a suitable "stressing" agent for WCR larvae 
2. The performance of a SK strategy against neonate WCR larvae was studied in maize planted small containers in the greenhouse to assess potential synergies between formulated $M$. brunneum conidia and turmeric.

a. Repellent effects of turmeric were demonstrated against neonate WCR larvae

b. Turmeric did not impact $M$. brunneum establishment and growth, excluding any negative side effects through turmeric's antifungal properties with a combination of both SK agents.

c. The application of wet $M$. brunneum formulated beads only or in combination with turmeric failed in larval control. SK is therefore not feasible for WCR control due to the lack of WCR larval control with M. brunneum alone.

3. The performance of an AK strategy against wireworms (Agriotes spp.) was studied under field conditions in organic potato fields across three field seasons. The first two field seasons looked into the interaction between $\mathrm{CO}_{2}$ and $M$. brunneum to evaluate the enhancement of wireworm control with $\mathrm{CO}_{2}$. Each $\mathrm{AK}$ agent was encapsulated in a wet bead and then tested as a co-application through the mixture of "attract" and "kill" beads. The third field season tested a wet and technical dry co-formulation with both AK agents encapsulated within one bead to examine a more practical AK formulation for farmers. The performance of AK agents was tested in different field soil types to assess $\mathrm{CO}_{2}$ emission and $M$. brunneum virulence and growth.

a. $\mathrm{CO}_{2}$ levels in soil increased significantly over $4-6$ weeks with an application of AK beads. M. brunneum virulence and growth was measured in all tested soil types, but was dependent on the type of AK bead used.

b. The combination of $\mathrm{CO}_{2}$ and $M$. brunneum enhanced wireworm control by up to $35 \%$ compared to a $M$. brunneum treatment alone, but only as a spot application underneath the seed potatoes. A band application of beads could enhance $M$. brunneum performance. A wet AK formulation, either as coapplication or co-formulation of AK components, performed better ( 48\%) than a dry AK co-formulation ( 25\%).

c. An AK approach can enhance wireworm control with $M$. brunneum but depends on the type of application and formulation of AK agents. It therefore requires further development to make this approach practical feasible for farmers. 


\section{General introduction}

Root-feeding insects are widely recognized as herbivores which can influence agricultural productivity. Their life-cycle is divided in a below-ground and an above-ground life stage which consists of oviposition, larval feeding in or on plant roots, pupation, adult flight and mating (Brown \& Gange, 1990). Root feeding occurs usually at the larval stage, which additionally tends to be relatively longlived (Johnson \& Rasmann, 2015). Thus, root-feeding insects are behaviorally as well as physiologically well adopted in the soil matrix as they frequently have to cope with and cannot rapidly disperse from unfavorable conditions in comparison to above-ground insects (Barnett \& Johnson, 2013). Insect movement in the soil seems to be dependent on body size whereas larger soil insects tend to borrow through the soil and smaller insects make use of existing channels, drought cracks and cavities (Brown \& Gange, 1990). Some insects may even use roots as an indirect pathway by burrowing or tunneling into the root tissue (e.g. Strnad \& Bergman, 1987).

These root-feeding larval stages of the western corn rootworm (WCR) Diabrotica virgifera virgifera LeConte (Coleoptera: Chrysomelidae) and click beetles Agriotes spp. Eschscholtz (Coleoptera: Elateridae), referred to as wireworms, are significant soil pests (Parker \& Howard, 2001, Gray et al., 2009). The WCR is an oligophagous (Branson \& Ortman, 1969), univoltine pest with an overwintering egg stage, larval hatch in spring and adult emergence beginning in June (Toepfer \& Kuhlmann, 2006). Root feeding of WCR larvae disrupts water and nutrient uptake of maize (Zea mays L.) (Kahler et al., 1985, Spike \& Tollefson, 1989) and, at high larval densities eventually leads to plant lodging (Spike \& Tollefson, 1991). Thus, significant yield losses of up to $30-50 \%$ in maize, depending on environmental conditions and population density, have been reported (Chiang et al., 1980). Wireworms in contrast, are polyphagous semivoltine species completing their life-cycle over two to four years with seven to nine larval instars (Vernon \& van Herk, 2013, Traugott et al., 2015). About 10,000 wireworm species are known worldwide with the predominant species causing economic damage in central Europe belonging to the genus of Agriotes spp. (Vernon \& van Herk, 2013). Damage occurs to multiple crops including potatoes (Solanum tuberosum L.) (e.g. Johnson et al., 2008), winter wheat (Triticum 
aestivum L.) (e.g. Vernon et al., 2009) and maize (e.g. Blot et al., 1999), to name but a few.

Although these two root-feeding insects have different life history traits, they both have to encounter host plant roots after larval hatch as well as throughout their lifetime to survive and mature during larval development as all other rootfeeding insects do. Such an encounter occurs not by chance but through the use of a broad range of semiochemical cues in the soil (Hiltpold \& Turlings, 2012). An encounter by chance, however, was the state of scientific knowledge on root herbivore behavior in the first half of the $20^{\text {th }}$ century; Thorpe et al. (1947) stated that burrowing through the soil matrix with the least resistance was the major trigger in larval movement, although they observed an attraction of wireworms (Agriotes spp.) by several isolated plant root components. This knowledge was revolutionized by Klingler (1957) and Doane et al. (1975) who proposed a direct response mechanisms towards semiochemical cues such as carbon dioxide $\left(\mathrm{CO}_{2}\right)$ sources by the black vine weevil (Otiorhynchus sulcatus F.) larvae and several wireworm species, respectively. Since then, it has been widely recognized that $\mathrm{CO}_{2}$, the most abundant gaseous root exudate in the soil, serves as a major attractant for root-feeding insects (Johnson \& Nielsen, 2012). Its low molecular weight might be of an additional advantage as it allows a rapid diffusion through the soil, making recognition over a long distance possible (Villani \& Wright, 1990, Pline \& Dusenbery, 1987).

Regarding the ubiquitous nature of $\mathrm{CO}_{2}$ in the soil through soil respiration (Lundegardh, 1927), Turlings et al. (2012) argued that $\mathrm{CO}_{2}$ may rather serve as a response activator for host plant location than a key attractant. This is due to the line of arguments that the presence of roots induces the presence of $\mathrm{CO}_{2}$, whereas the presence of $\mathrm{CO}_{2}$ does not necessarily induce the presence of roots.

Besides $\mathrm{CO}_{2}$, specific volatile and plant root metabolites are also emitted into the rhizosphere and bulk soil, comprising attractive and repellent properties, which may additionally be used for host-plant location (Wenke et al., 2010, Johnson \& Gregory, 2006). It is hypothesized that mono- and oligophagous rootfeeding insects (= WCR) depend on a combination of specific and general root metabolites, whereas polyphagous root-feeding insects (= wireworms) depend on the latter only (Jones \& Coaker, 1978). Once root-feeding insects have physically encountered their potential host-plant, contact chemosensory phagostimulants $(=$ 
predominantly primary compounds) and / or deterrents (= predominantly secondary compounds) come into play which elicit an acceptance or rejection behavior (Johnson \& Gregory, 2006). A conceptual model, regarding the chemically-mediated pathway of host-plant location and selection by root-feeding insects was proposed by Johnson \& Gregory (2006) and modified by Hiltpold \& Turlings (2012) (Fig. 1).

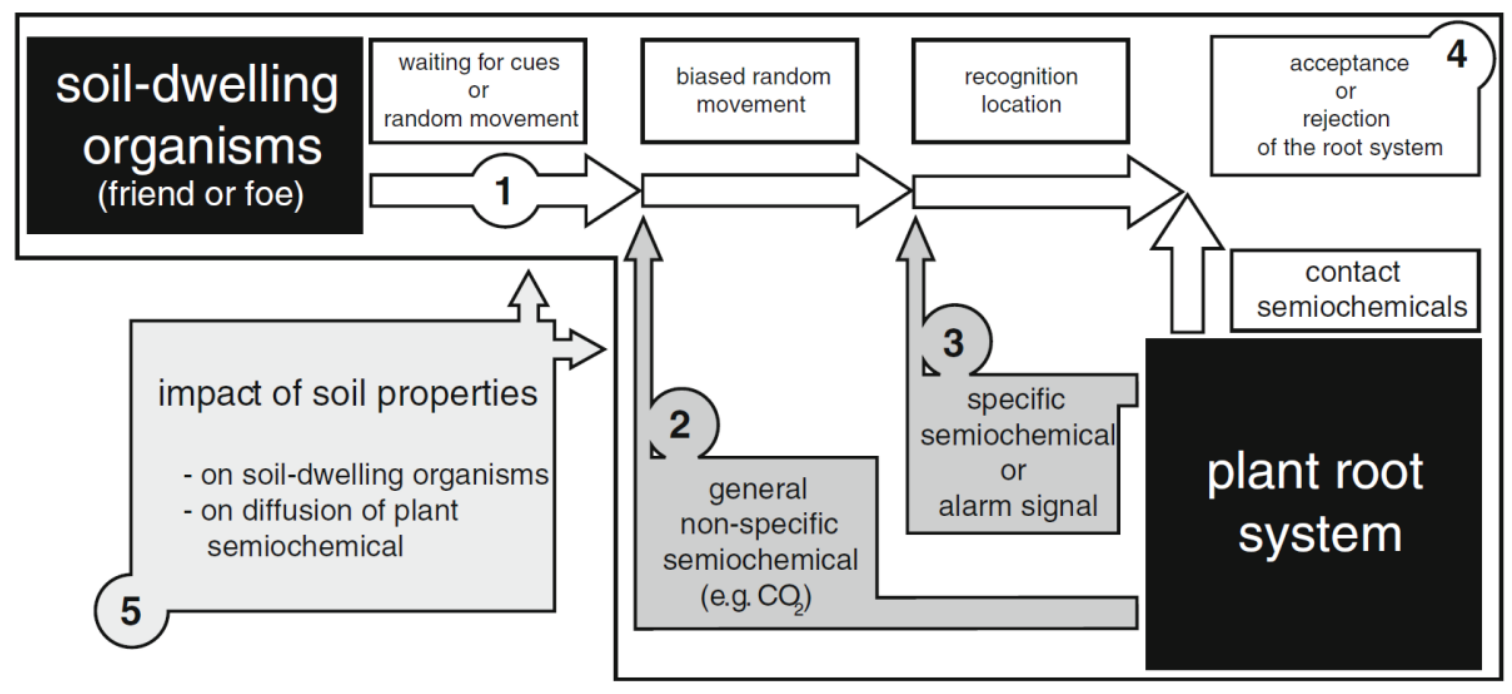

Fig. 1: Schematic illustration of a conceptual model for chemically-mediated pathway host location by soil-dwelling organisms (= root-feeding insects) (Hiltpold \& Turlings (2012).

If this conceptual model (Fig. 1) can be applied for a practical use, an interference at any of the suggested chemical signaling pathways offers great potential to control root-feeding insects due to their inability of host-plant location or acceptance (Hiltpold \& Turlings, 2012). The adoption of pathway interference, on the basis of a general non-specific semiochemical (Fig. 1) has been previously indicated by Bernklau et al. (2004), who demonstrated the potential properties of the ubiquitous gas $\mathrm{CO}_{2}$ as an attractant for WCR larvae, if exposed simultaneously to artificial $\mathrm{CO}_{2}$ sources and maize roots. They also observed the inability of WCR larvae to locate maize roots if exposed to baker's yeast (Saccharomyces cerevisiae Meyen ex Hansen), a $\mathrm{CO}_{2}$ generating source, when evenly mixed throughout soil in soil tub bioassays. Moreover, WCR larval host-plant location might be disrupted by interfering the recognition of specific semiochemicals (Fig. 1), given the above hypothesis for oligophagous root-feeding insects, such as 6Methoxy-2-benoxazoninone (MBOA), a benzoxazinoid for WCR larvae, released by growing maize seedlings (Bjostad \& Hibbard, 1992). 
The adoption from theory into practice has been recently approached by Vernon et al. (2015) who addressed an "attract-and-kill" strategy (AK) to control wireworms (Agriotes obscurus L., Melanotus spp. Eschscholtz) in potatoes by a companion planting of wheat seeds (Triticum aestivum L.) treated with fipronil and / or thiamethoxam. Thus, wireworms were lured to an attractant (= wheat seed) and consequently killed by the attendant insecticide, which improves concurrently the insecticidal efficacy (El-Sayed et al., 2009). Therein, a reduction of potato tuber damages ranging between $67-81 \%$ was achieved, which led to the assumption of a possible reduction of the required active ingredient (a.i.) compared to a conventional in-furrow application. As to that, Schumann et al. (2013) approached a similar AK strategy in maize planted rhizotron experiments for the control of WCR larvae using $\mathrm{CO}_{2}$ emitting beads, on the basis of $S$. cerevisiae, in combination with Force $1.5 \mathrm{G}$ (a.i.: tefluthrin). Thus, they observed an aggregation of larvae around $\mathrm{CO}_{2}$ beads as well as an increase of mortality by approximately $30 \%$ over a conventional application.

Besides the use of attractive semiochemicals to interfere the chemical signal pathway of host-plant location by root-feeding insects, the use of repellent compounds may also be taken into account. Those compounds have so far mainly been used for the control of above-ground insects (e.g. mosquitos) (Isman, 2006), but not specifically tested for root-feeding insects. Thus, little is known about repellents for root-feeding insects, albeit Hibbard \& Bjostad (1989) and Hibbard \& Bjostad (1990) reported of the organophosphate insecticide (a.i. fonofos) and fractions of germinating corn as repellent compounds for WCR larvae. Repellent compounds may induce stress situations for root-feedings insect due to the interference of host-plant location making the insect more susceptible to biological control agents (BCAs) such as entomopathogenic fungi (EPF) (Butt, 2002).

Root-feeding insect control takes a two-pronged approach if a manipulation of the chemically-mediated pathway of the host-plant is included. A successful behavioral manipulation may ensure crop protection, but does not reduce a rootfeeding insect population. This circumstance has particularly been taken into consideration for semivoltine species, such as wireworms, as they might damage subsequent crops. However, a potential circumvention might be the combination of semiochemical cues with insecticides or BCAs. With respect to the implementation of the (EC) No regulation 1107/2009 (European Parliament and the Council of the 
European Union, 2009b) and Directive 2009/128/EC (European Parliament and the Council of the European Union, 2009a) BCAs are of particular interest for the EU member states within the approach of an integrated pest management. Therein EPF gained increasing attention in recent years by researches (e.g. Kabaluk et al., 2005, Ericsson et al., 2007) and enterprises, reflected by 129 myconinsecticide registered and undergoing registration products in 2006 (de Faria \& Wraight, 2007). The option of in vitro mass production of infective propagules (e.g. aerial conidia) make EPF attractive for a commercial use (Jackson et al., 2010).

The EPF Metarhizium anisopliae (Metschnikoff) Sorokin sensu lato from the order Hypocreales (Ascomycota) (Bischoff et al., 2009) are of particular interest, due to their potential to control WCR (Pilz et al., 2007) and click beetle (Thomas, 1940) larvae. These fungi occur naturally in soil and rely on arthropod hosts to grow and spread, although saprophytic stages may also be involved (Meyling \& Eilenberg, 2007). The infection is initiated through an adhesion of conidia, followed by the development of a germ tube and an appressorium onto the external cuticle. Thus follows the formation of an infection peg, a penetration plate and penetrating hyphae to overcome the insect cuticle and a release of blastospores into the haemocoel. The death of the insect eventually results due to a combination of mechanical damage, nutrient exhaustion and toxicosis (Hajek \& St. Leger, 1994) (Fig. 2).

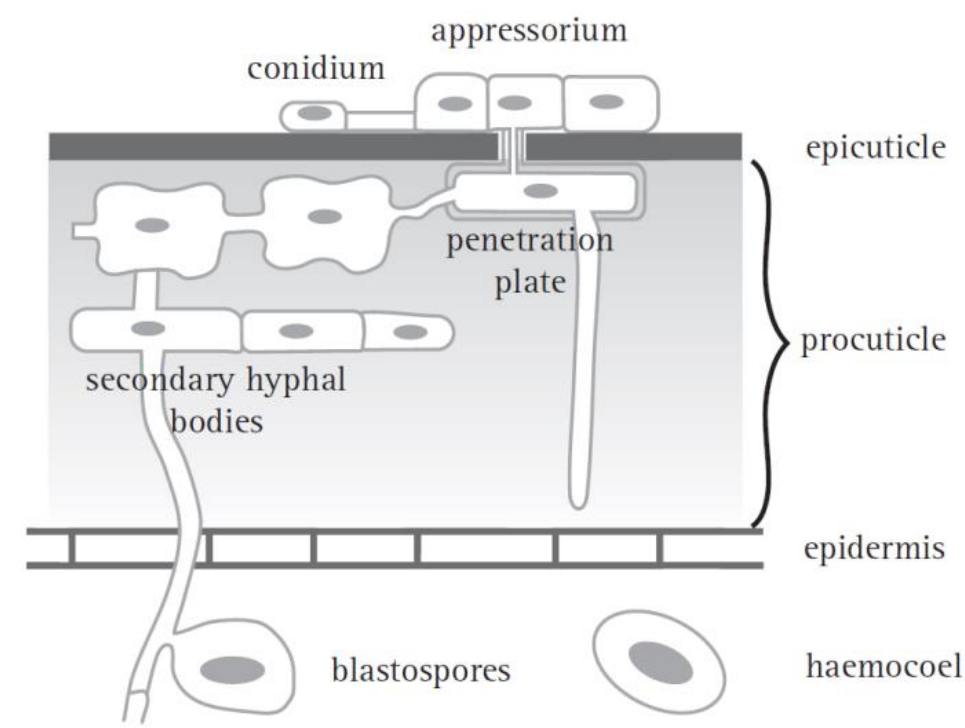

Fig. 2: Schematic representation of infection structures of Metarhizium spp. (Moore et al., 2011). 


\section{Objectives}

The present study aimed to develop novel strategies using sodium alginate formulations to control the larval stages of the western corn rootworm (Diabrotica virgifera virgifera LeConte) (WCR) and click beetles (Agriotes spp. Eschscholtz) (= wireworms) on the basis of the entomopathogenic fungus Metarhizium brunneum (Metschnikoff) Sorokin in combination with semiochemicals. WCR larval control was addressed with a "stress-and-kill" (SK) strategy in laboratory and greenhouse experiments combining turmeric (Curcuma longa L.) as a repellent extract (= stress) with encapsulated $M$. brunneum conidia (= kill). Wireworm control was addressed with an "attract-and-kill" (AK) strategy in field experiments through the combination of encapsulated baker's yeast (Saccharomyces cerevisiae Meyen ex Hansen) as a carbon dioxide attractant and encapsulated M. brunneum conidia (= kill) to reduce potato tuber damage.

1. Response mechanisms of WCR larvae exposed to botanical extracts (Chapter 1 \& 2)

a. Do botanical extracts comprise repellent properties against WCR larvae?

b. Can larval spatial distribution and behavior be altered with turmeric as a repellent botanical extract?

2. Evaluation of a SK strategy against WCR larvae (Chapter 2)

a. Does turmeric enhance the control of WCR larvae with encapsulated M. brunneum conidia?

b. Does turmeric affect $M$. brunnuem establishment in the soil?

3. Evaluation of an AK strategy against wireworms (Chapter $3 \& 4$ )

a. Do AK formulations build up carbon dioxide gradients over a sufficient time period to attract wireworms?

b. Do AK formulations build up sufficient $M$. brunneum spore densities in the field for wireworm control?

c. Does an AK strategy enhance wireworm control with $M$. brunneum in potatoes?

d. Are technical AK formulations practical feasible for wireworm control? 


\title{
Chapter 1
}

\section{Screening of botanical extracts for repellence against western corn rootworm larvae}

\author{
Michael A. Brandl ${ }^{\star}$, Mario Schumann, B. Wade French \\ and Stefan Vidal
}

${ }^{*}$ Corresponding author

This chapter is published in:

Journal of Insect Behavior (2016), Volume 29, Issue 4, pp 395 - 414

Please access via: http://link.springer.com/article/10.1007/s10905-016-9571-3

(c) Springer Science+Business Media New York 2016
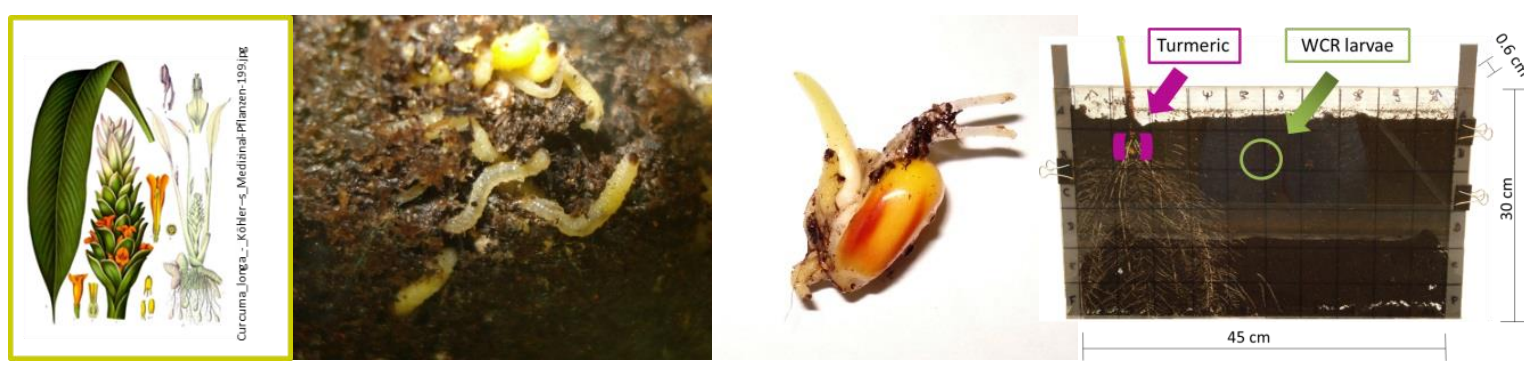
Chapter 2

\section{A stress-and-kill approach using a combination of}

\section{turmeric and Metarhizium brunneum for western corn}

\section{rootworm larval control}

Michael A. Brandl*, Mario Schumann, Michael Przyklenk, Anant Patel and Stefan Vidal

* Corresponding author

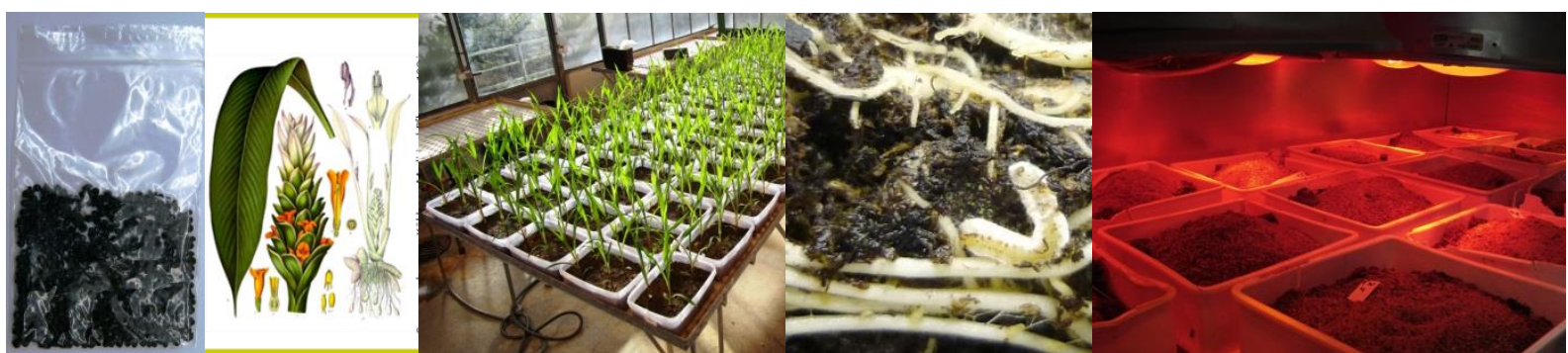




\title{
A stress-and-kill approach using a combination of turmeric and Metarhizium brunneum for western corn rootworm larval control
}

\author{
M. A. Brandl ${ }^{1}$, M. Schumann ${ }^{1}$, M. Przyklenk ${ }^{2}$, A. Patel $^{2}$ and S. Vidal ${ }^{1}$ \\ ${ }^{1}$ Georg-August-Universität, Department of Crop Sciences, Agricultural Entomology, \\ Grisebachstraße 6, 37077 Göttingen, Germany \\ ${ }^{2}$ University of Applied Sciences, WG Fermentation and Formulation of Biologicals and Chemicals, \\ Faculty of Engineering and Mathematics, Interaktion 1, 33619 Bielefeld, Germany
}

\begin{abstract}
The western corn rootworm Diabrotica virgifera virgifera LeConte (Coleoptera: Chrysomelidae) is a major pest in maize (Zea mays L.). Larval feeding causes severe damage to roots, leading to a disruption of nutrient and water uptake and lodging at high pest densities. Host-plant location mostly relies on semiochemical cues with carbon dioxide being the most common one. The present study investigated a "stress-and-kill" strategy using turmeric (Curcuma longa L.) as a stressor to disrupt host-plant location through repellence and enhance biological western corn rootworm larval control of the entomopathogenic fungus Metarhizium brunneum (Metschnikoff) Sorokin as a killing agent. A two choice bioassay was conducted in Petri dishes to assess the repellence of turmeric towards neonate western corn rootworm larvae. The stress-and-kill approach with a combination of turmeric and $M$. brunneum was tested in a greenhouse trial in small containers. M. brunneum conidia were encapsulated in sodium alginate as a carrier material. Neither the use of encapsulated $M$. brunneum only nor a combination with turmeric resulted in sufficient western corn rootworm larval control, despite measured turmeric repellence and $M$. brunneum growth. A stress-and-kill approach cannot enhance biological control with $M$. brunneum and requires further development to fully exploit its potential for western corn rootworm control.
\end{abstract}

Keywords: Diabrotica virgifera virgifera, Metarhizium brunneum, turmeric, stress-and-kill 


\section{Introduction}

The western corn rootworm (WCR), Diabrotica virgifera virgifera LeConte, (Coleoptera: Chrysomelidae) is a major pest of maize (Zea mays L.) causing yield losses and estimated costs for control of about $\$ 1$ billion and $\$ 472$ million annually in the United States and in Europe, respectively (Wesseler \& Fall, 2010, Metcalf, 1986). It is a univoltine species, which overwinters at the egg stage, larvae hatch in spring and adults emerge from the beginning of June in Europe and of July in the United States (Toepfer \& Kuhlmann, 2006, Levine \& Oloumisadeghi, 1991). Larvae and adults damage the plant by root and silk feeding, whereas mostly larval feeding results in economic losses (Meinke et al., 2009).

Traditional control strategies have failed in recent years as resistance to crop rotation through a fidelity loss in egg laying (Gray et al., 2009), insecticides (Wright et al., 2000) and genetically modified cultivars (Gassmann et al., 2011) has evolved in areas with high WCR pressure. This generates the need for biological control agents with the potential for large scale commercialization such as entomopathogenic nematodes and fungi (Ehlers, 2001, Zimmermann, 1993).

The entomopathogenic fungus (EPF) Metarhizium brunneum (Metschnikoff) Sorokin is a natural antagonist for a wide range of insects including the WCR (Pilz et al., 2008). Metschnikoff (1880) discovered the fungus on Anisoplia austriaca Herbst (Coleoptera: Scarabaeidae) and described it as the "green muscardine" disease based on its green colored conidia. Metarhizium spp. occurs ubiquitously in the soil at natural densities of about 1,000 colony forming units (cfu) / $\mathrm{g}$ soil (Scheepmaker \& Butt, 2010). EPF densities vary greatly, attributed to several factors such as land management (Meyling \& Eilenberg, 2007), geographical location (Bidochka et al., 1998) and soil type (Keller et al., 2003).

The use of EPF is traditionally based on an inundative biological control approach with a mass-release of conidia to control the targeted pest solely by the released conidia themselves (Eilenberg et al., 2001). A subsequent secondary cycling control through a horizontal infection with EPF progenies is, however, only partially successful (Thomas et al., 1995). Control variability originates through conidia inactivation within weeks after release (Fargues et al., 1983), through the exposure to various biotic and abiotic factors (Inglis et al., 2001) and host pest density dependence (Thomas et al., 1995). Frequent EPF applications, EPF coatings (e.g. clay; Fargues et al., 1983), sodium (Na)-alginate formulations (e.g. 
Pereira \& Roberts, 1991), or oil formulations (e.g. Xavier-Santos et al., 2011) are meant to increase conidia persistence and survival. EPF efficacy as well as the chances of a secondary cycling are therefore increased and may eventually evolve in an improved pest control.

EPF efficacy may additionally be enhanced, if target organisms are stressed as it increases their susceptibility towards an EPF infection (Butt, 2002). Stress conditions are generated by a stressor comprising any stimulus or succession of stimuli, which disrupt the normal homeostasis of an organism (Steinhaus \& Martignoni, 1970), including nutritional shortage, crowding effects, pesticide exposures and / or environmental conditions (Butt, 2002). Hiromori \& Nishigaki (2001) for instance, discovered synergistic effects with a combination of Metarhizium anisopliae (Metschnikoff) Sorokin and two insecticides (active ingredient (a.i.) fenitrothion / a.i. teflubenzuron = stressors), leading to an increased mortality of Anomala cuprea Hope larvae through weakening the host immune system. Botanical mixtures of compounds may also act as stressors in a combination with EPF. Previous results determined turmeric oil (Curcuma longa L.) as a repellent for second and third instar WCR larvae on the basis of induced behavioral and spatial alterations (Brandl et al., 2016).

The present study investigates turmeric repellence against neonate WCR larvae and exploits its synergy with $M$. brunneum (strain: BIPESCO5) encapsulated in a Na-alginate formulation to evaluate a "stress-and-kill" (SK) mechanism as a control option for WCR larvae.

\section{Materials and methods}

Turmeric repellence against neonate WCR larvae was assessed in the laboratory with two choice bioassays in soil filled Petri dishes (experiment 1). Three different concentrations were screened with the lowest concentration being used for a subsequent greenhouse trial (experiment 2). Small plastic containers were used to evaluate the combination of turmeric and $M$. brunneum on reducing WCR larval densities and plant damage. 


\section{WCR larvae}

WCR eggs from a non-diapausing strain (Branson, 1976) were obtained from the USDA-ARS North Central Agricultural Research Laboratory (Brookings, South Dakota, USA), which performs similar to the wild-type strains (Hibbard et al., 1999). Eggs were incubated upon arrival in the original shipped Petri dishes at $25^{\circ} \mathrm{C}$ and $65 \%$ relative air humidity $(\mathrm{RH})$ (Mytron $\mathrm{GmbH}$, Heiligenstadt, Germany). Soil was kept moist and egg development was monitored daily using a binocular microscope (Leica, Wild, M3Z, Wetzlar, Germany) until use in an experiment (details see below "experiment 1 and 2").

Eggs were incubated until larval hatch in experiment 1 and neonate larvae used in the experiment within 48 hours after hatch. In experiment 2 eggs were extracted from the soil seven days before the expected larval hatch and isolated from soil debris with tap water in a $250 \mu \mathrm{m}$-sieve (Retsch $\mathrm{GmbH}$, Haan, Germany). Adhering particles and non-viable eggs were removed in two steps on the basis of specific gravity differences with a magnesium sulphate solution (First step: $50 \mathrm{~g}$ $\mathrm{MgSO}_{4}$ / 1 I $\mathrm{H}_{2} 0$; second step: $437.5 \mathrm{~g} \mathrm{MgSO}_{4} / 1 \mathrm{I} \mathrm{H}_{2} \mathrm{O}$ ), as eggs with a high specific gravity $(1.10-1.17)$ are regarded as non-viable due to damage or low hatch quality (Palmer et al., 1976). Clean eggs were evenly distributed in a $0.15 \%$ agar suspension (Carl Roth $\mathrm{GmbH}$, Karlsruhe, Germany) and adjusted to a density of 100 eggs / $\mathrm{ml}$ agar solution by counting the number of eggs in ten $20 \mu$ droplets under a binocular microscope (M3Z, Leica, Wild, Wetzlar, Germany). The required egg density was inoculated in the soil of the small containers and the hatching date and rate were monitored by placing eggs in Petri dishes (diameter: $9 \mathrm{~cm}$; eight replications with 40 eggs / Petri dish) (Sarstedt AG \& Co., Nümbrecht, Germany) with wet filter papers (Schleicher \& Schuell GmbH, Dassel, Germany). Petri dishes were covered with a black cloth and placed between small containers in the greenhouse and checked daily under a binocular microscope (Leica, Wild, M3Z, Wetzlar, Germany). WCR larval hatch started 15 days after inoculation and lasted for 14 days. The overall hatching rate of larvae was $64 \%$.

\section{Turmeric}

Turmeric (Curcuma longa L.) oil extract was obtained from NeemBiotech Laboratory Units (Cardiff, United Kingdom) and stored in a cooling chamber $\left(6^{\circ} \mathrm{C}\right)$ until use. 
Metarhizium brunneum

The EPF, M. brunneum (strain BIPESCO5, originally isolated form Cydia pomonella (Zimmermann et al., 2013)), was provided by FYTOVITA spol. s.r.o. (Ostrozska Lhota, Czech Republic). M. brunneum conidia were encapsulated in spherical wet alginate beads (referred to as "EPF-beads" from herein), with the same method as Vemmer et al. (2016) encapsulated baker's yeast (Saccharomyces cerevisiae Meyen ex Hansen). Alginate beads (diameter: $2.7 \pm$ $0.2 \mathrm{~mm}$ ) were formulated by ionic gelation with $9.6 \times 10^{8}$ conidia $/ \mathrm{g}$ EPF-bead. The composition of beads was made up of sodium $(\mathrm{Na})$-alginate solution $(90 \%=$ $2 \% \mathrm{Na}$-alginate and $98 \%$ demineralized water) and EPF conidia (10\%), based on studies on bead composition (Przyklenk, M., 2016, personal communication). EPF-beads were stored in a cooling chamber at $6^{\circ} \mathrm{C}$ until use.

\section{Experiment 1}

A two choice bioassay was conducted with WCR neonates with three turmeric concentrations ("High": $2 \mu$ l turmeric / g peat soil, "Medium": $1 \mu$ l turmeric / g peat soil, "Low": $0.5 \mu$ l turmeric / g peat soil). The concentrations were based on preliminary dose-response bioassays using late second instar WCR larvae with 1 $\mu$ turmeric / g peat soil. This dose was calculated where no significant repellent effects were observed anymore (Brandl, M.A., unpublished results).

Petri dishes (diameter: $14 \mathrm{~cm}$ ) (Sarstedt AG \& Co., Nümbrecht, Germany) were filled with $50 \mathrm{~g}$ peat soil (Fruhstorfer Erde, Typ P25, Hawita Gruppe GmbH, Vechta, Germany) and moistened with $10 \mathrm{ml}$ tap water. Two maize seeds (cultivar: Ronaldinio, KWS SAAT SE, Einbeck, Germany) were placed on opposite ends at the margin of a Petri dish. Maize seeds were previously soaked in tap water for 24 $\mathrm{h}$ and pre-germinated on moistened paper towels (TORK, Mannheim, Germany) in a glass beaker (400 ml, DURAN Group GmbH, Wertheim / Main, Germany) for 48 h at $25^{\circ} \mathrm{C}$ and $65 \% \mathrm{RH}$ in an incubator (Mytron $\mathrm{GmbH}$, Heiligenstadt, Germany). Maize seeds with visible embryonic root growth (radical root $>1.5 \mathrm{~cm}$ ) were used in the experiment.

Treatments were applied across the soil surface on one half of the Petri dish ("treated section") using a PVC (Kistenpfennig AG, Mainz, Germany) template with eleven evenly distributed holes marking the spot for a treatment application. $A$ 
$9 \mu \mathrm{l}$ treatment solution was applied in each of the eleven marked spots (= $99 \mu \mathrm{l} /$ treated section) with a Multipette ${ }^{\circledR}$ (Eppendorf AG, Hamburg, Germany). Each treatment consisted of $0.5 \mu \mathrm{l}$ Tween ${ }^{\circledR} 80$ (Carl Roth $\mathrm{GmbH}$, Karlsruhe, Germany), the appropriate turmeric concentration (High, Medium, Low) and the corresponding amount of tap water to obtain a $99 \mu$ solution. Tap water was applied on the other half of the Petri dish ("non-treated section") with the same procedure as for the treated section. A "Tween" (Tween ${ }^{8} 80$ in treated and tap water in non-treated section) and "Control" (tap water in treated and non-treated section) treatment were setup in addition to the three turmeric treatments ( $N=12$ Petri dishes / treatment).

A small portion of peat soil in the center of the Petri dish was removed with a spatula and ten newly hatched neonate larvae were inserted with a fine brush (marten hair, 10 / 309 boesner Versandservice $\mathrm{GmbH}$, Witten, Germany). The soil was placed back in the Petri dish to cover larvae with soil. Petri dishes were closed with a lid and sealed with Parafilm $M \circledR$ (Bemis Company Inc., Neenah, USA) to prevent larval escape. Each lid contained a hole (diameter: $6 \mathrm{~cm}$ ) covered with gauze (Voile, 100\% polyester, mesh size: $0.25 \mathrm{~mm}$; Alfatex, Göttingen, Germany) to ensure aerial exchange. Petri dishes were randomly placed in a climate room (photoperiod: $16 \mathrm{~h} / 8 \mathrm{~h}(\mathrm{~L}: \mathrm{D})$; air temp. $25 \pm 3^{\circ} \mathrm{C}$ and $65 \pm 5 \% \mathrm{RH}$ ) and watered with $5 \mathrm{ml}$ tap water after $48 \mathrm{~h}$. After $72 \mathrm{~h}$ the number of WCR larvae in the treated and non-treated section was counted by splitting each section into four equally sized portions. Each portion was submerged in $800 \mathrm{ml}$ tap water to separate larvae from the soil with the floating technique (Montgomery et al., 1979). Maize seedlings and roots were dissected using a scalpel (B. Braun Melsungen AG, Melsungen, Germany) and examined for larvae under a binocular microscope (Leica, Wild, M3Z, Wetzlar, Germany).

\section{Experiment 2}

\section{Experimental set up}

The SK approach with a combination of EPF-beads and turmeric against WCR larvae was tested in a two choice greenhouse experiment $\left(22 \pm 5^{\circ} \mathrm{C}\right.$ and $45 \% \mathrm{RH})$ in plastic containers (33 x $21.5 \times 12.5 \mathrm{~cm}$; Gies $\mathrm{GmbH}$ \& Co Kunststoffwerk KG, Niedersaula, Germany). Seven evenly distributed holes were 
drilled at the bottom of each plastic container (diameter: $0.7 \mathrm{~cm}$ ) to avoid waterlogging and covered with gauze (Voile, 100\% polyester, mesh size: $0.25 \mathrm{~mm}$; Alfatex, Göttingen, Germany) to prevent larval escape. Each container was split into two halves (= sections) and treated with either EPF-beads ("Mb"), turmeric (" $T$ ") or a combination of both (“Mb+T") in one section (“Mb 1/2", " $T$ 1/2", " $M b+T$ $1 / 2$ ') or in both sections (“Mb 1/1", " $T 1 / 1$ ", " $M b+T 1 / 1$ ") of the container and with EPF-beads and turmeric in either section ("Mb vs. $T$ 1/2"). A treatment with two non-treated sections served as the "Control" ( $N=10$ containers / treatment).

\section{Treatment preparation}

Field (sand: $7.90 \%$, silt: $71.78 \%$, clay: $20.32 \%$ ) and peat soil (Fruhstorfer Erde, Typ P25, Hawita Gruppe $\mathrm{GmbH}$, Vechta, Germany) were mixed at a ratio of 1:1 and steam sterilized (Steba Elektrogeräte $\mathrm{GmbH}$ \& Co. KG, Typ 250K1, Elektro-Futterdämpfer, Strullendorf, Germany) prior to use in the experiment. The corresponding soil volume of a container section (4.4 liters) was filled in plant pots $(16.5 \times 16.5 \times 15 \mathrm{~cm})$ for treatment preparation and transferred to the container after 13 days. All plant pots were regularly watered until transfer to the container. Pots with soil for an EPF-bead treatment were prepared by soil transfer into a bucket (diameter: $28 \mathrm{~cm}$, depth: $30 \mathrm{~cm}$ ), treated with $10 \mathrm{~g}$ EPF-beads $\left(=2.5 \times 10^{15}\right.$ conidia ha ${ }^{-1} / 3.0 \times 10^{6}$ conidia $^{-1}$ soil) and evenly mixed by hand for $10 \mathrm{~s}$ to create a homogenous distribution in the soil. Thereafter the treated soil was placed back into plant pots. EPF-beads were applied on the same day when the soil mixture was filled into the plant pots to allow EPF establishment prior to transfer into the small containers.

Pots with soil for a turmeric treatment and the control pots were left untreated until the day it was transferred to the small container. The turmeric emulsion was prepared as described in experiment 1 with the same proportion of tap water, Tween® 80 , and turmeric. Plant pots were treated with a $1 \mathrm{ml}$ turmeric emulsion using a pipette (Pipetman, Gilson, Inc., Middleton, USA; corresponding to the Low dose of experiment 1: $0.5 \mu$ turmeric / $\mathrm{g}$ soil) and homogenously distributed in the soil with the same method as described for an EPF-bead application. Non-treated soil served as a control half (= section). When soil was transferred, each container was divided into two halves (= sections) with a PVC (Kistenpfennig AG, Mainz, Germany) template and the soil from a pot was 
carefully emptied into its corresponding section. The PVC template was removed after each section was filled and ensured that treatments of two soil sections would not get mixed during soil transfer.

\section{Maize and WCR eggs}

Maize seeds (cultivar: Ronaldinio, KWS SAAT SE, Einbeck, Germany) were sown in multiport trays with the same soil mixture as used for treatment preparation (diameter: $4.7 \mathrm{~cm}$, depth: $5.5 \mathrm{~cm}$ ) and transferred to a container on the same day than the treated soil from the plant pots $(\mathrm{BBCH} 11$; Lancashire et al., 1991). The adhering soil on the root system was removed by carefully shaking the plant. Two maize plants were planted in each section at 7.5 and $17 \mathrm{~cm}$ distance between plants in one and both sections, respectively. 50 WCR eggs were inoculated in $5 \mathrm{~cm}$ soil depth halfway between two maize plants of both sections (= $8.5 \mathrm{~cm}$ distance from each plant; 100 eggs / container). Maize plants were watered daily and fertilized weekly with $0.3 \%$ Hakaphos ${ }^{\circledR}$ Blau (COMPO Expert, Münster, Germany).

\section{Assessment of WCR larvae, plant growth and M. brunneum}

The experiment was terminated 21 days after the first larval hatch just before pupation set in to fulfil quarantine regulations in Germany. Maize plants were cut $2-3 \mathrm{~cm}$ above the soil surface, stored in paper bags $(22 \times 32 \mathrm{~cm})$, dried in a heating cabinet (Memmert $\mathrm{GmbH}+\mathrm{Co}$. $\mathrm{KG}$, Schwabach, Germany) at $60^{\circ} \mathrm{C}$ for $96 \mathrm{~h}$ and weighed (Scale: PEJ 4200-2M, Kern \& Sohn, Balingen, Germany) to assess dry above-ground plant biomass for each container section. This parameter was used as an alternative to the node-injury scale (Oleson et al., 2005) as root damage assessment after larval heat extraction (see below) was not possible. Thus reflecting WCR larval root damage on shoot characteristics (Riedell, 1989) due to high larval density for $\mathrm{BBCH} 12$ / 13 at hatch. Larval density in each container section was assessed by isolating larvae from the soil with a heat extraction at $60^{\circ} \mathrm{C}$ for $72 \mathrm{~h}$ in an adapted Kempson chamber (Kempson et al., 1963). The number of extracted WCR larvae were counted and stored in $70 \%$ ethanol $\left(\mathrm{C}_{2} \mathrm{H}_{6} \mathrm{O}\right)$.

M. brunneum establishment was analyzed by re-isolating conidia from the soil on a selective medium to estimate the colony forming units (cfu) / g soil. Two 
soil samples in the treated section of a single container were taken with a cylindrical soil core sampler (diameter: $1.8 \mathrm{~cm}$ ) along the entire $10 \mathrm{~cm}$ soil depth in treatment Control, Mb 1/2 and Mb+T 1/2. Soil samples were placed in Zip-lock ${ }^{T M}$ plastic bags $(13 \times 8 \mathrm{~cm})$ and stored in a cooling chamber $\left(6^{\circ} \mathrm{C}\right)$. M. brunneum isolation was done within two weeks after soil sampling using the plate pouring method (Jürg Enkerli, personal communication, ISS Agroscope, Zürich, Switzerland). Soil samples were sieved with a $5 \mathrm{~mm}$-sieve (Retsch $\mathrm{GmbH}$, Haan, Germany), $5 \mathrm{~g}$ of sieved soil weighed into $50 \mathrm{ml}$ Falcon tubes (Sarstedt AG \& Co., Nümbrecht, Germany) and suspended in $25 \mathrm{ml}$ sterile water with $0.1 \%$ Tween $80 \AA$. Falcon tubes were inverted seven times every 30 min to release $M$. brunneum propagules from the soil matrix (Inglis et al., 2012). $100 \mu$ l of the supernatant was pipetted (Eppendorf AG, Hamburg, Germany) on semi-selective media (Strasser et al., 1996) in Petri dishes (diameter: $9 \mathrm{~cm}$ ) (Sarstedt AG \& Co., Nümbrecht, Germany) and spread with a Drigalski spatula. Petri dishes were sealed with Parafilm® and incubated in a dark climate cabinet (Mytron $\mathrm{GmbH}$, Heiligenstadt, Germany) at $25^{\circ} \mathrm{C}$ for 14 days to enhance fungal growth. The number of cfu present were counted and identified on genus level $(=M$. brunneum sensu lato (s.I.)) based on morphological criteria (Humber, 2012) with light microscopy (500X magnification, BH2-HLSH, Olympus Corporation, Tokyo, Japan).

Virulence of EPF-beads was also verified with the Galleria bait method (Zimmermann, 1986) at the same time. Small plastic containers $(10 \times 7 \times 5 \mathrm{~cm})$ were filled with a $30 \mathrm{~g}$ soil mixtures of peat soil (Fruhstorfer Erde, Typ P25, Hawita Gruppe GmbH, Vechta, Germany) and vermiculite (diameter: 2 - $8 \mathrm{~mm}$, ethnoshop24.de, thinex new media, Dortmund, Germany) at a ratio of 5:1 and moistened with $8 \mathrm{ml}$ tap water using a pipette (Eppendorf AG, Hamburg, Germany). Plastic container lids were perforated with ten holes each, to ensure aerial exchange. An EPF treatment "Mb" with $3 \mathrm{~g}$ EPF-beads evenly mixed into the soil and an untreated "Control' was set-up. Five mealworm (Tenebrio molitor L.) larvae (length: $1.7-2.5 \mathrm{~cm}$ ) were inserted in each container and six replicates (= containers) were set up for each treatment. The small plastic containers were placed at $25^{\circ} \mathrm{C}$ in a dark climatic cabinet (Mytron $\mathrm{GmbH}$, Heiligenstadt, Germany) to enhance fungal outgrowth of EPF-beads. Virulence assessment was conducted twice, 7 and 12 days past insertion (dpi) of EPF-beads and mealworms, as all 
mealworm larvae in the $M b$ treatment were regarded as dead at the second assessment date. Dead mealworms with no visible mycosis were surface sterilized (Lacey \& Solter (2012) using ethanol $\left(\mathrm{C}_{2} \mathrm{H}_{6} \mathrm{O}\right)(70 \%)$ and sodium hypochlorite $(\mathrm{NaOCl})(1 \%)$ and placed into moist chambers (Petri dish (Sarstedt AG \& Co., Nümbrecht, Germany); diameter: $5.5 \mathrm{~cm}$ with autoclaved moist filter paper (Schleicher \& Schuell GmbH, Dassel, Germany)) to speed up a potential mycosis.

\section{Statistical analysis}

The number of WCR larvae extracted from the soil, roots and seedlings by hand in experiment 1 or through a Kempson extraction procedure in experiment 2, were termed as "recovered larvae". Data on total larval recovery per treatment were analyzed using one-way ANOVA with the number of larvae recovered as the dependent and treatments as the independent variable. Differences between treatments were tested with a Tukey HSD test $(\alpha=0.05)$. The abundance of recovered WCR larvae within the treated section and the non-treated section of both experiments is given as a percentage of the number of total recovered larvae (= \% recovered larvae). Pairwise comparison of \% recovered larvae in a treated section and a non-treated section were tested with Wilcoxon paired-sample test ( $\alpha$ $=0.05)$ or a paired-sample t-test $(\alpha=0.05)$ when paired differences were normally distributed. In experiment 2 one container from the $M b$ vs. T 1/2 treatment was excluded from the analysis as a higher number of WCR larvae were extracted than numbers of eggs were originally applied.

The above-ground dry biomass per plant of a container (i.e. averaged across 4 plants) was analyzed between treatments with a one-way ANOVA. Dry biomass per plant of a container section (i.e. averaged across 2 plants) was tested with a paired-sample t-test within each treatment between a treated and a nontreated section.

The numbers of cfu / g soil was assessed with the non-parametric KruskalWallis test $(\alpha=0.05)$, followed by a multiple comparison test on ranks between treatments ( $R$ package pgirmess, function kruskalmc Giraudoux, 2015). EPF virulence in mealworms was assessed with a contingency table test. The number of occurrences in the virulence test were pooled across replicates and dates, and arranged in a $2 \times 2$ contingency table. Occurrences refer to the frequencies of mealworms being categorized as "alive" or "dead" (columns) within treatment 
Control and Mb (rows). A Pearson's chi-squared analysis with a Yates' continuity correction was conducted to assess independency (null hypothesis) of categorical frequencies.

All values are presented as the mean \pm standard error. All analyses were done using R, version 3.0.2 (R Development Core Team, 2013). Graphs were created with SigmaPlot, version 11.0 (Analytical Software, Tallahasee, FI, USA).

\section{Results}

\section{Experiment 1}

The total number of WCR larvae recovered differed significantly between treatments $\left(F_{4,55}=3.16 ; p<0.05\right.$, one-way ANOVA $)$ and was significantly higher in the Control $(7.08 \pm 0.58)$ than in the Medium $(4.50 \pm 0.61)$ treatment. No differences were detected between the Control and Low (5.50 $\pm 0.42 ; p=0.23$ ), High (6.08 $\pm 0.55 ; p=0.67)$ and Tween $(6.08 \pm 0.48 ; p=0.67)$ treatment. The $\%$ of recovered larvae was significantly higher in the non-treated section ( $>85 \%$ of recovered larvae) than in the treated section $(<15 \%)$ in all turmeric treatments (Wilcoxon rank sum test; Low: $\mathrm{W}=0.5, \mathrm{p}<0.001$; Medium: $\mathrm{W}=3, \mathrm{p}<0.001$; High: $\mathrm{W}=0, \mathrm{p}<0.001)$ and did not significantly differ in the Control $(\mathrm{t}=-1.47, \mathrm{df}=$ $11, p=0.17$, paired $t$-test $)$ and Tween $(t=1.51, d f=11, p=0.16$, paired t-test) treatment $(41-59 \%$ on either side) (Fig. 1). 


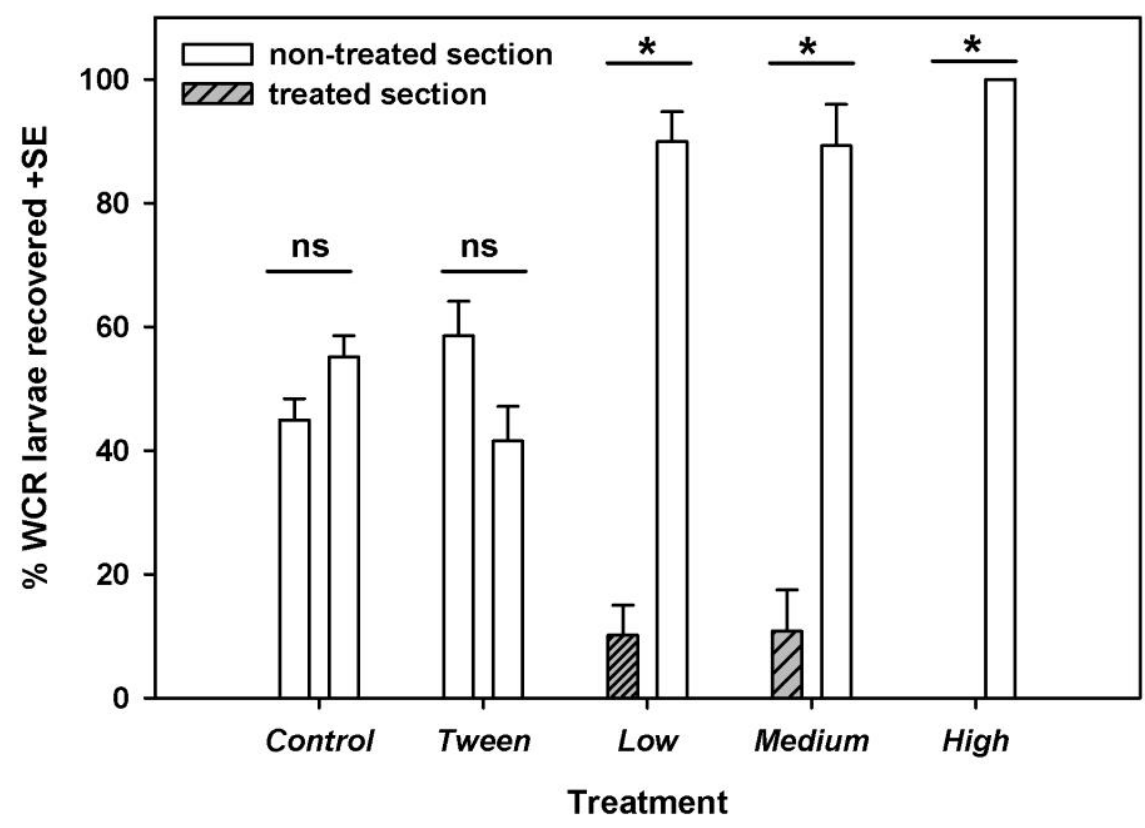

Fig. 1: Two choice bioassay (Experiment 1): WCR larval abundance in $\%$ of larvae recovered in a turmeric treated and non-treated section at three application rates (Low. $0.5 \mu \mathrm{l} /$ Medium: $1 \mu \mathrm{l} / \mathrm{High}: 2 \mu \mathrm{l}$ turmeric oil per gram soil) against a non-treated Control and Tween ${ }^{\circledR}\left(0.5 \mu \mathrm{l} /\right.$ treated section). Asterisks $\left(^{*}\right)$ above standard error (SE) bars indicate significant differences in larval recovery at $p<0.05$ (paired t-test / Wilcoxon rank sum test); ns: not significant.

\section{Experiment 2}

The $\%$ of recovered larvae did not significantly differ between the two sections in the container in the non-treated Control $(\mathrm{W}=30.5, \mathrm{p}=0.15$, Wilcoxon rank sum test) and treatments with two treated sections (paired t-test: $M b 1 / 1: t=$ 0.53, $\mathrm{df}=9, \mathrm{p}=0.61 ; T 1 / 1: \mathrm{t}=0.43, \mathrm{df}=9, \mathrm{p}=0.68, ; \mathrm{Mb}+T$ 1/1: $\mathrm{t}=-0.07, \mathrm{df}=9$, $\mathrm{p}=0.95$ ) (Fig. 2a). In treatments with one treated section the \% of recovered larvae was significantly lower in a turmeric treated section (paired t-test: $T$ 1/2: $\mathrm{t}=$ 2.70, $\mathrm{df}=9, \mathrm{p}<0.05$, ) and significantly higher in an EPF-bead treated section (paired t-test: $t=2.59, \mathrm{df}=9, \mathrm{p}<0.05$ ) than in the respective non-treated section (Fig. 2a). The \% recovered larvae did not significantly differ between a treated and non-treated section when turmeric and EPF-bead treatments were combined (paired t-test: $M b+T 1 / 2: \mathrm{t}=-0.62, \mathrm{df}=9, \mathrm{p}=0.55$ ), neither did they differ when turmeric and EPF-beads were applied in each section separately (paired t-test: $M b$ vs. $T$ 1/2: $\mathrm{t}=-0.67, \mathrm{df}=8, \mathrm{p}=0.52$ ) (Fig. 2a). The total number of recovered larvae from both sections of the containers did not significantly differ between treatments $\left(F_{7,71}=1.24, p=0.29\right.$, one-way ANOVA) (Fig. $\left.2 b\right)$. 

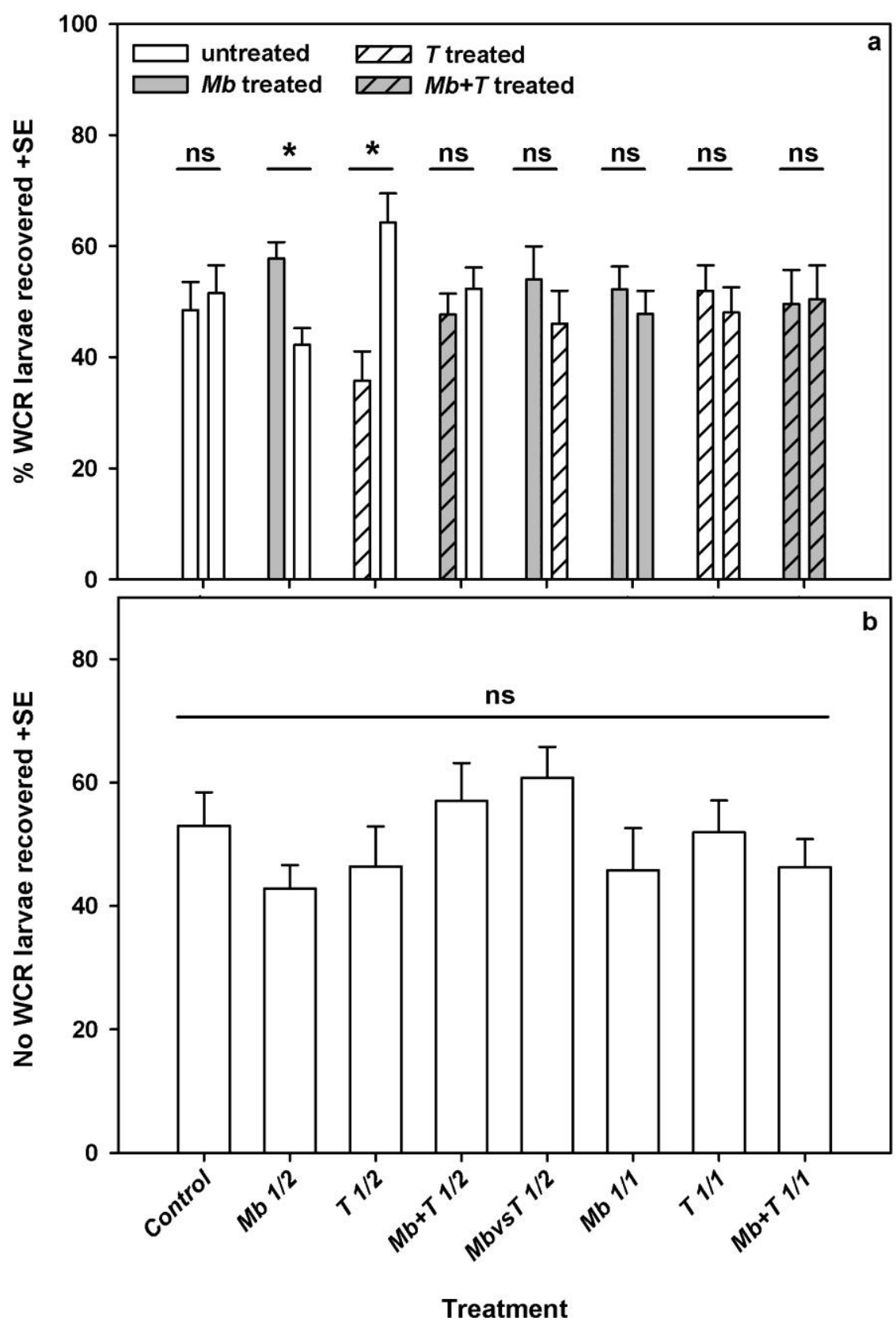

Fig. 2: Choice-test container (Experiment 2): a) WCR larval abundance in \% of recovered larvae (+ standard error (SE)) in a container half (= section) with a treatment application in one (1/2) or two sections (1/1). Treatments: non-treated Control, Mb: EPF-beads (encapsulated Metarhizium brunneum (strain: BIPESCO5) conidia), T: Turmeric oil, Mb+T: EPF-bead and turmeric oil combination, Mb vs. $T$ (= MbvsT): EPF-bead versus turmeric oil. Asterisks above standard error (SE) bars indicate significant differences in larval abundance at $p<0.05$ (paired-t test / Wilcoxon paired-sample test); ns: not significant. b) Total number of WCR larvae (+SE) recovered in a section (1/2) and full (1/1) treated containers. One-way ANOVA, ns: not significant. 
The pairwise comparison of plant dry biomass between the two sections did not result in any significant differences within all treatments (paired t-test: Control: $t$ $=-1.03, \mathrm{df}=9, \mathrm{p}=0.33 ; M b 1 / 2: \mathrm{t}=-0.58, \mathrm{df}=9, \mathrm{p}=0.57 ; T 1 / 2: \mathrm{t}=-0.99, \mathrm{df}=9$, $\mathrm{p}=0.34 ; M b+T$ 1/2: $\mathrm{t}=0.75, \mathrm{df}=9, \mathrm{p}=0.47 ; M b 1 / 1: \mathrm{t}=2.11, \mathrm{df}=9, \mathrm{p}=0.06 ; T$ 1/1: $\mathrm{t}=-0.58, \mathrm{df}=9, \mathrm{p}=0.57 ; M b+T$ 1/2: $\mathrm{t}=0.89, \mathrm{df}=9, \mathrm{p}=0.39)$, except for $M b$ vs. $T 1 / 2(\mathrm{t}=-6.83, \mathrm{df}=9, \mathrm{p}<0.01$, paired t-test) (Fig. 3a). The average plant dry biomass / container did not significantly differ between treatments $\left(F_{7,72}=1.35, p=\right.$ 0.24, one-way ANOVA) (Fig 3b).

EPF-bead application significantly increased the number of isolated cfu / $\mathrm{g}$ soil $\left(\mathrm{H}_{2,27}=20.87, \mathrm{p}<0.001\right.$, Kruskal-Wallis test). The number of cfu / $\mathrm{g}$ soil was significantly higher with an EPF-bead treatment (Mb 1/2: $1230 \pm 263 \mathrm{cfu} / \mathrm{g}$ soil) than in the Control (no detectable level of cfu / $\mathrm{g}$ soil) and did not significantly differ to an EPF-bead treatment with turmeric $(M b+T$ 1/2: $1695 \pm 175 \mathrm{cfu} / \mathrm{g}$ soil). Mealworm mortality was significantly affected by an EPF-bead application $\left(\mathrm{X}^{2}=\right.$ 45.52, $\mathrm{df}=1, \mathrm{p}<0.001$, chi-squared test). All mealworms treated with EPF-beads died with $97 \%$ of mealworms showing mycosis. In the Control treatment three (out of 30 ) mealworms were found dead but with no signs of mycosis. 


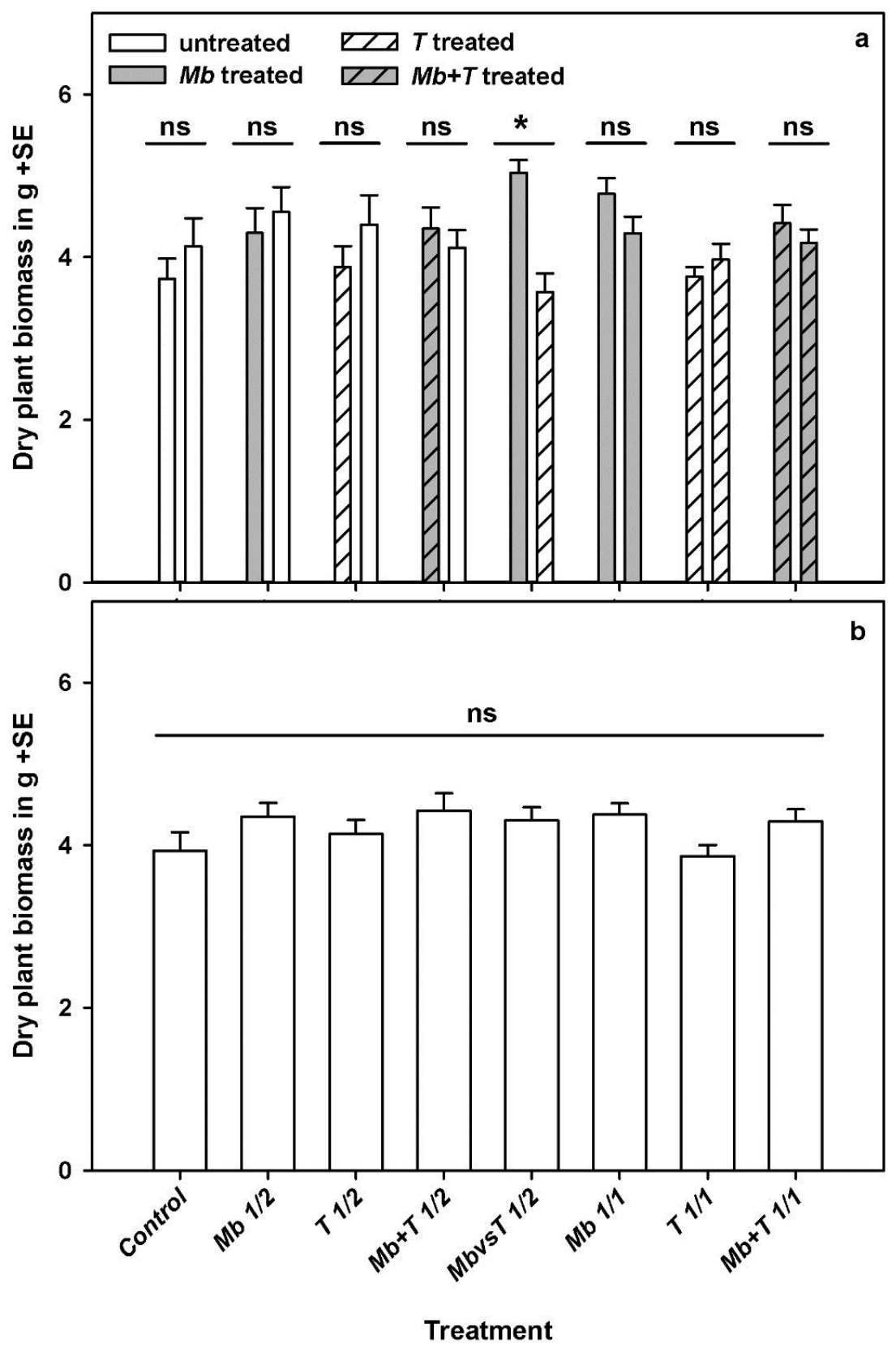

Fig. 3: Choice-test container (Experiment 2): a) Comparisons of single dry plant biomass (+ standard error (SE)) of maize grown in a container section with a treatment application in one (1/2) or two sections (1/1). Treatments: non-treated Control, Mb: EPF-beads (encapsulated Metarhizium brunneum (strain: BIPESCO5) conidia), T: Turmeric oil, Mb+T: EPF-bead and turmeric oil combination, Mb vs. $T$ (= MbvsT): EPF-bead versus turmeric oil. Asterisks above standard error (SE) bars indicate significant differences in dry plant biomass at $p<0.05$ (paired-t test); ns: not significant. b) Total Dry plant biomass (+SE) of maize grown in containers, which were treated section (1/2) or on the whole (1/1). Oneway ANOVA, ns: not significant. 


\section{Discussion}

A manipulation of pest behavior, by disrupting host feeding and host finding, are key factors in plant protection (Foster \& Harris, 1997). This study demonstrated repellence of turmeric (Curcuma longa L.) towards WCR larvae at the neonate and during larval development under controlled laboratory (experiment 1) and greenhouse (experiment 2) conditions. It confirms previous work which identified turmeric as a repellent against second and third instar larvae (Brandl et al., 2016). The application of EPF-beads (Metarhizium brunneum, BIPESCO5) only or in combination with turmeric failed to control WCR larvae. A synergy between turmeric and $M$. brunneum could therefore not be measured making an implementation of a "stress-and-kill" (SK) approach using these agents not feasible as a control option for WCR larvae.

\section{Turmeric}

A displacement of WCR larvae through repellence could be observed across all turmeric variants in both experiments with larvae being pushed into the non-treated sections. Thus, WCR larval host-plant location behavior, triggered by carbon dioxide $\left(\mathrm{CO}_{2}\right)$ as a general location cue and followed by more specific and contact cues (Hiltpold \& Turlings, 2012, Bernklau et al., 2013, Bernklau \& Bjostad, 1998), was subsequently disrupted. Reasons for the host-plant location disruption are most likely multifactorial. The underlying physiological mechanisms are not known as this investigation only looked into a "single input-output relationship", at which stimuli inputs are modified to record behavioral outputs (= black box approach) (Harris \& Foster, 1995). Turmeric's fumigant toxicity (Tripathi et al., 2002) led to a lower WCR larval recovery in experiment 1 as larvae entering the treated sections died by fumigation. This effect was dose dependent as a significant reduction was only found in the Medium but not in the Low treatment. Greater repellency in the High treatment led to a complete avoidance of the treated section by WCR larvae and therefore did not significantly impact on larval recovery. A dose dependent repellency was also observed for the lesser grain borer (Rhyzopertha dominica F.) exposed to turmeric oil without taking the underlying physiological mechanisms into account (Jilani \& Saxena, 1990).

A shift in larval distribution of WCR larvae in experiment 2 (treatment $T$ 1/2, Fig. 2a) indicates that larvae were repelled during their development up to five 
weeks after turmeric application in the soil. This effect was also partially observed for the Mb vs T 1/2 treatment, which however was not as distinctive, indicating an unknown interaction of both agents. The persistence of repellence over such a time period could be sufficient to target hatching larvae under field conditions (Toepfer \& Kuhlmann, 2006). A maximum repellency of all larvae avoiding turmeric treated soil as measured in experiment 1 , however, could not be measured. A potential decrease in turmeric repellency over time, as measured after two weeks for the lesser grain borer (Jilani \& Saxena, 1990) and the red flour beetle (Tribolium castaneum Herbst) (Jilani et al., 1988), could have resulted in WCR immigration into a turmeric treated section later during larval development. This immigration may have increased at a later instar stage as second instar larvae tend to be less sensitive towards turmeric repellence (Brandl, M. A., unpublished data) due to changes in receptor sensitivities as previously described for tobacco hornworms (Manduca sexta L.) (Blaney et al., 1986). An encapsulation as done for M. brunneum conidia in this study and other botanicals (Brandl et al., 2016) could also be tested for turmeric to stabilize its repellence in the soil over time.

\section{Metarhizium brunneum}

There was a non-significant low reduction in larval densities with an EPFbead treatment ("Mb", Fig. 2b) comparable to studies by Pilz et al. (2009) and Rudeen et al. (2013), despite M. brunneum outgrowth through the Na-alginate barrier of EPF-beads and infection of mealworm larvae. The Na-alginate barrier provided a favorable environment (e.g. > $93 \%$ relative humidity), required for successful conidial germination (Gillespie \& Claydon, 1989) to support $M$. brunneum establishment in the soil. The number of isolated M. brunneum s.l. conidia $\left(\sim 1.5 \times 10^{3} \mathrm{cfu} / \mathrm{g}\right.$ soil $=\sim 1.25 \times 10^{12}$ conidia / ha) was lower than originally applied $\left(=2.5 \times 10^{15}\right.$ conidia / ha) and not sufficient to infect a high number of WCR larvae successfully. Higher inoculum densities $\left(1 \times 10^{16}-1 \times 10^{17}\right.$ conidia / ha) than applied in this study are suggested for small, root-feeding and short-living insects, such as are WCR larvae (Ferron, 1978), and may have resulted in a higher reduction of larval densities. However, such a high number of conidia may not be economically feasible anymore.

Intensive watering could have caused conidial loss as a result from vertical movement in the soil through water infiltration (Inglis et al., 2001). The use of 
EPF-beads may have also decreased $M$. brunneum conidia distribution in the soil compared to an application of conidia in a suspension, given the size of the released inoculum (EPF-bead: Diameter: $2.7 \pm 0.2 \mathrm{~mm}$; Conidia: Length: $5.0-7.0$ $\mu \mathrm{m}$, width: $2.0-3.5 \mu \mathrm{m}$ (Bischoff et al., 2009)). Subsequently the contact of WCR larvae with $M$. brunneum conidia was lower compared to an unformulated conidia suspension. In contrast, Jaronski (2010) argues that the use of granules (i.e. here used EPF-beads) changes the "numbers game" as root-feeding insects acquire a larger number of conidia by merely brushing against the granule. Furthermore, the time period of coming into contact with conidia is generally short for WCR larvae due their cryptic and protected feeding habit within roots for the majority of their development (Strnad \& Bergman, 1987). This could also lead to failure of WCR larval control as a targeted insect must come into contact with a sufficient number of M. brunneum conidia to become infected (Jaronski, 2010).

The aggregation of WCR larvae within the treated section of treatment $M b$ 1/2 (Fig. 2a) could be the result of an increased microbial soil respiration (Lundegardh, 1927) originating from EPF-beads, also observed for Pseudomonas fluorescens cells encapsulated in alginate (Trevors, 1991). An application of EPFbeads elevates $\mathrm{CO}_{2}$ levels for up to three weeks after their application (Brandl, $\mathrm{M}$. A., unpublished data). WCR larvae may have been attracted and immigrated into a treated section as $\mathrm{CO}_{2}$ gradients are used to locate potential host plants (Strnad et al., 1986) (Fig. 2). Furthermore, attractive cues released by Metarhizium spp. towards subterranean termites to generate higher mortality rates have been identified (Engler \& Gold, 2004). Such cues have so far never been reported for WCR larvae and should be considered in subsequent EPF control strategies, such as an attract-and-kill approach.

\section{Turmeric and Metarhizium brunneum}

A combined application of turmeric and EPF-beads $(M b+T$ 1/2, Mb vs. $T$ 1/2) could not enhance the reduction of larval densities or increase plant biomass compared to a single application of either treatment. A behavior altering stress agents could therefore not increase the susceptibility towards a killing agent (Ansari et al., 2008). Turmeric neither affected M. brunneum and plant growth, despite its known antifungal (Damalas, 2011) and phytotoxic (Khattak et al., 2005) properties. There even appears to be a beneficial effect on plant growth through a 
combination of EPF-beads and turmeric separately applied into each section (Mb vs. $T$ 1/2; Fig. 3a) possibly through endophytic colonization of $M$. brunneum (Sasan \& Bidochka, 2012, Garcia et al., 2011). Negative side effects can therefore be excluded, making M. brunneum and turmeric compatible SK agents. The SK failure reasons are speculative, but can mainly be related back to the lack of performance of each SK agent through potential loss of turmeric repellency over time and low establishment levels of $M$. brunneum. It may therefore be worthwhile to test different application rates of each SK agent to fully exploit their SK potential. Furthermore other stressing agents components such as insecticides (Hiromori \& Nishigaki, 2001) or entomopathogenic nematodes (Ansari et al., 2004) have successfully been tested in a SK approach with M. brunneum and could also be evaluated for the control of WCR larvae.

\section{Conclusion}

The use of formulated $M$. brunneum conidia only or in combination with turmeric in a SK approach could not enhance the biological control of WCR larvae. Higher application rates and other stress components need to be tested to further evaluate $M$. brunneum as a control agent of WCR larvae. Other types of formulations to increase $M$. brunneum outgrowth or the delivery of conidia to the target organisms (e.g. endophytic colonization (Vidal \& Jaber, 2015)) should also be considered to fully exploit control with $M$. brunneum.

\section{Acknowledgements}

These studies were funded by means of the $7^{\text {th }}$ Framework Programme of the European Union 282767 as a part of the project INBIOSOIL (http://inbiosoil.uni-goettingen.de). We would like to thank Bianca Tappe, Daniel Kretschmar and Marie Nörthemann for their technical assistance. Furthermore we would like to thank NeemBiotech Laboratory Units (Cardiff, United Kingdom) for providing the turmeric oil extract, the Institute of Microbiology (University of Innsbruck, Austria) for providing the strain BIPESCO5 and FYTOVITA spol. s.r.o. (Ostrozska Lhota, Czech Republic) for the mass production of M. brunneum aero conidia. Finally we would like to thank Dr. Christian Ahl (Georg-August-Universität 
Göttingen, Germany) for conducting the soil analysis and Chad Nielson for delivering the WCR eggs.

\section{References}

Ansari, M. A., Shah, F. A. \& Butt, T. M. (2008) Combined use of entomopathogenic nematodes and Metarhizium anisopliae as a new approach for black vine weevil, Otiorhynchus sulcatus, control. Entomologia Experimentalis Et Applicata, 129, 340-347.

Ansari, M. A., Tirry, L. \& Moens, M. (2004) Interaction between Metarhizium anisopliae CLO 53 and entomopathogenic nematodes for the control of Hoplia philanthus. Biological Control, 31, 172-180.

Bernklau, E. J. \& Bjostad, L. B. (1998) Reinvestigation of host location by western corn rootworm larvae (Coleoptera: Chrysomelidae): $\mathrm{CO}_{2}$ is the only volatile attractant. Journal of Economic Entomology, 91, 1331-1340.

Bernklau, E. J., Hibbard, B. E. \& Bjostad, L. B. (2013) Isolation and characterization of host recognition cues in corn roots for larvae of the western corn rootworm (Coleoptera: Chrysomelidae). Journal of Economic Entomology, 106, 2354-2363.

Bidochka, M. J., Kasperski, J. E. \& Wild, G. a. M. (1998) Occurrence of the entomopathogenic fungi Metarhizium anisopliae and Beauveria bassiana in soils from temperate and near-northern habitats. Canadian Journal of Botany-Revue Canadienne De Botanique, 76, 1198-1204.

Bischoff, J. F., Rehner, S. A. \& Humber, R. A. (2009) A multilocus phylogeny of the Metarhizium anisopliae lineage. Mycologia, 101, 512-530.

Blaney, W. M., Schoonhoven, L. M. \& Simmonds, M. S. J. (1986) Sensitivity variations in insect chemoreceptors - a review. Experientia, 42, 13-19.

Brandl, M. A., Schumann, M., French, B. W. \& Vidal, S. (2016) Screening of botanical extracts for repellence against Western corn rootworm larvae. Journal of Insect Behavior, 29, 395-414.

Branson, T. F. (1976) The selection of a non-diapause strain of Diabrotica virgifera (Coleoptera: Chrysomelidae). Entomologia Experimentalis Et Applicata, 20, 148-154. 
Butt, T. M. (2002) Use of entomogenous fungi for the control of insect pests. In: Esser, K. \& Bennett, R. (eds.) The Mycota. Berlin: Springer.

Damalas, C. A. (2011) Potential uses of turmeric (Curcuma longa) products as alternative means of pest management in crop production. Plant Omics, 4, $136-141$.

Ehlers, R. U. (2001) Mass production of entomopathogenic nematodes for plant protection. Applied Microbiology and Biotechnology, 56, 623-633.

Eilenberg, J., Hajek, A. \& Lomer, C. (2001) Suggestions for unifying the terminology in biological control. Biocontrol, 46, 387-400.

Engler, K. M. \& Gold, R. E. (2004) Effects of multiple generations of Metarhizium anisopliae on subterranean termite feeding and mortality (Isoptera: Rhinotermitidae). Sociobiology, 44, 211-240.

Fargues, J., Reisinger, O., Robert, P. H. \& Aubart, C. (1983) Biodegradation of entomopathogenic hyphomycetes - influence of clay coating on Beauveria bassiana blastospore survival in soil. Journal of Invertebrate Pathology, 41, $131-142$.

Ferron, P. (1978) Biological-control of insect pests by entomogenous fungi. Annual Review of Entomology, 23, 409-442.

Foster, S. P. \& Harris, M. O. (1997) Behavioral manipulation methods for insect pest-management. Annual Review of Entomology, 42, 123-146.

Garcia, J. E., Posadas, J. B., Alejandro, P. \& Lecuona, R. E. (2011) Metarhizium anisopliae (Metschnikoff) Sorokin promotes growth and has endophytic activity in tomato plants. Advances in Biological Research, 5, 22-27.

Gassmann, A. J., Petzold-Maxwell, J. L., Keweshan, R. S. \& Dunbar, M. W. (2011) Field-evolved resistance to Bt maize by western corn rootworm. Plos One, 6.

Gillespie, A. T. \& Claydon, N. (1989) The use of entomogenous fungi for pestcontrol and the role of toxins in pathogenesis. Pesticide Science, 27, 203215.

Giraudoux, P. (2015) Data analysis in ecology. R package version 1.6.2.

Gray, M. E., Sappington, T. W., Miller, N. J., Moeser, J. \& Bohn, M. O. (2009) Adaptation and invasiveness of western corn rootworm: Intensifying research on a worsening pest. Annual Review of Entomology, 54, 303-321. 
Harris, M. O. \& Foster, S. P. (1995) Behavior and integration. In: Cardé, R. T. \& Bell, J. B. (eds.) Chemical ecology of insects 2. New York, US: SpringerScience + Business Media Dordrecht.

Hibbard, B. E., Barry, B. D., Darrah, L. L., Jackson, J. J., Chandler, L. D., French, L. K. \& Mihm, J. A. (1999) Controlled field infestations with western corn rootworm (Coleoptera: Chrysomelidae) eggs in Missouri: Effects of egg strains, infestation dates, and infestation levels on corn root damage. Journal of the Kansas Entomological Society, 72, 214-221.

Hiltpold, I. \& Turlings, T. C. J. (2012) Manipulation of chemically mediated interactions in agricultural soils to enhance the control of crop pests and to improve crop yield. Journal of Chemical Ecology, 38, 641-650.

Hiromori, H. \& Nishigaki, J. (2001) Factor analysis of synergistic effect between the entomopathogenic fungus Metarhizium anisopliae and synthetic insecticides. Applied Entomology and Zoology, 36, 231-236.

Humber, R. A. (2012) Identification of entomopathogenic fungi. In: Lacey, L. A. (ed.) Manual of Techniques in Invertebrate Pathology London, UK: Academic Press.

Inglis, G. D., Enkerli, J. \& Goettel, M. S. (2012) Laboratory techniques used for entomopathogenic fungi: Hypocreales. In: Lacey, L. A. (ed.) Manual of Techniques in Invertebrate Pathology. London, UK: Academic Press.

Inglis, G. D., Goettel, M. S., Butt, T. M. \& Strasser, H. (2001) Use of hyphomycetous fungi for managing insect pests. In: Butt, T. M., Jackson, C. \& Magan, N. (eds.) Fungi as Biocontrol Agents. Progress, Problems and Potential. Wallingford, UK: CABI Publishing.

Jaronski, S. T. (2010) Ecological factors in the inundative use of fungal entomopathogens. Biocontrol, 55, 159-185.

Jilani, G. \& Saxena, R. C. (1990) Repellent and feeding deterrent effects of turmeric oil, sweetflag oil, neem oil, and a neem-based insecticide against lesser grain borer (Coleoptera: Bostrychidae). Journal of Economic Entomology, 83, 629-634.

Jilani, G., Saxena, R. C. \& Rueda, B. P. (1988) Repellent and growth-inhibiting effects of turmeric oil, sweetflag oil, neem oil, and "margosan-o" on red flour beetle (Coleoptera: Tenebrionidae). Journal of Economic Entomology, 81, 1226-1230. 
Keller, S., Kessler, P. \& Schweizer, C. (2003) Distribution of insect pathogenic soil fungi in Switzerland with special reference to Beauveria brongniartii and Metharhizium anisopliae. Biocontrol, 48, 307-319.

Kempson, D., Lloyd, M. \& Gherardi, R. (1963) A new extractor for woodland litter. Pedobiologia, 3, 1-21.

Khattak, S., Saeed-Ur-Rehman, Shah, H. U., Ahmad, W. \& Ahmad, M. (2005) Biological effects of indigenous medicinal plants Curcuma longa and Alpinia galanga. Fitoterapia, 76, 254-257.

Lacey, L. A. \& Solter, L. F. (2012) Initial handling and diagnosis of diseased invertbrates. In: Lacey, L. A. (ed.) Manual of Techniques in Invertebrate Pathology London, UK: Academic Press.

Lancashire, P. D., Bleiholder, H., Vandenboom, T., Langeluddeke, P., Stauss, R., Weber, E. \& Witzenberger, A. (1991) A uniform decimal code for growthstages of crops and weeds. Annals of Applied Biology, 119, 561-601.

Levine, E. \& Oloumisadeghi, H. (1991) Management of diabroticite rootworms in corn. Annual Review of Entomology, 36, 229-255.

Lundegardh, H. (1927) Carbon dioxide evolution and crop growth. Soil Science, 23, 417-453.

Meinke, L. J., Sappington, T. W., Onstad, D. W., Guillemaud, T., Miller, N. J., Judith, K., Nora, L., Furlan, L., Jozsef, K. \& Ferenc, T. (2009) Western corn rootworm (Diabrotica virgifera virgifera LeConte) population dynamics. Agricultural and Forest Entomology, 11, 29-46.

Metcalf, R. L. (1986) Foreword. In: Krysan, J. L. \& Miller, T. A. (eds.) Methods for the Study of Pest Diabrotica. New York, US: Springer.

Metschnikoff, E. A. (1880) Zur Lehre über Insectenkrankheiten. Zoologischer Anzeiger 3, 44-47.

Meyling, N. V. \& Eilenberg, J. (2007) Ecology of the entomopathogenic fungi Beauveria bassiana and Metarhizium anisopliae in temperate agroecosystems: Potential for conservation biological control. Biological Control, 43, 145-155.

Montgomery, M. E., Musick, G. J., Polivka, J. B. \& Nielsen, D. G. (1979) Modifiable washing-flotation method for sparation of isect egs and Irvae from soil. Journal of Economic Entomology, 72, 67-69. 
Oleson, J. D., Park, Y. L., Nowatzki, T. M. \& Tollefson, J. J. (2005) Node-injury scale to evaluate root injury by corn rootworms (Coleoptera: Chrysomelidae). Journal of Economic Entomology, 98, 1-8.

Palmer, D. F., Windels, M. B. \& Chiang, H. C. (1976) Changes in specific gravity of developing Western corn rootworm eggs. Environmental Entomology, 5, 621-622.

Pereira, R. M. \& Roberts, D. W. (1991) Alginate and cornstarch mycelial formulations of entomopathogenic fungi, Beauveria bassiana and Metarhizium anisopliae. Journal of Economic Entomology, 84, 1657-1661.

Pilz, C., Keller, S., Kuhlmann, U. \& Toepfer, S. (2009) Comparative efficacy assessment of fungi, nematodes and insecticides to control western corn rootworm larvae in maize. Biocontrol, 54, 671-684.

Pilz, C., Wegensteiner, R. \& Keller, S. (2008) Natural occurrence of insect pathogenic fungi and insect parasitic nematodes in Diabrotica virgifera virgifera populations. Biocontrol, 53, 353-359.

R Development Core Team (2013) R: A language and environment for statistical computing. R foundation for statistical computing, http://www.R-project.org/ Vienna, Austria

Riedell, W. E. (1989) Western corn rootworm damage in maize: greenhouse technique and plant response. Crop Science, 29, 412-415.

Rudeen, M. L., Jaronski, S. T., Petzold-Maxwell, J. L. \& Gassmann, A. J. (2013) Entomopathogenic fungi in cornfields and their potential to manage larval western corn rootworm Diabrotica virgifera virgifera. Journal of Invertebrate Pathology, 114, 329-332.

Sasan, R. K. \& Bidochka, M. J. (2012) The insect-pathogenic fungus Metarhizium robertsii (Clavicipitaceae) is also an endophyte that stimulates plant root development. American Journal of Botany, 99, 101-107.

Scheepmaker, J. W. A. \& Butt, T. M. (2010) Natural and released inoculum levels of entomopathogenic fungal biocontrol agents in soil in relation to risk assessment and in accordance with EU regulations. Biocontrol Science and Technology, 20, 503-552.

Steinhaus, E. A. \& Martignoni, M. E. (1970) An abridged glossary of terms used in invertebrate pathology, US, USDA, Forest Service, Pacific Northwest Forest and Range Experiment Station. 
Strasser, H., Forer, A. \& Schinner, F. (1996) Development of media for the selective isolation and maintenance of virulence of Beauveria brongniartii. In: Jackson, T. A. \& Glare, T. R. (eds.) Proceedings $3^{\text {rd }}$ International Workshop on Microbial Control of Soil Dwelling Pests. Lincoln, New Zealand: AgResearch.

Strnad, S. P. \& Bergman, M. K. (1987) Distribution and orientation of western corn rootworm (Coleoptera: Chrysomelidae) larvae in corn roots. Environmental Entomology, 16, 1193-1198.

Strnad, S. P., Bergman, M. K. \& Fulton, W. C. (1986) First-instar western corn rootworm (Coleoptera: Chrysomelidae) response to carbon dioxide. Environmental Entomology, 15, 839-842.

Thomas, M. B., Wood, S. N. \& Lomer, C. J. (1995) Biological control of locusts and grasshoppers using a fungal pathogen - the importance of secondary cycling. Proceedings of the Royal Society B-Biological Sciences, 259, 265270.

Toepfer, S. \& Kuhlmann, U. (2006) Constructing life-tables for the invasive maize pest Diabrotica virgifera virgifera (Coleoptera: Chrysomelidae) in Europe. Journal of Applied Entomology, 130, 193-205.

Trevors, J. T. (1991) Respiratory activity of alginate-encapsulated Pseudomonas fluorescens cells introduced into soil. Applied Microbiology and Biotechnology, 35, 416-419.

Tripathi, A. K., Prajapati, V., Verma, N., Bahl, J. R., Bansal, R. P., Khanuja, S. P. S. \& Kumar, S. (2002) Bioactivities of the leaf essential oil of Curcuma longa (Var. Ch-66) on three species of stored-product beetles (Coleoptera). Journal of Economic Entomology, 95, 183-189.

Vemmer, M., Schumann, M., Beitzen-Heineke, W., French, B. W., Vidal, S. \& Patel, A. (2016) Development of a $\mathrm{CO}_{2}$ releasing co-formulation based on starch, Saccharomyces cerevisiae and Beauveria bassiana attractive towards western corn rootworm larvae. Pest Management Science.

Vidal, S. \& Jaber, L. R. (2015) Entomopathogenic fungi as endophytes: plantendophyte-herbivore interactions and prospects for use in biological control. Current Science, 109, 46-54. 
Wesseler, J. \& Fall, E. H. (2010) Potential damage costs of Diabrotica virgifera virgifera infestation in Europe - the 'no control' scenario. Journal of Applied Entomology, 134, 385-394.

Wright, R. J., Scharf, M. E., Meinke, L. J., Zhou, X. G., Siegfried, B. D. \& Chandler, L. D. (2000) Larval susceptibility of an insecticide-resistant western corn rootworm (Coleoptera: Chrysomelidae) population to soil insecticides: Laboratory bioassays, assays of detoxification enzymes, and field performance. Journal of Economic Entomology, 93, 7-13.

Xavier-Santos, S., Lopes, R. B. \& Faria, M. (2011) Emulsifiable oils protect Metarhizium robertsii and Metarhizium pingshaense conidia from imbibitional damage. Biological Control, 59, 261-267.

Zimmermann, G. (1986) The Galleria bait method for detection of entomopathogenic fungi in soil. Journal of Applied Entomology, 102, 213215.

Zimmermann, G. (1993) The entomopathogenic fungus Metarhizium anisopliae and its potential as a biocontrol agent. Pesticide Science, 37, 375-379.

Zimmermann, G., Huger, A. M. \& Kleespies, R. G. (2013) Occurrence and prevalence of insect pathogens in populations of the Codling moth, Cydia pomonella L.: A long-term diagnostic survey. Insects, 4, 425-446. 


\section{Chapter 3}

\section{Wireworm damage reduction in potatoes with an attract-and-kill strategy using Metarhizium brunneum}

Michael A. Brandl*, Mario Schumann, Michael Przyklenk, Anant Patel and Stefan Vidal

* Corresponding author

This chapter is submitted to:

Journal of Pest Science

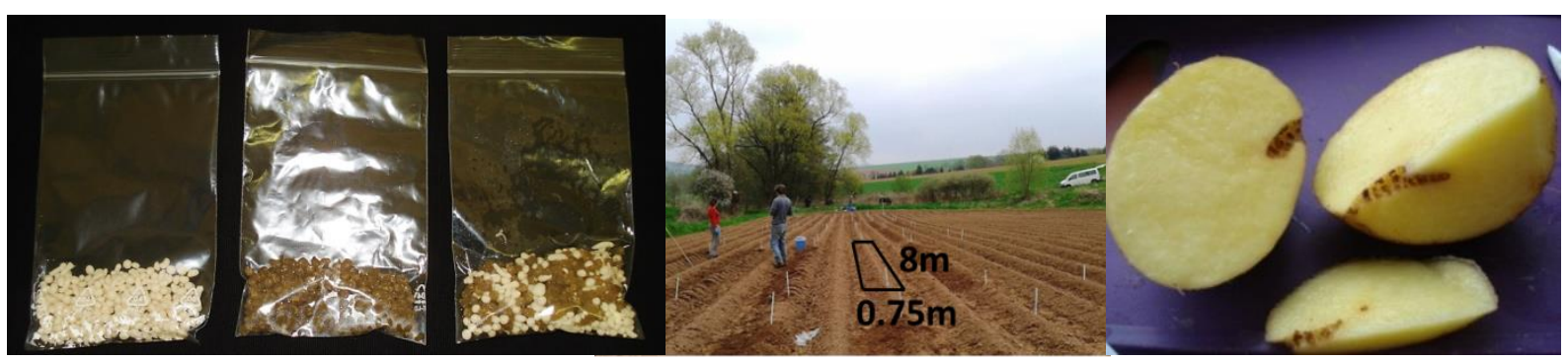




\title{
Wireworm damage reduction in potatoes with an attract-and-kill strategy using Metarhizium brunneum
}

\author{
M. A. Brandl ${ }^{1, *}$, M. Schumann ${ }^{1}$, M. Przyklenk ${ }^{2}$, A. Patel ${ }^{2}$ and S. Vidal ${ }^{1}$ \\ ${ }^{1}$ Georg-August-Universität Göttingen, Department of Crop Sciences, Agricultural Entomology, \\ Grisebachstrasse 6, 37077 Göttingen, Germany \\ ${ }^{2}$ University of Applied Sciences Bielefeld, WG Fermentation and Formulation of Biologicals and \\ Chemicals, Faculty of Engineering and Mathematics, Interaktion 1, 33619 Bielefeld, Germany \\ *Corresponding author.Tel.: +49 551 3933733, E-mail address: mbrandl1@gwdg.de
}

\section{Abstract}

Innovative wireworm control strategies are required to implement integrated pest management on the basis of the (EC) No regulation 1107/2009 and Directive 2009/128/EC. Entomopathogenic fungi, such as Metarhizium brunneum (Metschnikoff) Sorokin, are potential biological control agents for wireworm control but do not achieve high control efficacies in the field when applied as a conidia suspension. In a two year study, wireworm control with a novel attract-and-kill strategy aimed at enhancing M. brunneum efficacies in organic potato production systems in Lower Saxony, Germany. The approach is based on the attraction of wireworms (Agriotes spp. Eschscholtz) towards an artificial carbon dioxideemitting source, using baker's yeast (Saccharomyces cerevisiae Meyen ex Hansen) in combination with $M$. brunneum conidia for wireworm infection. Both components were encapsulated in alginate as a carrier material. An application of these beads within the potato rows during potato planting reduced wireworm tuber damage by $37-75 \%$ relative to the untreated control and was able to enhance the efficacy of M. brunneum by up to $35 \%$ through an attract-and-kill approach compared to beads without a carbon dioxide source only. This strategy offers a high potential to promote biological wireworm control as an alternative to insecticide use by potentially reducing the inoculum compared to an inundate $M$. brunneum conidia release strategy.

Keywords: Wireworms, potato, encapsulation, Metarhizium brunneum, carbon dioxide, attract-and-kill 


\section{Introduction}

Wireworms, the larvae of click beetles (Coleoptera: Elateridae), are polyphagous agricultural pests (Traugott et al., 2015). There are about 10,000 species described worldwide and 672 in Europe (Vernon \& van Herk, 2013, Traugott et al., 2015). 39 species are known to attack potatoes (Solanum tuberosum L.) (Jansson \& Seal, 1994), with the dominant species Agriotes lineatus L., Agriotes obscurus L. and Agriotes sputator L. in Northern Europe causing economic damage (Parker \& Howard, 2001).

Since the 1990s wireworms have regained importance as major pests worldwide, comparable to the wireworm damage problems in the early $1900 \mathrm{~s}$ (Vernon \& van Herk, 2013). One main hypothesis for an increased wireworm damage proposes the loss of effective long-term non-specific insecticides such as organochlorides, organophosphates and carbamates, which reduced wireworm populations for many years, thus protecting crop stand and yield (Parker \& Howard, 2001). Newer classes of insecticides may be effective as well, but differ profoundly with regard to their persistence in the soil and their mode of action against several wireworm species. Pyrethroids (e.g. tefluthrin) and neonicotinoids (e.g. thiamethoxam, clothianidin, or imidacloprid), for instance, are known to be repellent to $A$. obscurus wireworms, inducing a morbidity effect followed by a subsequent full recovery after 24 h (van Herk \& Vernon, 2007, van Herk et al., 2008a, van Herk et al., 2008b). Phenylpyrazoles (e.g. fipronil) are effective for wireworm control (van Herk et al., 2008b), but are currently phased out by a moratorium in Europe (European Food Safety Authority, 2013) due to potential environmental risks, such as leaching, high toxicity to aquatic species or bees and indirect effects on non-target organisms (Gunasekara et al., 2007). Further factors contributing to an increased wireworm abundance in arable fields are attributed to changes in farming practices, such as the adoption of minimum tillage practices (Vernon \& van Herk, 2013), or the conversion of old pastures into arable fields (Parker \& Howard, 2001).

Current partial control measures for adult click beetles may include pheromone trapping of males resulting in increased numbers of unmated females and reduced oviposition behavior due to foliar applications of pyrethroids at peak flight activities of the beetles (Vernon \& van Herk, 2013). Wireworms may be 
partially controlled by preventative measures such as crop rotation (Thomas, 1940), the avoidance of susceptible crops planted immediately after crops favored by click beetles (Parker \& Howard, 2001) and a repeated cultivation, leading to a decline in wireworm populations within $3-4$ years (Fox, 1961). Direct control measures include soil amendments, predominantly achieved by incorporating cruciferous plants with insecticidal properties into the soil (Furlan et al., 2010) and repeated soil disturbance by ploughing to desiccate eggs, larvae, pupa, and adults. They may also include the use of resistant potato cultivars (Johnson et al., 2008), whereas this approach is discussed controversially (Thomas, 1940). Limited wireworm control options necessitate new, effective and sustainable control strategies. In addition EU member states are to transpose the (EC) No regulation 1107/2009 (European Parliament and the Council of the European Union, 2009b) and Directive 2009/128/EC (European Parliament and the Council of the European Union, 2009a) into national action plans. These regulations promote an integrated pest management approach, with non-chemical methods being given priority, including the use of biological control agents (BCAs).

Historically, the most frequently observed BCAs attacking wireworms are species of the entomopathogenic fungus (EPF) Metarhizium anisopliae (Metschnikoff) Sorokin sensu lato from the order Hypocreales (Ascomycota), described as the green muscardine disease (Thomas, 1940, Bischoff et al., 2009). This fungus occurs naturally in the soil and relies on arthropod hosts to grow and spread, although saprophytic stages may also be involved (Meyling \& Eilenberg, 2007). Research using this fungus dates back to 1914 where it was used to control wireworms of the genus Melanotus spp. under field conditions, but with limited success (Hyslop, 1915). More recent studies focusing on inundative approaches, reported of significant increases in the number of mycosed wireworms ( $A$. obscurus), when $M$. anispoliae conidia were applied at high doses $\left(6.38 \times 10^{15}\right.$ conidia / ha) in the field (Kabaluk et al., 2007).

Applications of EPF for soil pest control commonly rely on an inundative propagule release to increase the chance of pests contacting infective conidia (Meyling \& Eilenberg, 2007). A potential approach to increase the likelihood of conidia contact is an "attract-and-kill" (AK) tactic, which exploits wireworm attraction towards carbon dioxide $\left(\mathrm{CO}_{2}\right)$ (Doane et al., 1975) and wireworm susceptibility to EPF. Such an approach has been shown to increase the efficacy 
of chemical pesticides (Vernon et al., 2015). In this context we hypothesized that the control efficacy with EPF will also be increased, potentially reducing the inoculum, and saving costs compared to an inundate EPF release strategy, alone.

A combination of a $\mathrm{CO}_{2}$ attractant with an EPF in an AK strategy would represent a new method to control wireworms. Our study tested such a strategy for protecting organic potatoes from wireworm (Agriotes spp. Eschscholtz) feeding damage. Specifically, we tested Metarhizium brunneum (Metschnikoff) Sorokin (strain: ART2825) and $\mathrm{CO}_{2}$-producing baker's yeast (Saccharomyces cerevisiae Meyen ex Hansen), with both agents being encapsulated in calcium alginate beads.

\section{Materials and methods}

\section{Field sites}

All trials were conducted on organic farms in Lower Saxony, Germany (Table S1). Field sites were selected based on cropping history and farmers' previous experience with wireworm damage to ensure high pest pressure. All trials were within cultivated potato fields and separated by three untreated potato rows and $2 \mathrm{~m}$ at row ends. Prior potato planting fields were either mulch cultivated (field 1) or ploughed (fields $2-7$ ). Field sites were cultivated according to the requirements of the organic farming associations and Good Agricultural Practice (BMELV, 2010) (Table S2).

\section{Environmental conditions}

Soil was sampled to $25 \mathrm{~cm}$ at eight locations diagonally across the entire trial site in untreated buffer potato rows using a cylindrical soil core sampler (diameter: $1.8 \mathrm{~cm}$ ) prior trial setup. Samples were mixed in Zip-lock ${ }^{\mathrm{TM}}$ plastic bags, stored at $6^{\circ} \mathrm{C}$ with chemical and physical soil parameters analyzed for soil $\mathrm{pH}$, soil nitrogen $(\mathrm{N})$, soil calcium carbonate $\left(\mathrm{CaCO}_{3}\right)$, soil humus and soil texture by the Department of Agricultural Soil Science, Georg-August Universität Göttingen, Germany. Weather data were recorded by weather stations within $40 \mathrm{~km}$ of field sites (Deutscher Wetterdienst, DWD, Offenbach, Germany) (Table S1). 


\section{Experimental design}

The AK strategy was studied during two growing seasons (2013 \& 2014) in seven fields (Table S1). Between three to five treatments per field were arranged in a randomized complete block design with six and eight replicates in 2013 and 2014, respectively (Table S2). A single row set up (Vernon et al., 2013) in a length-wise layout (Anonymous, 2012) was used. Individual plot sizes consisted of one $8 \mathrm{~m}$ potato row with untreated guard rows on either side (between row distance: $0.75 \mathrm{~m}$ ). Plots within a block were $2 \mathrm{~m}$ apart. Application pattern of AK beads (see below) differed between but not within fields. Treatments were applied once on / around the day (field $2-7$ ) of potato planting (BBCH 01; Hack et al., 2001) or at the time of tuber formation (field 1) (BBCH 40; Hack et al., 2001) either as a "spot" application between (fields $1 \& 2$ ) and underneath (fields $3-5$ ) seed potatoes or as a "band" application within the furrow underneath (fields $6 \& 7$ ) seed potatoes (Table S2). Wireworm damage was evaluated according to the European and Mediterranean Plant Protection Organization (EPPO) standards PP1/46 (Anonymous, 2005) by randomly sampling 100 tubers per plot (BBCH 99; Hack et al., 2001).

\section{Treatments}

"Attract": Commercially available baker's yeast (Saccharomyces cerevisiae Meyen ex Hansen) (Deutsche Hefewerke GmbH, Nürnberg, Germany) used as a $\mathrm{CO}_{2}$ source (Schumann et al., 2014a) and maize (Zea mays L.) starch, were encapsulated in wet spherical calcium alginate beads (diameter: $2.7 \pm 0.2 \mathrm{~mm}$ ) based on Na-alginate and demineralized water, according to Vemmer et al. (2016).

"Kill.s": An aqueous $4.5 \times 10^{7}$ conidia / $\mathrm{ml}$ suspension with aerial produced M. brunneum ART2825 conidia, originally isolated from A. obscurus in Switzerland (Kölliker et al., 2011), was prepared on the day of treatment application. Conidia were provided by Fytovita spol. s.r.o. (Ostrozska Lhota, Czech Republic) at an original concentration of $1 \times 10^{9}$ conidia $/ \mathrm{g} \mathrm{M}$. brunneum powder. Thus, $45.0 \mathrm{~g}$ conidia (Scale: PEJ 4200-2M, Kern \& Sohn, Balingen, Germany) were diluted in 1.0 I autoclaved purified water including 0.03\% Tween ${ }^{\circledR} 20$ (Carl Roth GmbH + Co. KG, Karlsruhe, Germany). The required conidial concentration was verified 
with light microscopy (200X magnification, BH2-HLSH, Olympus Corporation, Tokyo, Japan) using a hemocytometer (Thoma chamber, $0.10 \mathrm{~mm}$ depth).

"Kill": Aerial conidia were encapsulated in wet spherical beads (diameter: $2.7 \pm 0.2 \mathrm{~mm}$ ) using the same method as for production of the Attract beads with $2.5 \times 10^{7}$ conidia / $\mathrm{g}$ beads. The composition of beads was based on Na-alginate solution, EPF conidia and dead (autoclaved) baker's yeast based on studies on bead composition (Przyklenk et al. 2016, personal communication). Autoclaved baker's yeast served as an energy source for rapid $M$. brunneum conidia germination, growth and re-sporulation on bead surface and an enhancement of conidial virulence.

“Attract-and-Kill” (AK-co): A co-application of Attract and Kill beads.

\section{Treatment preparation and application}

Beads were weighed into Zip-lock ${ }^{\mathrm{TM}}$ plastic bags in the laboratory (Scale: PEJ 4200-2M, Kern \& Sohn, Balingen, Germany) and stored in the dark at $6^{\circ} \mathrm{C}$ for 24 - $48 \mathrm{~h}$ prior to application in the field. Treatments for a spot and band application were weighed in portions equivalent to an application at a single seed potato and within a whole plot, respectively. Kill.s treatment was prepared on the day of treatment application. All treatments, except for Kill.s, were stored in plastic bags and kept cool on the way from the laboratory to field sites.

Three types of treatment applications were tested in both years: In 2013, a spot application of treatments "between" (fields 1 \& 2) and "underneath" (field 3) seed potatoes; in 2014, a spot application of treatments "underneath" (fields 4 \& 5) and a band application of treatments "underneath" (fields 6 \& 7) seed potatoes (Table S2). Seed potato planting was done at the end of April on all field sites. In fields with "between" treatments, seed potatoes were planted by farmers and treatments applied one week ( $\mathrm{BBCH} 01$, field 2) twelve weeks $(\mathrm{BBCH} 40$, field 1) after planting. In fields with "underneath" treatments (spot \& band) potato rows without seed potatoes were set up by the farmers. Manual potato planting and treatment application were then done on the same day $(\mathrm{BBCH} 01$, fields $3-7)$ (Table S2).

For an "underneath" treatment application empty potato rows were opened up using a manual ridger to create $20 \mathrm{~cm}$ deep and $25 \mathrm{~cm}$ wide furrows along the middle of the potato row. For spot applications, $8.5 \mathrm{~g}, 9 \mathrm{~g}$ and $17.5 \mathrm{~g}$ of Attract, Kill 
and $A K$-co beads were applied every $32 \mathrm{~cm}$ (field 3 - 5). For a band application, $230 \mathrm{~g}, 240 \mathrm{~g}$ and $470 \mathrm{~g}$ of Attract, Kill and AK-co beads were spread along one furrow of the $8 \mathrm{~m}$ treated potato row (fields $6 \& 7)\left(=7.2 \times 10^{12} \mathrm{M}\right.$. brunneum conidia / ha). A potato tuber was placed every $32 \mathrm{~cm} \mathrm{(=} 40000$ tubers / ha) directly on the beads and potato rows were closed again and reshaped into ridges. For a spot "between" treatment application $20 \mathrm{~cm}$ deep holes (diameter: $5 \mathrm{~cm}$ ), centered between seed potatoes, were created by digging (fields 1 \& 2). Thereafter treatments applied and holes enclosed again. For a Kill.s treatment (fields $1-3$ ), a $5 \mathrm{ml}$ conidia suspension $\left(=7.2 \times 10^{12} \mathrm{M}\right.$. brunneum conidia / ha) was applied the same way as the beads in an "underneath" (field 3) and "between" (fields 1 \& 2) spot treatment using a pipette (Pipetman, Gilson, Inc., Middleton, USA. The untreated control consisted of planted potato rows only (“Control').

\section{Verification of materials' performance}

$\mathrm{CO}_{2}$ production of Attract beads

Attract performance was tested in ordinary round plastic pots (height: 14 $\mathrm{cm}$, diameter: $15 \mathrm{~cm}$ ) filled with $1.5 \mathrm{~kg}$ soil collected from the equivalent field site. Pots were set up within one week after bead application in the respective field site in 2013 and at the same time for all fields in 2014. An untreated control ("Control") and an Attract treatment with $8.5 \mathrm{~g}$ beads applied in $8 \mathrm{~cm}$ soil depth were set up with six and four replicates for each field soil in 2013 and 2014, respectively. Pots were placed in an open greenhouse to measure $\mathrm{CO}_{2}$ emission at outdoor temperatures and watered twice per week to maintain soil moisture between $10-$ $25 \%$ (v/v) water content. Soil temperature was measured (NiCr-Ni TypK, DOSTMANN Electronic, Wertheim-Reicholzheim, Germany) in $6 \mathrm{~cm}$ depth in 2014 only. Soil moisture was measured with an absolute humidity reader in $6 \mathrm{~cm}$ soil depth (2013: PCE-SMM 1, PCE, Meschede, Germany; 2014: TML 3 ThetaProbe, Delta-T devices, Cambridge, England). $\mathrm{CO}_{2}$ emission was measured with a handheld $\mathrm{CO}_{2}$ meter (CARBOCAP® GM70, Vaisala, Helsinki, Finland) by inserting a hollow metal pipe (diameter: $0.3 \mathrm{~cm}$, length: $10 \mathrm{~cm}$ ) connected with the probe into the soil every 10 to 15 days until no differences in $\mathrm{CO}_{2}$ production in comparison to the Control could be detected (compare Schumann et al., 2014a). Each 
measurement lasted for $8 \mathrm{~min}$ and the mean of the maximum and the minimum $\mathrm{CO}_{2}$ value were recorded.

Metarhizium brunneum viability, virulence and persistence

The viability of $M$. brunneum conidia in Kill.s and Kill treatments was assessed qualitatively with four replicates on cetyl trimethyl ammonium bromide based selective medium described by Posadas et al. (2012). A $100 \mu$ l conidia suspension (Kill.s) or ten beads (Kill) were applied in each Petri dish (diameter: 9 cm) (Sarstedt AG \& Co., Nümbrecht, Germany) and stored in a dark climatic cabinet (Mytron $\mathrm{GmbH}$, Heiligenstadt, Germany) at $22^{\circ} \mathrm{C}$ and $65 \%$ relative humidity. M. brunneum growth and sporulation was qualitatively assessed with light microscopy (500X magnification, BH2-HLSH, Olympus Corporation, Tokyo, Japan) for both treatments within all replicates.

M. brunneum (Kill.s, Kill) virulence was tested in Falcon tubes filled with field soil from each field site (Sarstedt AG \& Co., Nümbrecht, Germany). Wireworms (Agriotes spp.) collected from the field and identified to genus level were used in 2013 and $A$. lineatus from a wireworm rearing were used in 2014. Falcon tubes were filled with $40 \mathrm{ml}$ field soil and mixed with $5 \times 10^{7}$ conidia / tube (=2.5 $\pm 0.1 \mathrm{~g}$ Kill' beads / tube; $\sim 1.1 \times 10^{6}$ conidia / g soil) (2013: Control (= bare field soil), Kill and Kill.s treatment with six replicates / treatment; 2014: Control (= bare field soil) and Kill treatment with five replicates / treatment) and moistened with $5 \mathrm{ml}$ tap water. One wireworm (length: $1.2-1.7 \mathrm{~cm}$ ) was placed in a treated Falcon tube. A piece of carrot served as food supply and was placed on the soil surface. The tubes were stored in a dark climatic cabinet (Mytron $\mathrm{GmbH}$, Heiligenstadt, Germany) at $22^{\circ} \mathrm{C}$ and $65 \%$ relative humidity. Carrot slices were replaced after heavy feeding or when mold was observed. Wireworms were assessed for mortality and mycosis weekly, until all wireworms exposed to $M$. brunneum were dead. Dead wireworms without mycosis were surface sterilized according to Lacey \& Solter (2012) and placed into a $9 \mathrm{~cm}$ Petri dish moisture chambers to promote fungal growth if present.

M. brunneum (Kill) establishment and persistence in the field was studied by analyzing the numbers of colony forming units (cfu) per gram soil (in 2014 only). Four soil samples were taken every $100 \mathrm{~cm}$ within the core of potato row centers in $20 \mathrm{~cm}$ depth with a cylindrical soil core sampler (diameter: $1.8 \mathrm{~cm}$ ) in 
the Control and the $A K$-co treatment (replicates 1, 3, $5 \& 7$ ). The soil samples from one plot were mixed in a Zip-lock ${ }^{\mathrm{TM}}$ plastic bag and stored at $6^{\circ} \mathrm{C}$ before further processing. Sampling was done just before treatment application in April at tuber planting $(\mathrm{BBCH}$ 01) and after the treatment application on the day of potato harvest in August / September (BBCH 99; Hack et al., 2001). Isolation of fungal conidia was conducted within two weeks after soil sampling following a protocol provided by Dr. Jürg Enkerli (personal communication, 2014, ISS Agroscope, Zürich, Switzerland). Soil samples were sieved through a $5 \mathrm{~mm}$ mesh (RETSCH $\mathrm{GmbH}$, Haan, Germany) and a $5 \mathrm{~g}$ sub-sample was suspended in $25 \mathrm{ml}$ sterile water with $0.1 \%$ Tween $80 \AA$ (Carl Roth GmbH + Co. KG, Karlsruhe, Germany) in $50 \mathrm{ml}$ Falcon tubes. Each tube was inverted seven times every $30 \mathrm{~min}$ to release propagules from the soil matrix (Inglis et al., 2012). $100 \mu \mathrm{l}$ of the supernatant was spread on semi-selective media (Strasser et al., 1996) in a $9 \mathrm{~cm}$ Petri dish, and incubated in a dark climatic cabinet (Mytron $\mathrm{GmbH}$, Heiligenstadt, Germany) at 22 ${ }^{\circ} \mathrm{C}$. After 14 days Metarhizium spp. were identified by light microscopy (500X magnification, BH2-HLSH, Olympus Corporation, Tokyo, Japan) based on the morphological criteria ((i) conidiogenesis in dense hymenia, (ii) branching conidiophores, (iii) clavate / cylindrical conidia, (iiii) conidia chains) relevant for the genus level (Humber, 2012).

\section{Assessment of wireworm damage}

Potato tubers were manually harvested at the end of August / beginning of September (BBCH 99; Hack et al., 2001) by lifting tubers onto the soil surface with rakes and collecting 100 tubers per replicate within $6 \mathrm{~m}$ of row length, leaving $1 \mathrm{~m}$ from both plot ends. Tubers were stored in the dark at $12^{\circ} \mathrm{C}$ for a maximum of seven days and washed before assessment. Tuber damage was categorized according to EPPO guidelines PP1/46 by differentiating damage severity by classes based on the number of holes from wireworm feeding (class 1: $1-2$ holes, class 2: $3-5$ holes and class 3: $>5$ holes) per tuber (Anonymous, 2005). Wireworm feeding was defined by $a \geq 5 \mathrm{~mm}$ wireworm tunneling in the tuber flesh (Keiser et al., 2012). Wireworm damage was further differentiated by type, referring to wireworm holes only (WW) and wireworm holes with Drycore (Rhizoctonia solani Kühn) symptoms (WW+DC). 
Statistical analysis

Verification of materials performance

Attract: $\mathrm{CO}_{2}$ emission measured in the soil of a field site was pooled across all sampling dates and analyzed for treatment effect (Attract and Control) and field sites by years (2013: Fields 2 \& 3; 2014: Fields 4 - 7) using one-way ANOVA (GLM procedure). $\mathrm{CO}_{2}$ data of field 1 (2013) were not compared to field 2 and field 3 due to the delayed treatment setup. Soil moisture (2013 \& 2014) and soil temperature (2014) were used as predictors and field-sites used as the categorical factor. Differences between treatments were tested with a Tukey HSD test $(\alpha=$ 0.05). A Box-Cox transformation was conducted prior to analysis to normalize the residual distribution.

M. brunneum (Kill.s, Kill): Virulence was analyzed with a Kaplan-Meier survival analysis (log-rank test) (Kaplan \& Meier, 1958) to calculate the median lethal time $\left(\mathrm{LT}_{50}\right)$ to kill wireworms for each field soil. Holm-Sidak pairwise test $(\alpha=$ 0.05) was used to detect significant differences between treatments (Kill.s, Kill). Mycosed wireworms were referred to an "event", whereas symptomless as well as alive wireworms were "censored" within the log-rank test procedure. Establishment and persistence of Metarhizium spp. was tested with a Mann-Whitney $U$ test by comparing the number of isolated cfu / $\mathrm{g}$ soil in a control and $A K$-co plots for each field and sampling date.

\section{Wireworm tuber damage}

Treatments within site were compared using ANOVA followed by Tukey HSD test $(\alpha=0.05)$. The dependent variable was \% tubers within each plot with at least one WW feeding hole, transformed using arcsine to homogenize treatment variances. Outliers were removed according to Grubbs' test $(\alpha=0.05)$. Treatment efficacy was calculated as the reduction (or increase) in wireworm damage relative to the untreated Control according to

Abbott's formula (Abbott, 1987).

Wireworm damage type (WW / WW+DC) and wireworm damage severity (class 1 - 3) in each treatment was analyzed as categorical data on the basis of a 3-way contingency table with generalized linear models using Poisson errors $(R$, function glm; Crawley, 2013). Data from each treatment in each year were pooled 
prior to analysis. Data from Attract were not included in the analysis for 2014 as it was only tested once (field 5). The saturated model, including three-way and twoway interactions between all the explanatory variables, was simplified by comparing generalized linear models with and without interactions using a chisquare test with ANOVA to obtain a minimal adequate model. This model explained the association of the observed data verified by a non-significance of residual deviance (Crawley, 2013) with respect to hierarchy (Hofmann, 2003). Effects of explanatory variables in the minimal model, referring to ratios between treatments, damage type and damage severity were tested with a chi-square test on contingency tables and subjected to Tukey contrasts posteriori (Hothorn et al., 2008). In all analyses, overdispersion did not occur with roughly equal scaled residual (resid.) deviance (dev.) and residual degrees of freedom (df) (Crawley, 2013). Results were plotted as mosaic displays (Hartigan \& Kleiner, 1981, Hartigan \& Kleiner, 1984) using the vcdExtra package (Meyer et al., 2014, Meyer et al., 2006). Categorical counts are represented by tiles and expressed as percentage in relation to the categorical count proportions. The tile widths and heights refer to damage type and damage severity proportional to the total number of damaged tubers within and between treatments.

All analyses were done with STATISTICA, version 12 (StatSoft Inc., Tulsa, OK, USA). Kaplan-Meier survival analysis was done with SigmaPlot, version 11.0 (Analytical Software, Tallahasee, FI, USA) and categorical data assessment of tuber damage were done with $\mathrm{R}$, version 3.0.2 (R Development Core Team, 2013).

\section{Results}

Verification of materials' performance

$\mathrm{CO}_{2}$ production of Attract beads

$\mathrm{CO}_{2}$ level in the soil mixed with Attract beads was significantly higher than in bare soil (Contro) (field 1: $F_{1,9}=21.04, p<0.01$; fields $2 \& 3$ : $F_{1,20}=97.48, p<$ 0.0001 ; fields $4-7: F_{1,24}=35.70, p<0.0001$ ), and was significantly affected by soil type (2013: fields $2 \& 3: F_{1,20}=47.71, p<0.0001 ; 2014$ : fields $4-7: F_{3,24}=$ 
5.19, $p<0.001$ ), but not by a treatment $x$ soil type interaction (2013: fields 2 \& 3 : $F_{1,20}=0.28, p=0.60$; fields $\left.4-7: F_{3,24}=0.05, p=0.99\right) . C O_{2}$ emission by Attract beads lasted for 3 - 6 weeks and peaked after 9 - 12 days in 2013 (989- 6789 ppm increase in soil $\mathrm{CO}_{2}$ ) and 12 - 25 days in 2014 (1081 - 2410 ppm increase in soil $\mathrm{CO}_{2}$ ) (Table 1).

Table 1: Mean and peak ( \pm standard error (SE)) $\mathrm{CO}_{2}$ levels in parts per million (ppm) in soil from seven fields (2013: Fields 1 - 3; 2014: Fields $4-7$ ) treated with $\mathrm{CO}_{2}$ emitting beads (Attract) and untreated (Control). Asterisks $\left(^{*}\right)$ indicate significant differences between treatments / field soil, lower case letters a significant difference between field soils following a Tukey HSD Post-Hoc test $(\alpha=0.05)$ and days past insertion $(\mathrm{dpi})$ is when peak occurred.

\begin{tabular}{|c|c|c|c|c|c|c|c|c|c|c|c|c|c|}
\hline \multirow[b]{2}{*}{ Year } & \multirow{2}{*}{\multicolumn{2}{|c|}{ Field }} & \multicolumn{6}{|c|}{$\mathrm{CO}_{2}$ level mean $(\mathrm{ppm})( \pm \mathrm{SE})$} & \multicolumn{5}{|c|}{$\mathrm{CO}_{2}$ level peak (Attract) } \\
\hline & & & \multicolumn{3}{|c|}{ Control } & \multicolumn{3}{|c|}{ Attract } & \multicolumn{3}{|c|}{ ppm ( \pm SE) } & \multicolumn{2}{|l|}{ dpi } \\
\hline \multirow{3}{*}{$\stackrel{\text { m) }}{\stackrel{\infty}{N}}$} & 1 & & 1506.83 & \pm & 145.79 & 3127.50 & \pm & 409.46 & 6789.17 & \pm & 1314.28 & 9 & * \\
\hline & 2 & a & 649.50 & \pm & 24.21 & 1033.67 & \pm & 42.78 & 1639.17 & \pm & 126.41 & 12 & * \\
\hline & 3 & b & 518.83 & \pm & 15.34 & 733.58 & \pm & 35.24 & 989.17 & \pm & 73.98 & 12 & * \\
\hline \multirow{4}{*}{$\stackrel{+}{\circ}$} & 4 & a & 586.00 & \pm & 32.47 & 962.75 & \pm & 203.27 & 2410.00 & \pm & 966.29 & 25 & * \\
\hline & 5 & a & 584.58 & \pm & 7.12 & 779.17 & \pm & 26.05 & 1132.50 & \pm & 51.21 & 12 & * \\
\hline & 6 & a & 599.38 & \pm & 15.03 & 798.33 & \pm & 26.99 & 1081.25 & \pm & 22.86 & 12 & * \\
\hline & 7 & b & 759.50 & \pm & 95.46 & 1995.50 & \pm & 441.19 & 1122.50 & \pm & 60.84 & 12 & * \\
\hline
\end{tabular}

Metarhizium brunneum virulence and persistence

Mycosed wireworms were found in all M. brunneum treated field soils in 2013 and 2014. LT $_{50}$ could not be calculated for treatments Kill.s (field 2) and Kill (fields $4 \& 6$ ) as less than $50 \%$ of wireworms did not show mycosis at the time of trial termination. The $\mathrm{LT}_{50}$ for wireworms was shorter in the Kill.s (32 - 35 days past insertion (dpi)) than the Kill treatment (56 - 105 dpi in 2013 and 35 - 83 dpi in 2014) (Table 2). A significant delay could only be measured within the Kill treatment in field 3 compared to the Kill.s treatment (Holm-Sidak multiple comparison, $\mathrm{p}<0.01)$. 
Table 2: $\mathrm{LT}_{50}$ in days (median \pm standard error (SE)) and $95 \%$ upper and lower confidence intervals (Cl) of wireworm infection (Agriotes sp. (2013) and A. lineatus (2014)) with M. brunneum (strain: ART2825 conidia suspension (Kill.s) or bead (Kill) in seven field soils after weekly assessment (Kaplan-Meier survival analysis (log-rank test); asterisk ( ${ }^{*}$ ) indicates significant difference between treatments of field soil (Holm-Sidak pairwise tests $(\alpha=0.05))$.

\begin{tabular}{|c|c|c|c|c|c|c|c|c|c|c|c|}
\hline \multirow[b]{3}{*}{ Year } & \multirow[b]{3}{*}{ Field } & \multicolumn{4}{|c|}{ Kill.s } & \multicolumn{6}{|c|}{ Kill } \\
\hline & & \multirow{2}{*}{\multicolumn{2}{|c|}{ median \pm SE }} & \multicolumn{2}{|c|}{$95 \% \mathrm{Cl}$} & \multirow{2}{*}{\multicolumn{3}{|c|}{ median $\pm S E$}} & \multicolumn{3}{|c|}{$95 \% \mathrm{Cl}$} \\
\hline & & & & lower & upper & & & & lower & upper & \\
\hline \multirow{3}{*}{$\frac{m}{\circ}$} & 1 & $32 \pm$ & 6.86 & 18.56 & 45.44 & 81 & \pm & 6.26 & 68.73 & 93.27 & \\
\hline & 2 & \multicolumn{4}{|c|}{ n.a. } & 56 & \pm & 22.86 & 11.19 & 100.81 & \\
\hline & 3 & $35 \pm$ & 10.50 & 14.42 & 55.58 & 105 & \pm & 6.00 & 93.24 & 116.76 & * \\
\hline \multirow{4}{*}{$\stackrel{\nabla}{\stackrel{\sim}{\circ}}$} & 4 & \multicolumn{4}{|c|}{ n.t. } & \multicolumn{6}{|c|}{ n.a. } \\
\hline & 5 & \multicolumn{4}{|c|}{ n.t. } & 83 & \pm & 30.67 & 22.88 & 143.12 & \\
\hline & 6 & \multicolumn{4}{|c|}{ n.t. } & \multicolumn{6}{|c|}{ n.a. } \\
\hline & 7 & \multicolumn{4}{|c|}{ n.t. } & 35 & \pm & 16.43 & 2.80 & 67.21 & \\
\hline
\end{tabular}

n.t.: not tested, n.a. not available

An application of $A K$-co beads increased Metarhizium spp. abundance in all fields with up to $10,000 \mathrm{cfu} / \mathrm{g}$ soil measured in field 5 , but was only significantly higher compared to the untreated Control at the second time of soil sampling in August / September (BBCH 99) in field 5 (Mann-Whitney $U$ test: $z=-2.02, p<$ 0.05). Metarhizium spp. was isolated from the soil before treatment application (April / BBCH 01) in field 5 and field 6 (Table 3). 
Chapter 3: Wireworm damage reduction in potatoes with attract-and-kill

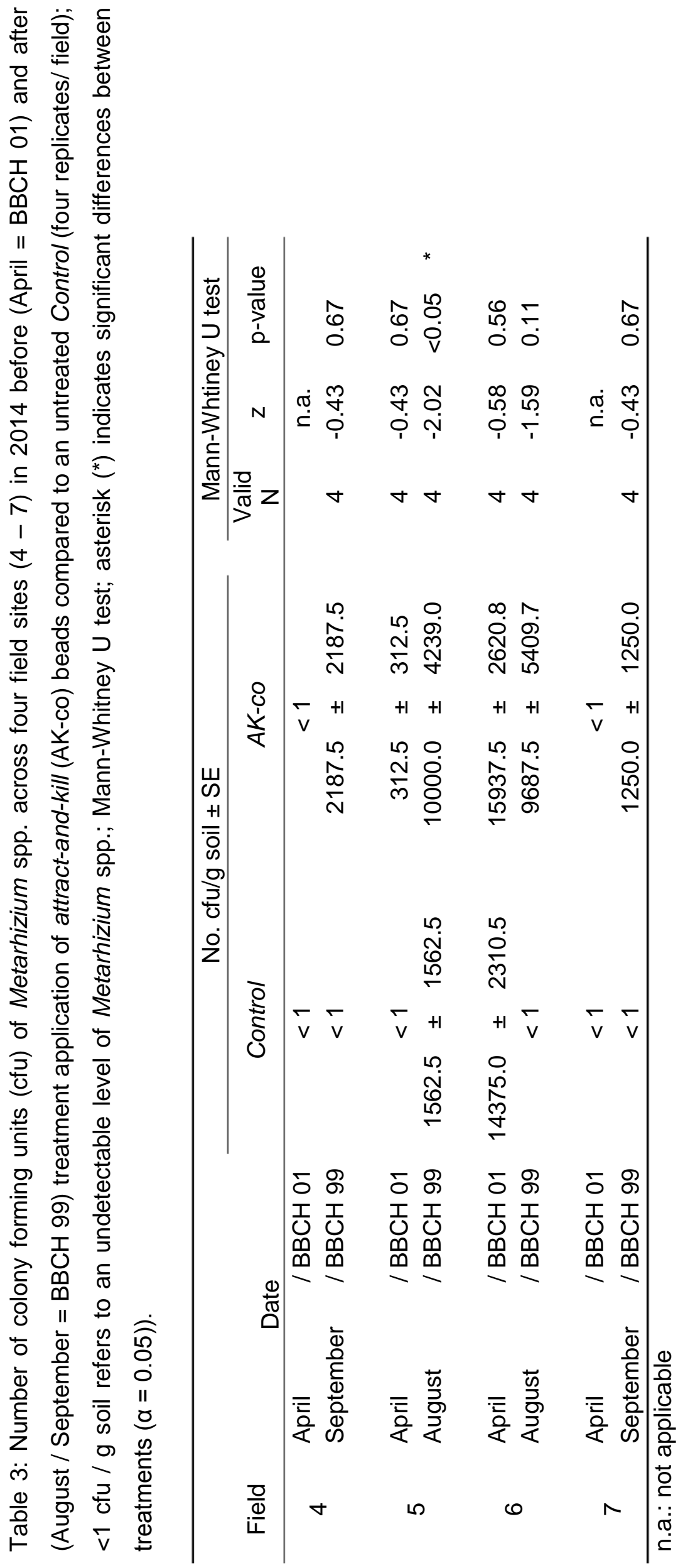


Wireworm tuber damage

Wireworm damage in the untreated Control ranged from $9-35 \%$ across all fields in both years. In 2013 tuber damage was neither significantly reduced with a late $(\mathrm{BBCH} 40)$ nor with an early $(\mathrm{BBCH} 01)$ spot application between potato tubers at field $1\left(F_{4,25}=0.60, p=0.66\right)$ and at field $2\left(F_{4,25}=1.07, p=0.39\right)$, respectively. An early ( $\mathrm{BBCH} 01)$ spot underneath application (fields $3-5$ ) reduced tuber damage in all M. brunneum treatments (Kill.s, Kill and AK-co) in both years, but was only significantly reduced with a spot underneath $A K$-co treatment (field 3: $F_{4,25}=3.26, p<0.05$; field 4: $F_{2,21}=5.19, p<0.05$; field 5: $F_{3,27}=$ $5.29, \mathrm{p}<0.01)$. An early (BBCH 01) band application in 2014 significantly reduced damage with a Kill, but not with an $A K$-co treatment (field 6: $F_{2,21}=3.71, p<0.05$; field 7: $\left.F_{2,21}=6.29, p<0.01\right)$. An Attract treatment never resulted in a reduced tuber damage compared to the untreated control level regardless of application type and time (field $1-3$ and field 5) (Fig. 1).

The efficacy of $M$. brunneum treatments was higher with an early application at $\mathrm{BBCH} 01$ (fields 2 - 7: $51-75 \%$ ) than a late application at $\mathrm{BBCH} 40$ (field 1: no efficacy found). The performance of an early application of $M$. brunneum treatments was affected by the type of application (Table 4): A Kill treatment reached a $55 \%$ efficacy with a band compared to $40-51 \%$ as a spot treatment. Performance of non-encapsulated conidia (Kill.s) was better in both spot treatments $(60-63 \%)$ than of encapsulated ones (Kill). An AK-co treatment performed better as a spot underneath (75\%) than a band (37\%) and a spot between treatment (56\%). An Attract only treatment did not result in a tuber damage reduction (Table 4). 
2013
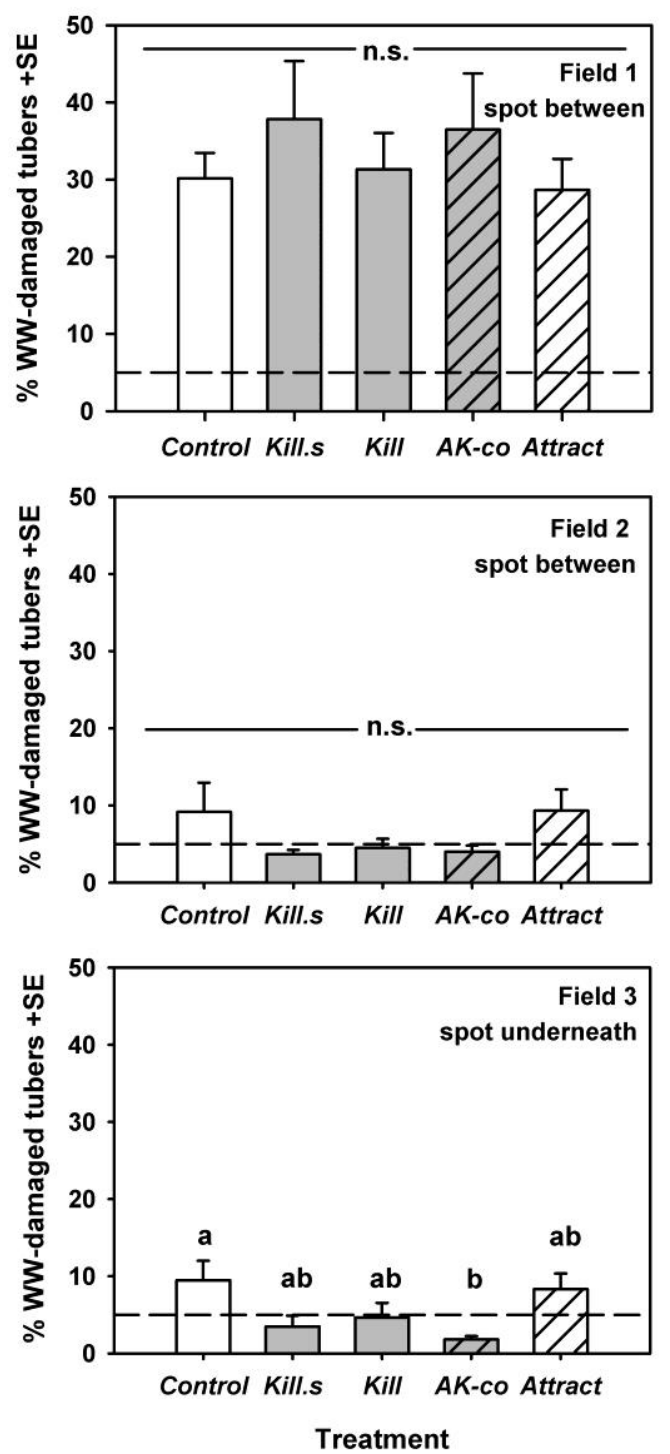

2014
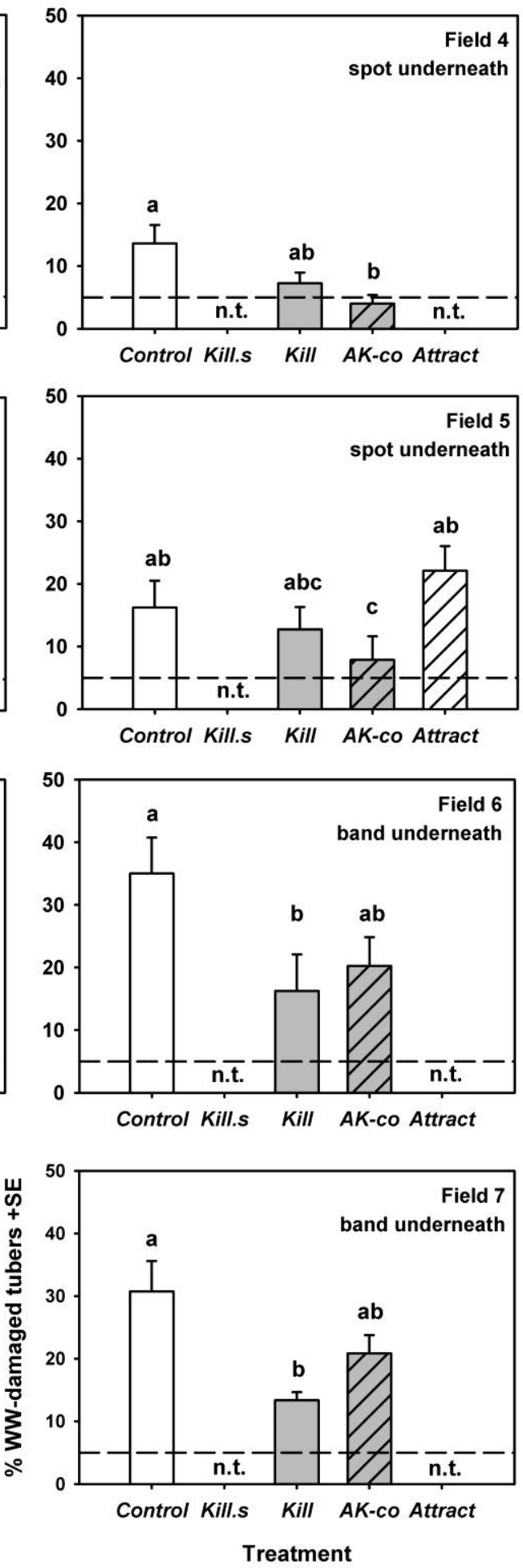

Fig. 1: Percentage of wireworm (WW)-damaged potato tubers (mean + standard error mean (SE)) at seven field-sites (2013: Fields 1 - 3; 2014: Fields $4-7$ ) with treatments applied at a spot between / underneath or in a band underneath seed potatoes Control: Untreated potato rows; Kill.s: M. brunneum (ART2825) conidia suspension; Kill: $M$. brunneum (ART2825) conidia beads; AK-co: attract and kill beads; Attract: Attract beads. One-way ANOVA; different lower case letters indicate significant difference after Tukey HSD test $(\alpha=0.05)$ (dashed line $(---)=5 \%$ economic threshold level; $n$. t. = not tested). 


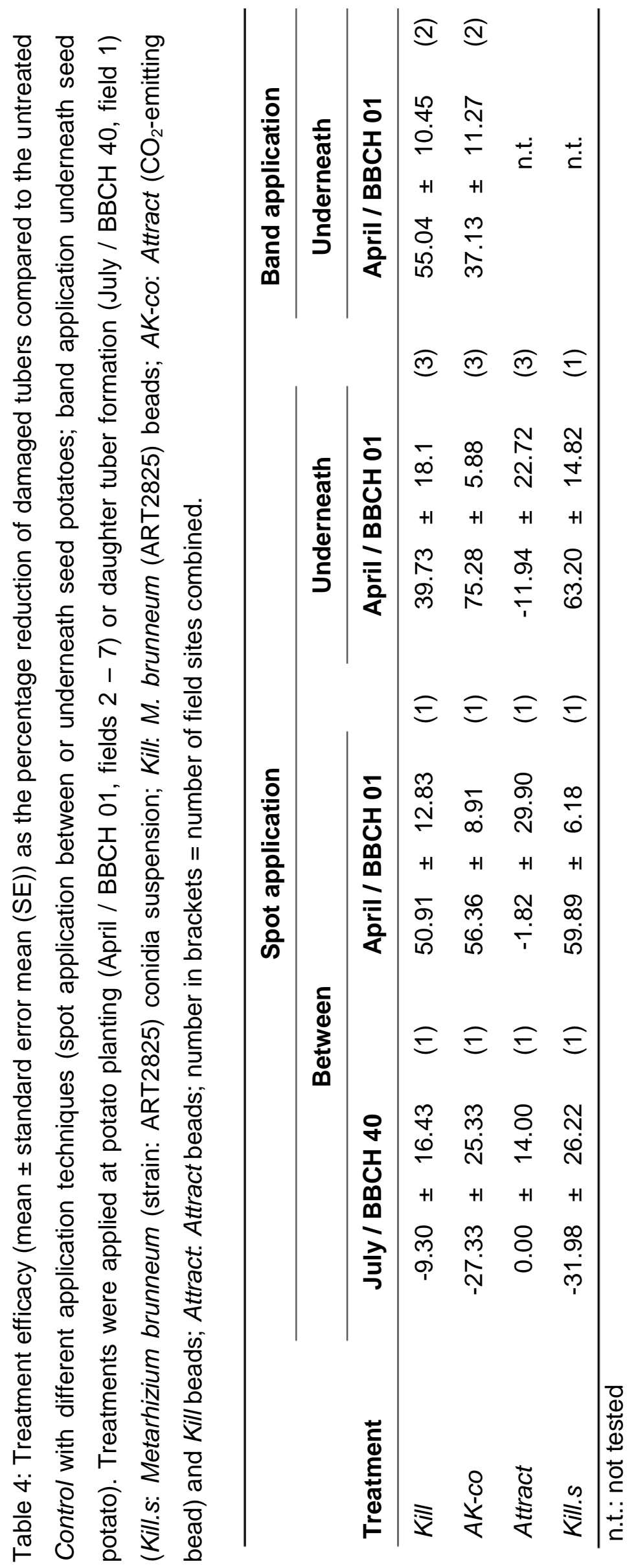


In 2013 damage pattern depended on a treatment $x$ damage type interaction (chi-square test: Resid. $d f=12$, resid. deviance (dev.) $=27.34 p<$ 0.001 ), as well as on a damage type $x$ damage severity interaction (chi-square test: Resid. df $=10$, resid. dev. $=37.85 p<0.001$ ). In 2014 damage pattern depended on a treatment $x$ damage type interaction (chi-square test: Resid. $d f=6$, resid. dev. $=22.69 p<0.001)$ and on a treatment $x$ damage severity interaction (chi-square test: Resid. $d f=8$, resid. dev. $=49,48 p<0.001$ ) (Fig. 2). The total \% of damaged tubers was significantly affected by treatments in 2014 (chi-square = 186.03, $p<0.001$ ), but not in 2013 (chi-square $=9.07, p=0.06$ ), not taking damage type and damage severity into account. In 2013 damaged potatoes ranged between 19 - 23\% overall in treatments, whereas in 2014 50\% of damaged tubers were recorded in the untreated Control and equal ratios of $25 \%$ tuber damages were recorded in the Kill and $A K$-co treatment. In both years, there were significantly more damaged tubers with wireworm holes than wireworm holes with Drycore symptoms (WW / WW+DC) (2013: chi-square $=98.67, p<0.001$; 2014: chi-square $=161.00, p<0.001$ ), when damage severity was not taken into account. The ratio of \% damaged tubers with wireworm holes to wireworm holes with dry core symptoms (WW / WW+DC) was smaller in the AK-co treatment (2013: 53\% / 47\%, 2014: 57\% / 42\%) than in the other tested treatments (2013: 63 - 68\% / 32 - 37\%; 2014: 67\% - 72\% / 29\% - 33\%). The tuber damage severities significantly differed by classes in both years (2013: chi-square $=1817.08, p<$ $0.001 ; 2014$ : chi-square $=2146.87, \mathrm{p}<0.001)$. Highest damage severity occurred within class 1 (2013: 89 - 94\% / 76 - 91\%; 2014: 84 - 94\% / 83 - 96\%), followed by class 2 (2013: 5 - 10\% / 7 - 19\%; 2014: 5 - 11\% / 5 - 11\%) and class 3 (2013: $0.6-2 \% / 1-8 \% ; 2014: 0.9-6 \% / 0-6 \%$ ) across all treatments (Fig. 2). 

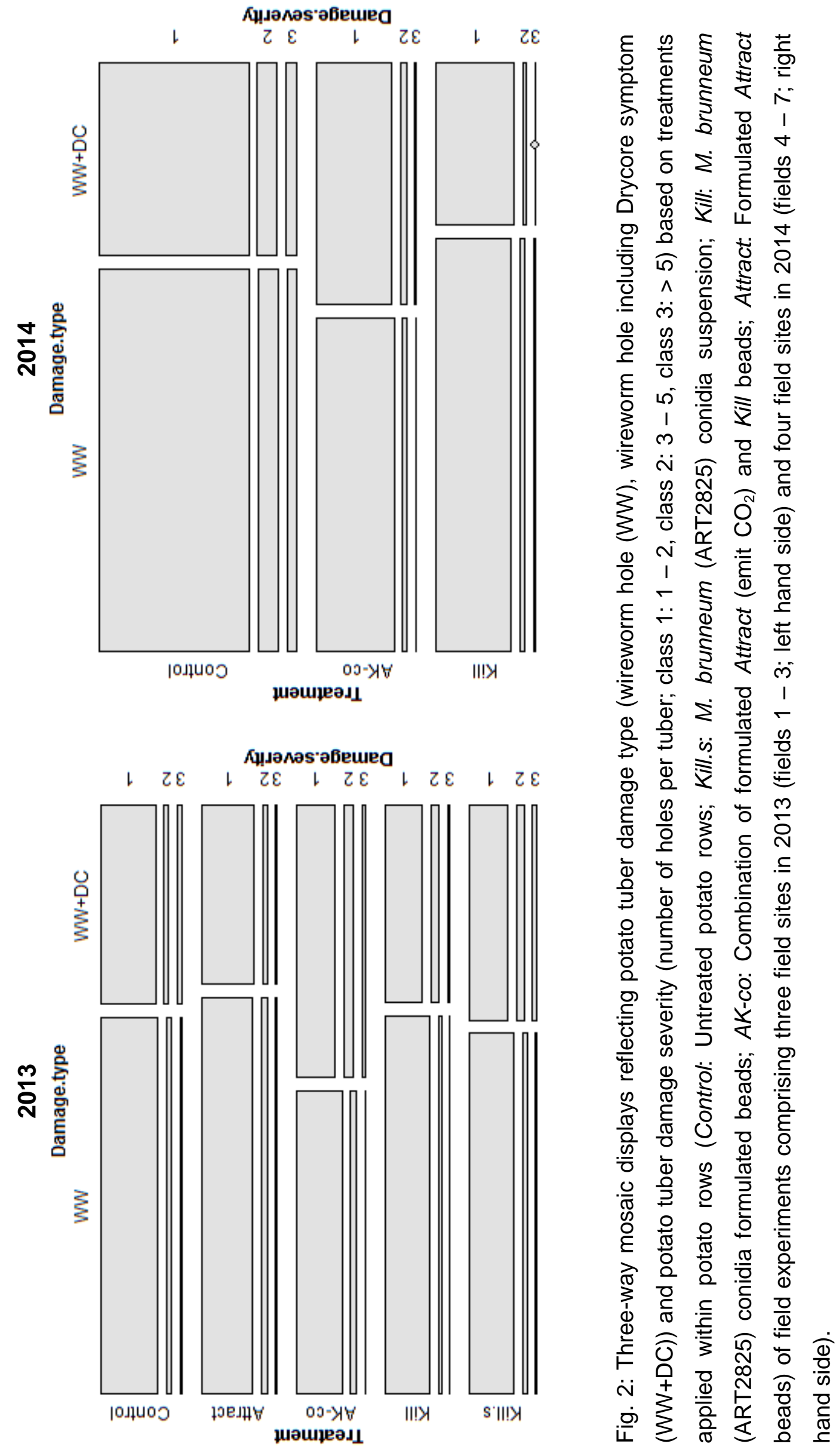


\section{Discussion}

This study aimed to test an "attract-and-kill" (AK) strategy against wireworms (Agriotes spp.) that might be implemented in organic potato production. Both attractant and infective agents were active in the soil, but differed in their activity in different soil types. The implementation of AK enhanced EPF efficacy and significantly reduced wireworm damage, but was dependent on the time and type of application. An early application as a spot treatment underneath the seed potato resulted in the highest efficacy and offers a new strategy for wireworm control.

Verification of materials' performance

$\mathrm{CO}_{2}$ production of Attract beads

The application of Attract beads in bare field soil increased $\mathrm{CO}_{2}$ soil levels up to 2.6-fold, depending on soil type and application dates (Table 1). $\mathrm{CO}_{2}$ emission in the soil lasted for at least four weeks, comparable to time spans with beads used by Schumann et al. (2014b) and Vemmer et al. (2016), and can be regarded as long enough to coincide with wireworm activity in spring (Traugott et al., 2015). A late application in July (BBCH 40) (Table 1; field 1) resulted in higher $\mathrm{CO}_{2}$ levels than an application in April ( $\left.\mathrm{BBCH} 01\right)$ (Table 1; fields $\left.2-7\right)$, most likely due to higher soil temperatures, which is in line with lab studies on temperature dependence of encapsulated baker's yeast (Pascal Humbert, personal communication, 2016, University of Applied Sciences, Bielefeld, Germany). Such an increase of $\mathrm{CO}_{2}$ levels can alter wireworm host location behavior and activity (Traugott et al., 2015) as differences of at least $1-2$ ppm may already be sufficient to recognize potential host plants by the wireworms (Doane et al., 1975).

The performance of Attract beads is described by Vemmer et al. (2016) and can be explained as follows: The starch acts as a carbon reservoir. Soil microorganisms producing exoenzymes with amylase activity degrade the starch molecules into mono- and disaccharides subsequently converted into $\mathrm{CO}_{2}$ molecules by the baker's yeast. Additionally, soil organism activity, temperature and moisture influence measured $\mathrm{CO}_{2}$ levels from soil (Lundegardh, 1927, Turpin, 
1920). Differences in pore size of coarse and fine textured soils may influence the activity patterns of aerobic and anaerobic microorganisms. Soils with small pore sizes (e.g. clay) increase activity of obligate and facultative anaerobes, consequently increasing soil respiration due to the exclusion of concomitant oxygen uptake (Rixon \& Bridge, 1968). This is reflected in the data on $\mathrm{CO}_{2}$ emission for sandy (fields $3,4 \& 6$ ), silty (fields $2,5 \& 7$ ) and clayey (field 1) field soils which resulted in low (568 ppm), intermediate (665 ppm) and high (1507 ppm) $\mathrm{CO}_{2}$ emissions, respectively (Table 1 / Table S1). Changes in microbial soil activity may therefore play an important role in $\mathrm{CO}_{2}$ production by Attract beads besides soil temperature, soil moisture and chemical soil properties (Raich \& Schlesinger, 1992, Rovira, 1953, Lundegardh, 1927).

Metarhizium brunneum - laboratory

Mycosed wireworms were found in all $M$. brunneum treatments and soil types. Wireworm death could not always be referred to an M. brunneum infection, accounting for the missing $\mathrm{LT}_{50}$ values (Table 2). An $\mathrm{LT}_{50}$ of $32-35$ days with non-encapsulated conidia (Kill.s) was longer than reported in previous studies using the same M. brunneum strain (ART2825) (e.g. Eckard et al., 2014). Wireworms collected from the field were not identified to species level in 2013. This may have resulted in a variable and prolonged $L T_{50}$ and a lower percentage of mycosed wireworms as susceptibility differs between wireworm species of the Agriotes spp. genus (Eckard et al., 2014). Furthermore, dipping wireworms into a conidia suspension, as done by Eckard et al. (2014), results in more homogenous M. brunneum inoculum attachment to the wireworm cuticle, which cannot be verified with a soil application technique used in this study. $\mathrm{LT}_{50}$ values of Kill beads in field soil for the 2014 field trials were comparable to 2013 (Table 2), despite the use of wireworm identified to species level (A. lineatus). The variability of the data in both years may therefore indicate that soil type influences $M$. brunneum infection. It is known that soil type affects conidial vertical movement and physical loss of inoculum (Inglis et al., 2001), most probably due to soil-water content relationship with soil texture (Saxton et al., 1986). Our data do not provide a clear picture, but a higher and faster infection was measured in clayey (field 1) and silty (field 7) soil than in sandy soil (field 3). 
Virulence enhancement could not be verified through the use of dead baker's yeast (Shah et al., 2005), within Kill beads and opposite to our expectations seemed to significantly increase $\mathrm{LT}_{50}$ values compared to a conidia suspension (Kill.s) (Table 2; field 3). This might be due to a later formation of infective conidia on the bead surface as M. brunneum needs to grow out of beads for an infection, and a more aggregated spatial distribution of conidia in the soil. Gillespie \& Claydon (1989) emphasize the need of EPF applications in "moistureretaining formulations" for a favourable environment (e.g. > 93\% relative humidity) to promote mycelial growth and conidial germinations. This can be especially important for improvement of soil pest control in the field where dryness may appear frequently.

\section{Metarhizium brunneum - field}

An AK-co application increased Metarhizium spp. abundance in the soil with both a spot and band application (Table 3), indicating an establishment and persistence within the potato growing period, required for the effectiveness of EPF (Inyang et al., 2000). Thus germinating M. brunneum conidia used starch as an energy source but would need to grow on root exudates or insects to truly "establish" in soil. Hu \& St Leger (2002) discussed rhizosphere competence as an attribute of EPF establishment and found higher EPF densities within the rhizosphere than within bare soil following an artificial application. This may be owed to the rhizosphere site being the most likely site of insect and pathogen interactions, thus maintaining EPF abundance (St. Leger, 2008). Whether conidia can persist up to the following cultivation period needs to be examined in more detail as densities tend to decrease rapidly during the winter period (Pilz et al., 2011). Biodegradation, physical weathering and percolation of conidia to deeper layers also affect persistence (Vanninen et al., 2000). An encapsulation may reduce these antagonistic factors to some extent (Vemmer \& Patel, 2013). Such persistence periods, however, would be vital to determine the need of a reapplication of $M$. brunneum beads for wireworm control in the following seasons.

Natural occurrence of Metarhizium spp. was found twice prior to AK-co treatment application (Table 3; field $5 \& 6$ ). The natural abundance of EPF is reported to be variable, influenced by various factors such as geographical location (Vanninen, 1996, Bidochka et al., 1998), land management (Meyling \& 
Eilenberg, 2007) and soil type (Keller et al., 2003). Arable land can contain lower EPF densities than other habitat types (e.g. meadows) due to the negative side effects of control measures (e.g. fungicide application such as benomyl; Mietkiewski et al., 1997) affecting host abundance (Keller et al., 2003). Nevertheless the data published on EPF incidence underline the potential contribution of Metarhizium spp. in the regulation of wireworm populations (Kabaluk et al., 2007), although not on an economic scale as damage levels in those fields were still high (Table 3). Because verification of Metarhizium spp. abundance in the tested fields via morphological characteristics (Humber, 2012) was performed by light microscopy, differentiation between natural and artificially introduced EPF strains was not possible. New diagnostic tools, using microsatellite markers, allowing identifying and comparing the introduced $M$. brunneum strain with those present in the field may have provided a better understanding of the fate of the introduced M. brunneum strain in these soils.

\section{Wireworm tuber damage}

Tuber damage in the untreated Control varied from $9-35 \%$ (Fig. 1) across all seven field sites due to their differences in cropping history, soil type, weed density, geographical features and the number of wireworms present within the specific field sites (Fox, 1961, Furlan, 2004, Cherry \& Stansly, 2008, Hermann et al., 2013, Parker \& Howard, 2001). Weed cover was not specifically monitored, although weed density can influence wireworm abundance (Parker \& Howard, 2001). Moreover, harvest dates may have influenced tuber damage with late dates (September) increasing the potential of tuber damages simply by a prolonged phase of tubers exposed to wireworms as compared to early dates (August) (Neuhoff et al., 2007).

An M. brunneum treatment resulted in better control with an early $(\mathrm{BBCH}$ 01) application during potato planting in April than during daughter tuber formation (BBCH 40) in June - August (Table S2 / Fig. 1). The times of treatment application during spring were chosen as wireworms' exhibit strong seasonal activity through a vertical movement in the soil profile. They tend to reside in the upper soil layers to feed on plant material in early spring and again in autumn (Traugott et at; 2015), when soil moisture and temperature are suitable (Parker \& Howard, 2001, Lafrance, 1968, Traugott et al., 2015), and move into deeper soil layers between 
these feeding periods (Traugott et al., 2015). Therefore, the likelihood of wireworm treatment encounter is increased as basically only the seed potato and the treatments are $\mathrm{CO}_{2}$ sources; whereas in the mid-summer multiple distracting $\mathrm{CO}_{2}$ sources such as daughter tubers or weeds are present in the field decreasing the likelihood of wireworm treatment encounter. Because time until M. brunneum infection of wireworms takes between three weeks to three months (Table 2), this period might therefore be too long to prevent wireworms from feeding on daughter tubers when a later application strategy of AK is implemented. As a consequence, tuber damage may be high and calls for a strategy targeting wireworms as early as possible with $M$. brunneum in the growing season.

The $A K$-co control efficacies ranged from $38-75 \%$ with an early application in April (Table 4), comparable to insecticidal control measures (Vernon et al., 2013). When M. brunneum conidia were applied highly concentrated (spot application underneath seed potato), tuber damage was significantly reduced and increased M. brunneum (Kill) efficacy by 35\% (Table 4). We hypothesize that a mixture of Attract and Kill beads interact synergistically through an increased probabilty of wireworms to come into contact with $M$. brunneum conidia. This interaction leads to a better infection than with a M. brunneum (Kill.s, Kill) treatment alone. The spot underneath treatment may also benefit by the attraction through the seed potato itself, increasing the probability of infection compared to a spot treatment between the tubers. Although the enhanced attraction to the seed potatoes may result in an increased feeding at these tubers, this additonal damage may not be detrimental to tuber yields, as seed potato feeding rarely affects plant growth (Parker \& Howard, 2001).

The application of Attract beads alone did not reduce tuber damage and supports the hypothesis of a temporary attraction of the wireworms, also discussed for AK field trials with western corn rootworm larvae (Diabrotica virgifera virgifera LeConte) (Schumann et al., 2014b). Preliminary laboratory trials using rhizotrons allowing to observe wireworm movement and activity showed that wireworms move to beads and also feed on beads, but move away after a certain time period when food sources are depleted searching for other food sources (Schumann, unpublished). This mechanism underlines the simultaneous need for a killing agent at the spot of attraction to enhance wireworm control efficacy. 
A band application of $A K-c o$ beads did neither significantly reduce tuber damage nor enhance $M$. brunneum efficacy. In this treatment the spatial arrangement of conidia differed to a spot treatment as conidia were spread across a larger soil volume, ultimately resulting in a lower number of conidia to attach to attracted wireworms. Furthermore, the use of two types of beads (Attract and Kill) led to a separation (up to $1 \mathrm{~cm}$ space between beads) when spread in a furrow during treatment set up, which was not the case in a spot treatment. This reduced the chance of a successful infection of the wireworms and attraction would therefore not always lead to a wireworm spore contact. In contrast, an $M$. brunneum band application alone (Kill) significantly reduced tuber damage. Increased emigration of wireworm from adjacent guard rows by the $\mathrm{CO}_{2}$ attractant towards the $A K-c o$ treated plots may have led to higher pest pressure without successful infection as compared to Kill treated plots only. An application of coformulated beads, with encapsulated baker's yeast and EPF in a single bead, may overcome this problem and should be considered as practically more feasible.

The proportion of wireworm damaged tubers showing Drycore (Rhizoctonia solani) symptoms increased with an $A K$-co application (Fig. 2). As this only occurred with $A K-c o$ beads combined, there may be an unknown interaction of the baker's yeast and the M. brunneum with other soil microorganisms. This finding needs to be evaluated in field experiments to avoid an increase of phytopathogenic fungi in soil and consequently at daughter tubers.

\section{Conclusion}

The AK approach offers a new strategy to enhance the efficacy of $M$. brunneum against wireworms, by combining $M$. brunneum with artificial $\mathrm{CO}_{2}$ sources. The activity of Attract and Kill components is influenced by soil properties and their efficacy affected by the spatial arrangements in the soil. Further evaluation of this strategy with more advanced formulations (e.g. dried co-encapsulation of $A K-c o$ components in one bead) to enable an application with technical equipment and testing lower doses per hectare to ensure cost-effectiveness is needed so that farmers can implement biological control against wireworms. 


\section{Acknowledgements}

These studies were funded by means of the $7^{\text {th }}$ Framework Programme of the European Union 282767 as a part of the project INBIOSOIL (http://inbiosoil.uni-goettingen.de). We would like to thank Bianca Tappe, Daniel Kretschmar and Marie Nörtemann for their technical assistance, numerous students, in particular Thies Fellenberg, for their contribution, and Dr. Christian Ahl (Georg-August-Universität Göttingen, Germany) for conducting the soil analysis. Furthermore we would like to thank Wilfried Dreyer (Ökoring AG, Visselhövede, Germany) for his professional support, Agroscope (Reckenholz, Switzerland) for providing the strain ART2825 and all farmers for providing field sites. Finally we would like to thank Todd Kabaluk (Agriculture and Agri-Food Canada) for commenting on a draft of the manuscript.

\section{Compliance with Ethical Standards}

Funding: Work on these studies was funded by means of the 7 th Framework Programme of the European Union 282767 as a part of the project INBIOSOIL (http://inbiosoil.uni-goettingen.de).

Conflict of Interest: The authors declare no conflict of interest.

Ethical approval: This article does not contain any studies with human participants or vertebrate animals performed by any of the authors.

\section{References}

Abbott, W. S. (1987) Abbotts formula - a method of computing the effectiveness of an insecticide. Journal of the American Mosquito Control Association, 3, 302-303.

Anonymous (2005) Wireworms. Bulletin OEPP/EPPO Bulletin, 35, 179-182.

Anonymous (2012) Design and analysis of efficacy evaluation trials. Bulletin OEPP/EPPO Bulletin, 42, 367-381.

Bidochka, M. J., Kasperski, J. E. \& Wild, G. a. M. (1998) Occurrence of the entomopathogenic fungi Metarhizium anisopliae and Beauveria bassiana in 
soils from temperate and near-northern habitats. Canadian Journal of Botany-Revue Canadienne De Botanique, 76, 1198-1204.

Bischoff, J. F., Rehner, S. A. \& Humber, R. A. (2009) A multilocus phylogeny of the Metarhizium anisopliae lineage. Mycologia, 101, 512-530.

Cherry, R. \& Stansly, P. (2008) Abundance and spatial distribution of wireworms (Coleoptera: Elateridae) in Florida sugarcane fields on muck versus sandy soils. Florida Entomologist, 91, 383-387.

Crawley, M. J. (2013) The R Book - second edition, London, UK, John Wiley \& Sons, Ltd.

Doane, J. F., Lee, Y. W., Klingler, J. \& Westcott, N. D. (1975) Orientation response of Ctenicera destructor and other wireworms (Coleoptera: Elateridae) to germinating grain and to carbon-dioxide. Canadian Entomologist, 107, 1233-1252.

Eckard, S., Ansari, M. A., Bacher, S., Butt, T. M., Enkerli, J. \& Grabenweger, G. (2014) Virulence of in vivo and in vitro produced conidia of Metarhizium brunneum strains for control of wireworms. Crop Protection, 64, 137-142.

European Food Safety Authority (2013) Conclusion on the peer review of the pesticide risk assessment for bees for the active substance fipronil. EFSA Journal, 11(5):3158, 1-51.

European Parliament and the Council of the European Union (2009a) Directive 2009/128/EC of the European Parliament and of the Council of 21 October 2009 establishing a framework for Community action to achieve the sustainable use of pesticides. Official Journal of the European Union, 52, 71-86.

European Parliament and the Council of the European Union (2009b) Regulation (EC) No 1107/2009 of the European Parliament and of the Council of 21 October 2009 concerning the placing of plant protection products on the market and repealing Council Directives 79/117/EEC and 91/414/EEC. Official Journal of the European Union, 52, 1-50.

Fox, C. J. S. (1961) The distribution and abundance of wireworms in the Annapolis Valley of Nova Scotia. Canadian Entomologist, 93, 276-279.

Furlan, L. (2004) The biology of Agriotes sordidus Illiger (Col., Elateridae). Journal of Applied Entomology, 128, 696-706. 
Furlan, L., Bonetto, C., Finotto, A., Lazzeri, L., Malaguti, L., Patalano, G. \& Parker, W. (2010) The efficacy of biofumigant meals and plants to control wireworm populations. Industrial Crops and Products, 31, 245-254.

Gillespie, A. T. \& Claydon, N. (1989) The use of entomogenous fungi for pestcontrol and the role of toxins in pathogenesis. Pesticide Science, 27, 203215.

Gunasekara, A. S., Truong, T., Goh, K. S., Spurlock, F. \& Tjeerdema, R. S. (2007) Environmental fate and toxicology of fipronil. Journal of Pesticide Science, 32, 189-199.

Hack, H., Gall, H., Klemke, T., Klose, R., Meier, U., Stauss, R. \& Witzen-Berger, A. (2001) Potato. In: Meier, U. (ed.) Growth stages of mono-and dicotyledonous plants. Germany: Federal Biological Research Centre for Agriculture and Forestry.

Hartigan, J. A. \& Kleiner, B. (1981) Mosaics for contingency tables. In: Eddy, W. F. (ed.) Computer Science and Statistics: Proceedings of the 13th Symposium on the Interface. New York, US: Springer-Verlag.

Hartigan, J. A. \& Kleiner, B. (1984) A mosaic of television ratings. American Statistician, 38, 32-35.

Hermann, A., Brunner, N., Hann, P., Wrbka, T. \& Kromp, B. (2013) Correlations between wireworm damages in potato fields and landscape structure at different scales. Journal of Pest Science, 86, 41-51.

Hofmann, H. (2003) Constructing and reading mosaicplots. Computational Statistics \& Data Analysis, 43, 565-580.

Hothorn, T., Bretz, F. \& Westfall, P. (2008) Simultaneous inference in general parametric models. Biometrical Journal, 50, 346-363.

Hu, G. \& St Leger, J. (2002) Field studies using a recombinant mycoinsecticide (Metarhizium anisopliae) reveal that it is rhizosphere competent. Applied and Environmental Microbiology, 68, 6383-6387.

Humber, R. A. (2012) Identification of entomopathogenic fungi. In: Lacey, L. A. (ed.) Manual of Techniques in Invertebrate Pathology London, UK: Academic Press.

Hyslop, J. A. (1915) Wireworms attacking cereal and forage crops. Bulletin of the U.S. Department of Agriculture, 156, 1-34. 
Inglis, G. D., Enkerli, J. \& Goettel, M. S. (2012) Laboratory techniques used for entomopathogenic fungi: Hypocreales. In: Lacey, L. A. (ed.) Manual of Techniques in Invertebrate Pathology. London, UK: Academic Press.

Inglis, G. D., Goettel, M. S., Butt, T. M. \& Strasser, H. (2001) Use of hyphomycetous fungi for managing insect pests. In: Butt, T. M., Jackson, C. \& Magan, N. (eds.) Fungi as Biocontrol Agents. Progress, Problems and Potential. Wallingford, UK: CABI Publishing.

Inyang, E. N., Mccartney, H. A., Oyejola, B., Ibrahim, L., Pye, B. J., Archer, S. A. \& Butt, T. M. (2000) Effect of formulation, application and rain on the persistence of the entomogenous fungus Metarhizium anisopliae on oilseed rape. Mycological Research, 104, 653-661.

Jansson, R. K. \& Seal, D. R. (1994) Biology and management of wireworm on potato. In: Zehnder, G. W., Powelson, M. L., Jansson, R. K. \& Raman, K. V. (eds.) Proceedings of the International Conference on "Advances in Potato Pest Biology and Management". St. Paul, US: American Phytopathological Society Press.

Johnson, S. N., Anderson, E. A., Dawson, G. \& Griffiths, D. W. (2008) Varietal susceptibility of potatoes to wireworm herbivory. Agricultural and Forest Entomology, 10, 167-174.

Kabaluk, J. T., Vernon, R. S. \& Goettel, M. S. (2007) Mortality and infection of wireworm, Agriotes obscurus [Coleoptera : Elateridae], with inundative field applications of Metarhizium anisopliae. Phytoprotection, 88, 51-56.

Kaplan, E. L. \& Meier, P. (1958) Nonparametric-estimation from incomplete observations. Journal of the American Statistical Association, 53, 457-481.

Keiser, A., Haberli, M. \& Stamp, P. (2012) Drycore appears to result from an interaction between Rhizoctonia solani and wireworm (Agriotes ssp.) evidence from a 3-year field survey. Potato Research, 55, 59-67.

Keller, S., Kessler, P. \& Schweizer, C. (2003) Distribution of insect pathogenic soil fungi in Switzerland with special reference to Beauveria brongniartii and Metharhizium anisopliae. Biocontrol, 48, 307-319.

Kölliker, U., Biasio, L. \& Jossi, W. (2011) Potential control of swiss wireworms with entomopathogenic fungi. IOBC/wprs Bulletin, 66, 517-520. 
Lacey, L. A. \& Solter, L. F. (2012) Initial handling and diagnosis of diseased invertbrates. In: Lacey, L. A. (ed.) Manual of Techniques in Invertebrate Pathology London, UK: Academic Press.

Lafrance, J. (1968) The seasonal movements of wireworms (Coleoptera: Elateridae) in relation to soil moisture and temperature in the organic soils of southwestern Quebec. The Canadian Entomologist, 100, 801-807.

Lundegardh, H. (1927) Carbon dioxide evolution and crop growth. Soil Science, 23, 417-453.

Meyer, D., Zeileis, A. \& Hornik, K. (2006) The strucplot framework: Visualizing multi-way contingency tables with vcd. Journal of Statistical Software, 17, $1-48$.

Meyer, D., Zeileis, A. \& Hornik, K. (2014) vcd: Visualizing Categorical Data. R package version 1.3-2.

Meyling, N. V. \& Eilenberg, J. (2007) Ecology of the entomopathogenic fungi Beauveria bassiana and Metarhizium anisopliae in temperate agroecosystems: Potential for conservation biological control. Biological Control, 43, 145-155.

Mietkiewski, R. T., Pell, J. K. \& Clark, S. J. (1997) Influence of pesticide use on the natural occurrence of entomopathogenic fungi in arable soils in the UK: Field and laboratory comparisons. Biocontrol Science and Technology, 7, 565-575.

Neuhoff, D., Christen, C., Paffrath, A. \& Schepl, U. (2007) Approaches to wireworm control in organic potato production. IOBC/wprs Bulletin, 30, 6568.

Parker, W. E. \& Howard, J. J. (2001) The biology and management of wireworms (Agriotes spp.) on potato with particular reference to the U.K. Agricultural and Forest Entomology, 3, 85-98.

Pilz, C., Enkerli, J., Wegensteiner, R. \& Keller, S. (2011) Establishment and persistence of the entomopathogenic fungus Metarhizium anisopliae in maize fields. Journal of Applied Entomology, 135, 393-403.

Posadas, J. B., Comerio, R. M., Mini, J. I., Nussenbaum, A. L. \& Lecuona, R. E. (2012) A novel dodine-free selective medium based on the use of cetyl trimethyl ammonium bromide (CTAB) to isolate Beauveria bassiana, 
Metarhizium anisopliae sensu lato and Paecilomyces lilacinus from soil. Mycologia, 104, 974-980.

R Development Core Team (2013) R: A language and environment for statistical computing. R foundation for statistical computing, http://www.R-project.org/ Vienna, Austria

Raich, J. W. \& Schlesinger, W. H. (1992) The global carbon-dioxide flux in soil respiration and its relationship to vegetation and climate. Tellus Series $B$ Chemical and Physical Meteorology, 44, 81-99.

Rixon, A. J. \& Bridge, B. J. (1968) Respiratory quotient arising from microbial activity in relation to matric suction and air filled pore space of soil. Nature, 218, 961-962.

Rovira, A. D. (1953) Use of the warburg apparatus in soil metabolism studies. Nature, 172, 29-30.

Saxton, K. E., Rawls, W. J., Romberger, J. S. \& Papendick, R. I. (1986) Estimating Generalized Soil-Water Characteristics from Texture. Soil Science Society of America Journal, 50, 1031-1036.

Schumann, M., Patel, A. \& Vidal, S. (2014a) Soil application of an encapsulated $\mathrm{CO}_{2}$ source and its potential for management of western corn rootworm larvae. Journal of Economic Entomology, 107, 230-239.

Schumann, M., Toepfer, S., Vemmer, M., Patel, A., Kuhlmann, U. \& Vidal, S. (2014b) Field evaluation of an attract and kill strategy against western corn rootworm larvae. Journal of Pest Science, 87, 259-271.

Shah, F. A., Wang, C. S. \& Butt, T. M. (2005) Nutrition influences growth and virulence of the insect-pathogenic fungus Metarhizium anisopliae. Fems Microbiology Letters, 251, 259-266.

St. Leger, R. J. (2008) Studies on adaptations of Metarhizium anisopliae to life in the soil. Journal of Invertebrate Pathology, 98, 271-276.

Strasser, H., Forer, A. \& Schinner, F. (1996) Development of media for the selective isolation and maintenance of virulence of Beauveria brongniartii. In: Jackson, T. A. \& Glare, T. R. (eds.) Proceedings $3^{\text {rd }}$ International Workshop on Microbial Control of Soil Dwelling Pests. Lincoln, New Zealand: AgResearch. 
Thomas, C. A. (1940) The biology and control ow wireworms: A review of the literature. The Pennsylvania State College, School of Agriculture and Experiment Station, State College, Pennsylvania, US, Bulletin 392.

Traugott, M., Benefer, C. M., Blackshaw, R. P., Van Herk, W. G. \& Vernon, R. S. (2015) Biology, ecology, and control of elaterid beetles in agricultural land. Annual Review of Entomology, Vol 60, 60, 313-334.

Turpin, H. W. (1920) The carbon dioxide of the soil air. Cornell University Agr. Exp. Sta., Memoir, 32, 315-362.

Van Herk, W. G. \& Vernon, R. S. (2007) Soil bioassay for studying behavioral responses of wireworms (Coleoptera: Elateridae) to insecticide-treated wheat seed. Environmental Entomology, 36, 1441-1449.

Van Herk, W. G., Vernon, R. S., Moffat, C. \& Harding, C. (2008a) Response of the pacific coast wireworm, Limonius canus, and the dusky wireworm, Agriotes obscurus (Coleoptera: Elateridae), to insecticide-treated wheat seeds in a soil bioassay. Phytoprotection, 89, 7-19.

Van Herk, W. G., Vernon, R. S., Tolman, J. H. \& Saavedra, H. O. (2008b) Mortality of a wireworm, Agriotes obscurus (Coleoptera: Elateridae), after topical application of various insecticides. Journal of Economic Entomology, 101, 375-383.

Vanninen, I. (1996) Distribution and occurrence of four entomopathogenic fungi in Finland: Effect of geographical location, habitat type and soil type. Mycological Research, 100, 93-101.

Vanninen, I., Tyni-Juslin, J. \& Hokkanen, H. (2000) Persistence of augmented Metarhizium anisopliae and Beauveria bassiana in Finnish agricultural soils. Biocontrol, 45, 201-222.

Vemmer, M. \& Patel, A. V. (2013) Review of encapsulation methods suitable for microbial biological control agents. Biological Control, 67, 380-389.

Vemmer, M., Schumann, M., Beitzen-Heineke, W., French, B. W., Vidal, S. \& Patel, A. (2016) Development of a $\mathrm{CO}_{2}$ releasing co-formulation based on starch, Saccharomyces cerevisiae and Beauveria bassiana attractive towards western corn rootworm larvae. Pest Management Science.

Vernon, R. S. \& Van Herk, W. G. (2013) Wireworms as pests of potato. In: Giordanengo, P., Vincent, C. \& Alyokhin, A. (eds.) Insect Pests of Potato. Oxford, UK: Academic Press. 
Vernon, R. S., Van Herk, W. G., Clodius, M. \& Harding, C. (2013) Further studies on wireworm management in Canada: Damage protection versus wireworm mortality in potatoes. Journal of Economic Entomology, 106, 786-799.

Vernon, R. S., Van Herk, W. G., Clodius, M. \& Tolman, J. (2015) Companion planting attract-and-kill method for wireworm management in potatoes. Journal of Pest Science, 1-15. 


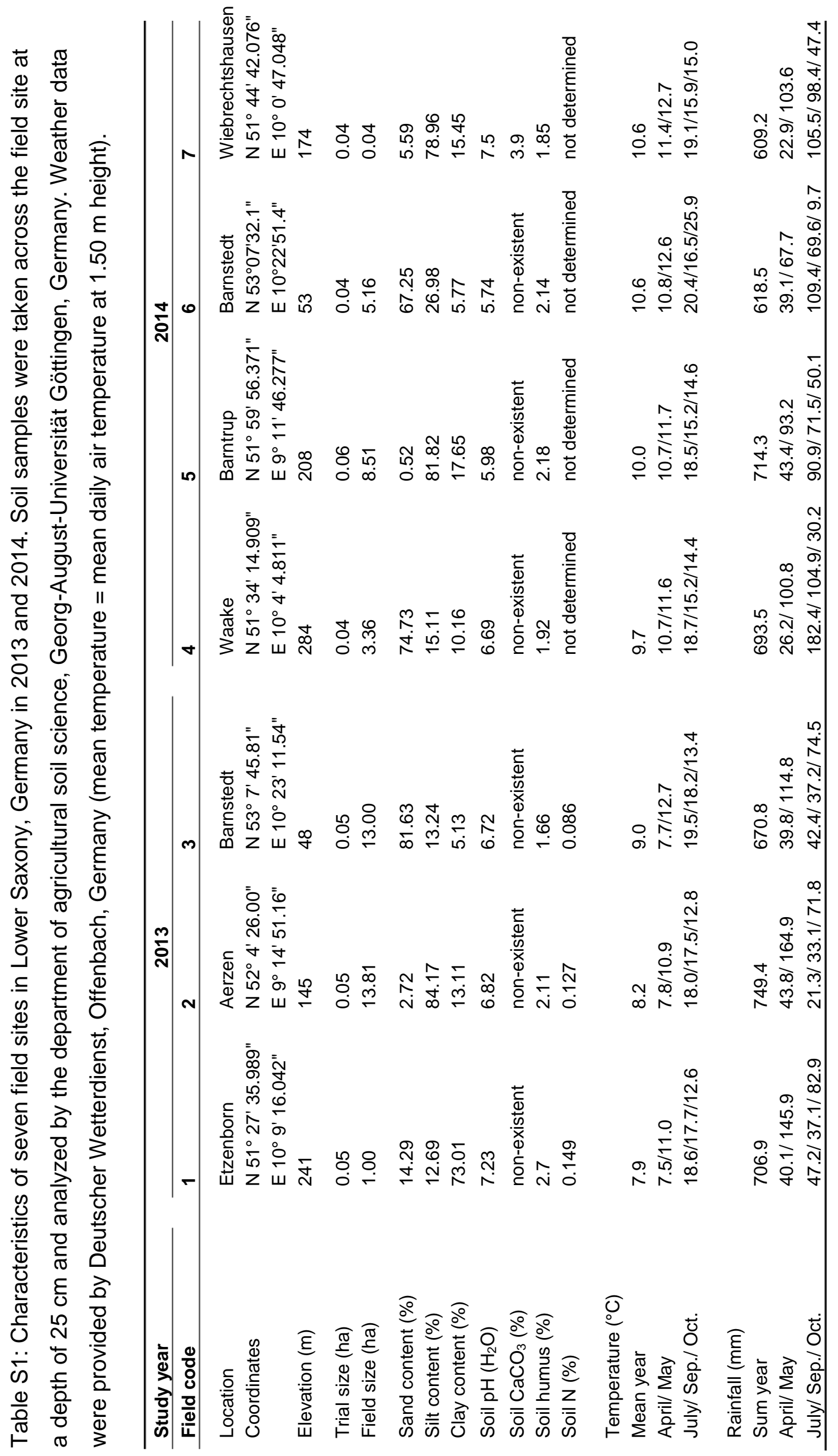


Chapter 3: Wireworm damage reduction in potatoes with attract-and-kill

$\sum i$

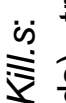

is

幽

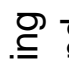

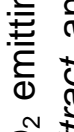

○ั

+ั

올 음

$\varangle$ त्व

胥

○

䒕

은

రृ

$\stackrel{\Phi}{\pi}$

汞

के $\widehat{\circ}$

实

ชิ $\stackrel{\sim}{\mathscr{\Upsilon}}$

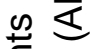

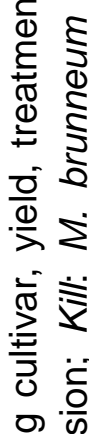

일

ヘ

б후 $\overline{0}$

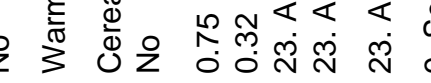

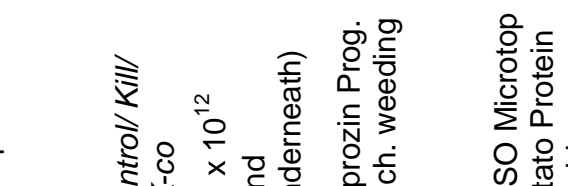

어ㅇㅠㅠㅁ음

눈응.믄

ธธ㇒

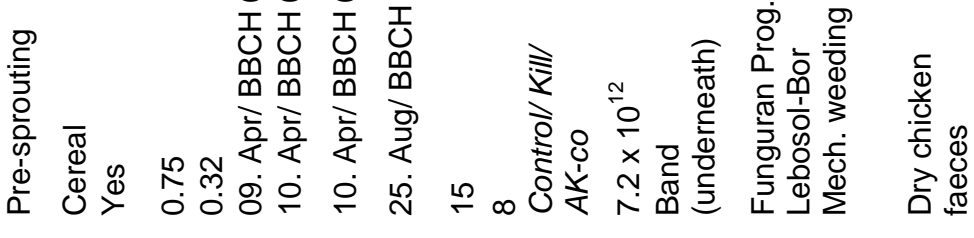

бо 5 .

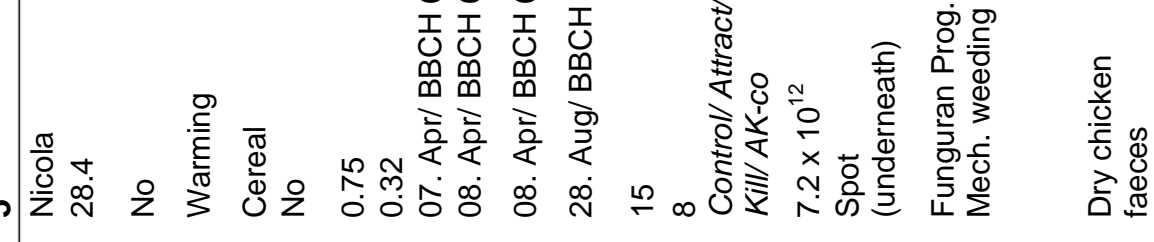

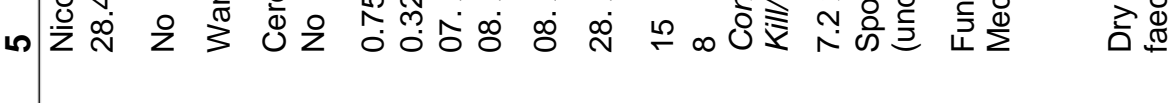

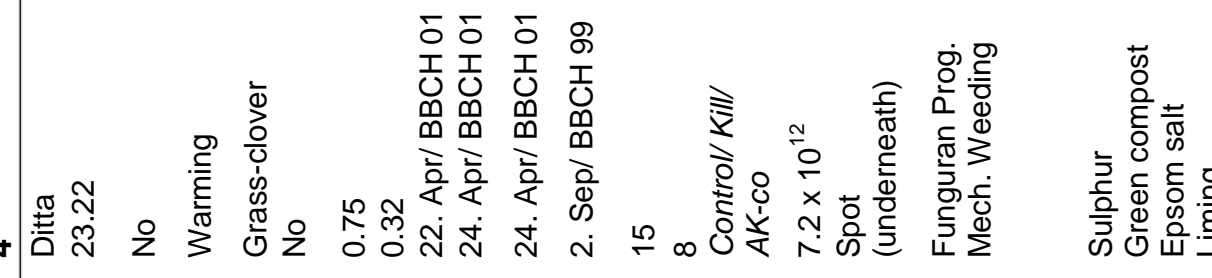
- 言

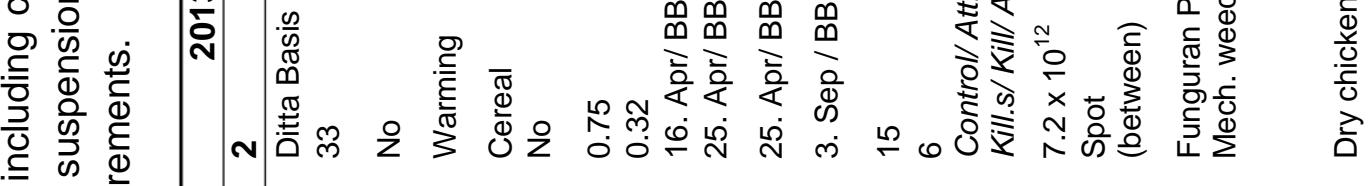

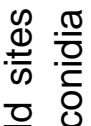

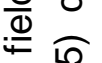

요용

苋 :

음

눙응

离

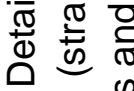

तi $\xi \stackrel{\text { ? }}{\circ}$

(ब) क

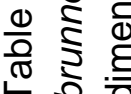

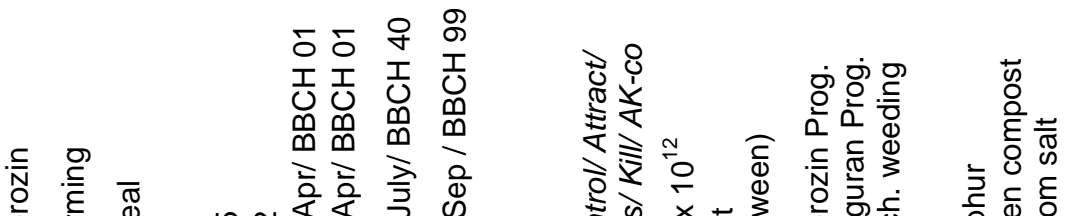

бо 5 .

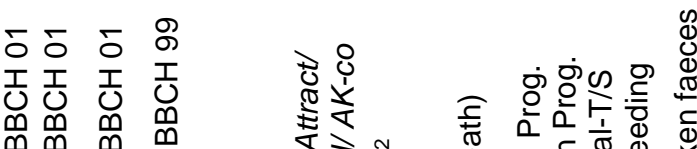

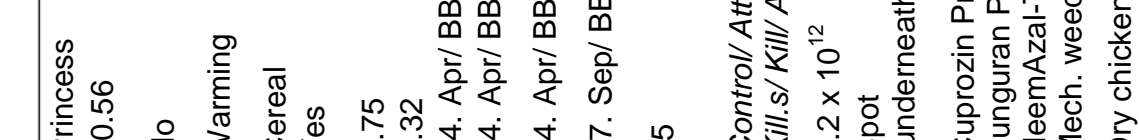

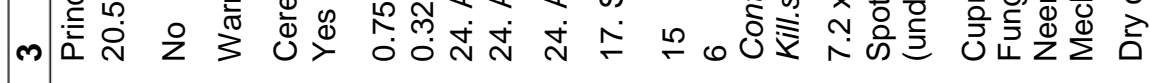

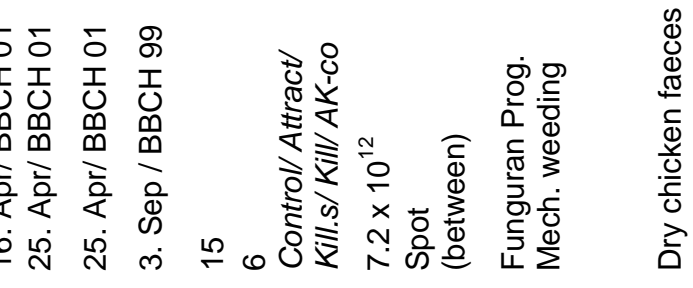

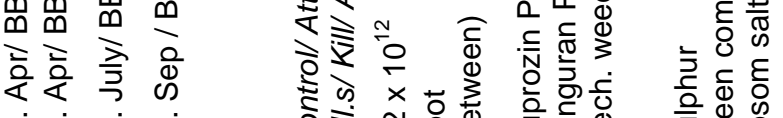

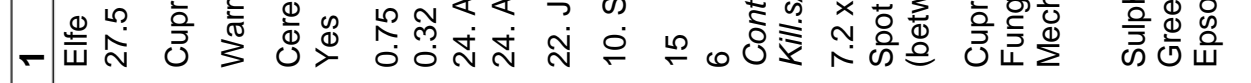

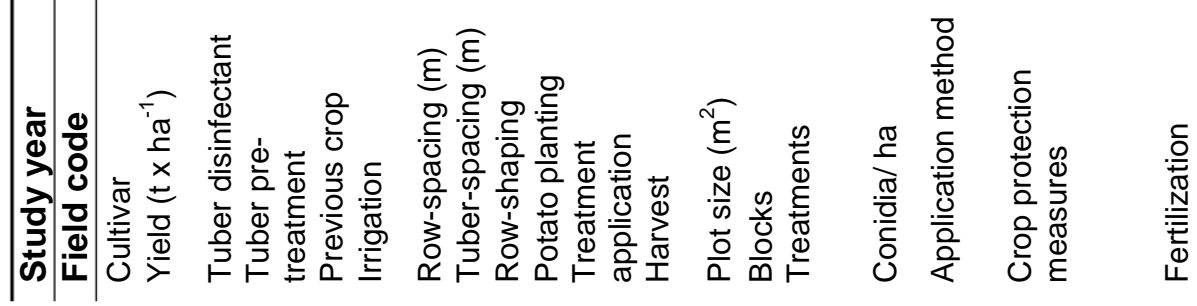

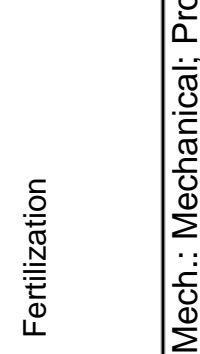


Chapter 4

\section{Technical attract-and-kill formulations for wireworm control with Metarhizium brunneum in potatoes}

Michael A. Brandl ${ }^{\star}$, Mario Schumann, Michael Przyklenk,

Anant Patel and Stefan Vidal

* Corresponding author

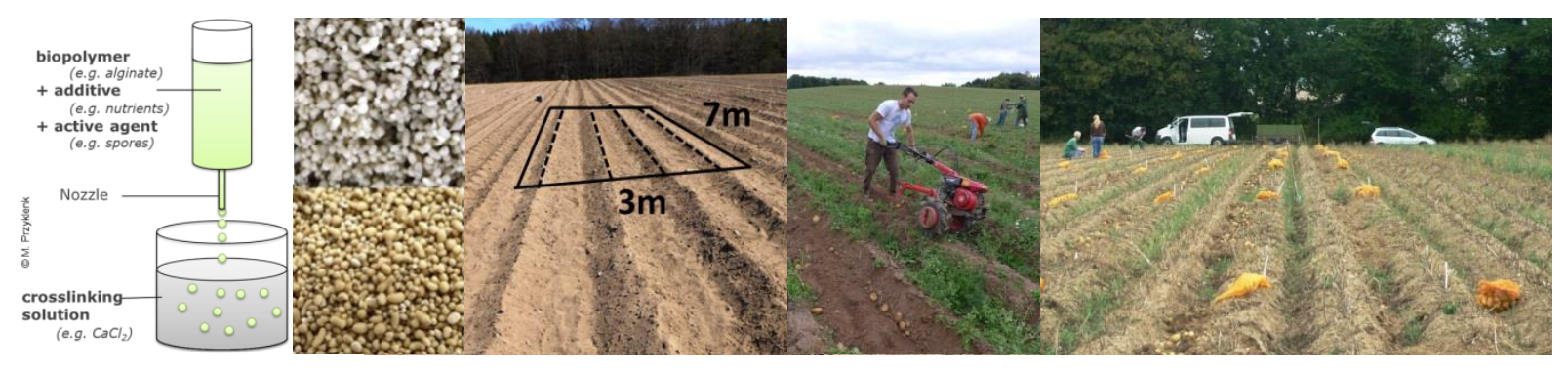




\title{
Technical attract-and-kill formulations for wireworm control with Metarhizium brunneum in potatoes
}

\author{
M. A. Brandl ${ }^{1, \star}$, M. Schumann ${ }^{1}$, M. Przyklenk ${ }^{2}$, A. Patel ${ }^{2}$ and S. Vidal ${ }^{1}$ \\ ${ }^{1}$ Georg-August-Universität Göttingen, Department of Crop Sciences, Agricultural Entomology, \\ Grisebachstrasse 6, 37077 Göttingen, Germany \\ ${ }^{2}$ University of Applied Sciences, WG Fermentation and Formulation of Biologicals and Chemicals, \\ Faculty of Engineering and Mathematics, Interaktion 1, 33619 Bielefeld, Germany \\ *Corresponding author. Tel.: +49 551 3933733, E-mail address: mbrandl1@gwdg.de
}

\section{Abstract}

Wireworm management in potato fields was tested with a novel attract-andkill strategy. Sodium alginate formulated beads containing baker's yeast (Saccharomyces cerevisiae Meyen ex Hansen) and the entomopathogenic fungus Metarhizium brunneum (Metschnikoff) Sorokin to attract and consequently kill wireworms (Agriotes spp. Eschscholtz) through a carbon dioxide gradient and subsequent mycosis were used. The performance of three different attract-and-kill bead treatments was compared on four organic potato field sites in Lower Saxony, Germany. The first treatment consisted of a co-application with two types of wet formulated beads containing either $S$. cerevisiae (= attract) or $M$. brunneum conidia (= kill). The second and third treatment consisted of a wet and dry coformulation containing both agents within one bead. Latter is regarded as a technical attract-and-kill formulation with a potential use for potato growers. All treatments were applied underneath seed potatoes at planting time either as a spot or a band application. Wireworm tuber damage was reduced by $36.26-$ $45.29 \%$ relative to the untreated control with a wet co-application and coformulation with either application type. A technical dry co-formulation resulted in better wireworm control with a spot $(40.19 \%)$ than a band application $(9.51 \%)$. An AK strategy therefore offers new perspectives for wireworm control in organic potato production systems but needs to be optimized for a practical feasibility use for farmers.

Keywords: Wireworms, potato, Metarhizium brunneum, carbon dioxide, co-formulation, attract-and-kill 


\section{Introduction}

Wireworms are the larval stage of click beetles (Coleoptera: Elateridae) and recognized as a serious agricultural pest worldwide (Traugott et al., 2015). Their importance in potato production is particularly given through a reduction in crop quality (Parker \& Howard, 2001) characterized with feeding damage as round holes on the surface and tunnels within the tuber flesh, both making tubers unmarketable. Furthermore, wireworm holes may facilitate the penetration of secondary pathogens such as Rhizoctonia solani Kühn resulting in the formation of Drycore symptoms (Keiser et al., 2012). The predominant species causing economic damage in Central Europe belong to the genus Agriotes spp. Eschscholtz, but also include species from other genera (e.g. Athous spp. Eschscholtz) (Vernon \& van Herk, 2013). Field sites may accommodate populations of several cohorts of more than one species, resulting from adult oviposition over consecutive years and a development time as semivoltine species, which commonly lasts over two to four years with seven to nine larval instars (Traugott et al., 2015, Vernon \& van Herk, 2013).

Environmental concerns and high risk assessments of insecticides (Howarth, 1991) led to the implementation of the (EC) No regulation 1107/2009 (European Parliament and the Council of the European Union, 2009b) and Directive 2009/128/EC (European Parliament and the Council of the European Union, 2009a) promoting the use of biological control agents (BCAs) within an integrated pest management approach. The use of BCAs such as entomopathogenic fungi (EPF) gained increasing attention by researchers and enterprises in recent years (Kabaluk et al., 2005, Ericsson et al., 2007) with 129 mycoinsecticide products being registered, undergoing registration or available on the market in 2006 (de Faria \& Wraight, 2007).

The EPF Metarhizium anisopliae (Metschnikoff) Sorokin (Hypocreales: Ascomycota) (Bischoff et al., 2009) sensu lato is a well-known potential candidate to control wireworms (Kabaluk et al., 2007, Thomas, 1940, Hyslop, 1915). Its nature is cosmopolitan, found worldwide in many types of soil, but rarely causes epizootics in the field during a cropping season compared to EPF species of the entomophthoralean order (Meyling \& Eilenberg, 2007, Hajek et al., 2007). Nevertheless hypocrealean fungi have received commercial attention, due to the 
ability of in vitro mass propagations of infective propagules (e.g. aerial conidia) for an inundative application as mainly also done for insecticides (Jaronski, 2010). Hence, a mass-release of conidia can result in immediate insect control (Eilenberg et al., 2001). Generally, the control of root-feeding insects requires $10^{14}-10^{15}$ conidia ha ${ }^{-1}$ to "win the numbers game" as the insect must physically contact sufficient numbers of EPF conidia to get infected (Jaronski, 2010). This "numbers game" may be changed using EPF granules or formulations covered with conidia as root-feeding insects acquire sufficient conidia to become infected through a single contact, thereby reducing the conventional application rate (Jaronski, 2010). A further approach to favor the "numbers game" might be an "attract-and-kill" (AK) strategy. An insect pest is lured to an attractant (e.g. semiochemical = attract), and subjected to an insecticide or EPF (= kill) killing off the insect (El-Sayed et al., 2009). This strategy has been tested for wireworm control in potatoes using wheat (Triticum aestivum L.) seeds treated with Fipronil and / or Thiamethoxam (Vernon et al., 2015) and formulated AK beads (compare chapter 3). Both strategies relied on the production of carbon dioxide $\left(\mathrm{CO}_{2}\right)$ levels in soil, a well-known general semiochemical cue in host location for many soil insects (Johnson \& Gregory, 2006, Johnson \& Nielsen, 2012), including wireworms (Doane et al., 1975).

The present study builds upon the results of chapter 3 , which demonstrated a synergistic effect for wireworm (Agriotes spp.) control through a co-application of "attract" and "kill" beads into the potato row. $\mathrm{CO}_{2}$ was produced through the digestion of maize starch with baker's yeast (Saccharomyces cerevisiae Meyen ex Hansen), both formulated in sodium ( $\mathrm{Na}$ )-alginate as a carrier material (= attract bead). The carrier material $\mathrm{Na}$-alginate was also used for the encapsulation of Metarhizium brunneum (strain: ART2825) conidia in combination with dead baker's yeast as a nutrition source (= kill bead). The main drawbacks of this approach were i) the separation of AK components and ii) potential difficulties for later use of wet beads with technical application equipment.

For a technical AK bead development, both AK agents need to be coencapsulated within a single bead and dried. This would assure on the one hand a simultaneous presence of the killing and attractant agent, on the other hand a prolonged shelf-life by the reduction of the water activity (Jackson et al., 2010) and improve the feasibility of application with standardized granulators. Coencapsulated AK beads were tested under field conditions in this study and their 
potential to be used as technical AK products for biological wireworm control is discussed.

\section{Materials and methods}

\section{Field sites and design}

Four field trials were carried out on organic potato fields (field code 1 - 4) in Lower Saxony, Germany, from April - September 2015 (Table S1 / Table S2). The fields were selected on the basis of bait trap catches, cropping history and farmer's previous experience with wireworm damage to ensure pest pressure. A field trial was embedded within cultivated potato fields and separated by three untreated potato rows and a $2 \mathrm{~m}$ buffer on the length and width of trial site, respectively. Fields were cultivated according to the requirements of organic farming and Good Agricultural Practice (BMELV, 2010). A geographic relief drift existed solely for field 4 , yet not for fields $1-3$, indicating inhomogeneous and homogenous soil textures, respectively (Toepfer et al., 2007).

All fields were ploughed and harrowed before potato planting and seed potatoes were planted in April on all fields. Potato planting was omitted on the embedded field trial and only the potato ridges were shaped. Potato planting and treatment application within a trial site was then done 1 - 8 days after potato ridge shaping (Table S2).

Field trials were arranged in a length-wise randomized complete block design to account for the control of possible heterogeneity of the site (e.g. relief drift) with six and eight replicates in field 4 and fields $1-3$, respectively (Table S2) (Anonymous, 2012). Individual plot sizes consisted of four treated $7 \mathrm{~m}$ potato rows planted on $0.75 \mathrm{~m}$ centers (= $21 \mathrm{~m}^{2} / \mathrm{plot}$ ) (Anonymous, 2005). Treatments were applied underneath seed potatoes either as a "band application" (fields $1-2$ ) or as a "spot application" (fields 3 - 4) at BBCH 01 (Hack et al., 2001). Wireworm damage was evaluated at $\mathrm{BBCH} 99$ (Hack et al., 2001) according to the European and Mediterranean Plant Protection Organization (EPPO) standards PP1/46 (Anonymous, 2005). 


\section{Environmental conditions}

Soil was sampled to $25 \mathrm{~cm}$ at ten locations, five within the potato rows and five between the potato rows, with a cylindrical soil core sampler (diameter: 1.8 $\mathrm{cm}$ ) diagonally across each trial site prior to trial preparation. Samples were mixed in Zip-lock ${ }^{\mathrm{TM}}$ plastic bags and stored at $6^{\circ} \mathrm{C}$ in a dark cooling chamber. All samples were analyzed for clay, silt and sand content, soil $\mathrm{pH}\left(\mathrm{H}_{2} \mathrm{O}\right)$, organic carbon $\left(\mathrm{CaCO}_{3}\right)$, humus and nitrogen $(\mathrm{N})$ content by Dr. Christian Ahl (Department of Agricultural Soil Science, Georg-August-Universität, Göttingen, Germany) (Table S1).

Daily air temperature and precipitation data were recorded at $2 \mathrm{~m}$ height by weather stations within $40 \mathrm{~km}$ distance of field sites to calculate the average temperature and precipitation per month during trial duration from April to September (Deutscher Wetterdienst, DWD, Offenbach, Germany) (Table S1). Soil temperature was measured using a data logger (Voltcraft@, Hirschau, Germany), which was placed into a Falcon tube (Volume $50 \mathrm{ml}$; Sarstedt AG \& Co., Nümbrecht, Germany) and buried in a potato row in $25 \mathrm{~cm}$ depth after planting. Temperature recording was done on an hourly basis and the average temperature per month calculated.

Weed cover within the potato fields was qualitatively assessed at the day of harvest using the "Göttinger Zähl- und Schätzrahmen", a squared open frame covering an area of $0.1 \mathrm{~m}^{2}$ to estimate vegetative soil cover (Heitefuß, 1987). No differences in weed cover were observed between treatments on any field site ranging between $20-35 \%$ across field sites.

\section{Treatments}

Three different "attract-and-kill" (AK) beads ("AK-co", "AK-wet" and " $A K$ $\left.d r y^{\prime}\right)$, were tested across all four field trials. Production of beads was based on ionic gelation using sodium $(\mathrm{Na})$-alginate as the carrier material according to Vemmer et al. (2016).

The $A K$-co treatment consisted of a combination of two separate types of wet $\left(\mathrm{a}_{\mathrm{w}}>0.9\right)$ beads ("Attract" beads and "Kill" beads, also tested as an AK treatment in chapter 3). Attract beads (diameter: $2.7 \pm 0.2 \mathrm{~mm}$ ) were encapsulated using commercially available baker's yeast (Saccharomyces cerevisiae) (Deutsche 
Hefewerke $\mathrm{GmbH}$, Nürnberg, Germany) in combination with maize (Zea mays L.) starch. Kill beads (diameter: $2.7 \pm 0.2 \mathrm{~mm}$ ) were formulated using $M$. brunneum (strain: ART2825) aero conidia (original concentration: $1 \times 10^{9}$ conidia / g M. brunneum powder), provided by Fytovita spol. s.r.o. (Ostrozska Lhota, Czech Republic), originally isolated from $A$. obscurus in Switzerland (Kölliker et al., 2011), in combination with dead (autoclaved) baker's yeast $\left(=2.5 \times 10^{7}\right.$ conidia / g beads) (compare chapter 3).

The AK-wet $\left(\mathrm{a}_{\mathrm{w}}>0.9\right)\left(=2.5 \times 10^{7}\right.$ conidia / g beads) and the AK-dry $\left(\mathrm{a}_{\mathrm{w}}<\right.$ 0.2) (= $8.3 \times 10^{7}$ conidia / g beads) treatment consisted of one type of bead, combining attract and kill agents as a co-formulation. AK-wet (diameter: $2.7 \pm 0.2$ $\mathrm{mm}$ ) and $A K$-dry (diameter: $1.0 \pm 0.2 \mathrm{~mm}$ ) were formulated with Na-solution (62.3\%: 2\% Na-alginate and 98\% demineralized water), M. brunneum conidia $(1 \%)$, maize starch $(20 \%)$ and living baker's yeast $(16.7 \%)$, based on studies of bead composition (Przyklenk M., personal communication). Drying of AK-dry beads was done using a fluid-bed dryer (Type 5, Glatt GmbH, Binzen, Germany).

\section{Treatment preparation and application}

Wet beads ( $A K-c 0, A K-w e t)$ and dry beads ( $A K$-dry) were prepared by weighing (Scale: PEJ 4200-2M, Kern \& Sohn, Balingen, Germany) the beads needed for one $7 \mathrm{~m}$ potato row of a plot into Zip-lock ${ }^{T M}$ plastic bags $(20 \times 30 \mathrm{~cm})$ and Falcon tubes (Volume $50 \mathrm{ml}$ ), respectively. Treatments were stored at $6^{\circ} \mathrm{C}$ in a dark cooling chamber 3 - 16 days until field application.

At all field sites potato rows were opened with a hand-operated rotovator (VIKING GmbH, Langkampfen / Kufstein, Austria) to create $25 \mathrm{~cm}$ deep and $30 \mathrm{~cm}$ wide furrows centrally along the potato rows. Thereafter bead application was done manually in all four furrows of the plot. For a band application (fields $1-2$ ) $208 \mathrm{~g} \mathrm{AK-wet} \mathrm{and} 81 \mathrm{~g} A K$-dry beads were evenly distributed along the furrow of a $7 \mathrm{~m}$ potato row. For a spot application (fields 3 - 4) $9.0 \mathrm{~g} \mathrm{AK-wet,} 3.7 \mathrm{~g} \mathrm{AK-dry} \mathrm{and}$ $18.5 \mathrm{~g} \mathrm{AK-co}$ (= $9.0 \mathrm{~g}$ attract beads and $9.0 \mathrm{~g}$ kill beads) beads were applied in portions every $32 \mathrm{~cm}$ along the furrow. With this application rate $9.9 \times 10^{12}$ and $1.28 \times 10^{13}$ M. brunneum conidia / ha were applied with wet (AK-co, AK-wet) and dry (AK-dry) beads, respectively. The higher application dose of $A K-d r y$ beads accounts for an existing $30 \%$ conidia vitality loss during bead drying process (Przyklenk M., personal communication). A seed potato was placed every $28 \mathrm{~cm}$ 
( 47,600 seed potatoes / ha, field 1) and $32 \mathrm{~cm} \mathrm{(} \mathrm{40,000} \mathrm{seed} \mathrm{potatoes} \mathrm{/} \mathrm{ha,}$ fields $2-4$ ) directly on the (portioned) beads and potato rows were closed and reshaped again into ridges by manual hoeing. The potato rows of the untreated control ("Control') were treated equally except for a treatment application.

Verification of materials' performance

Quality controls measuring $\mathrm{CO}_{2}$ emission, $M$. brunneum vitality and virulence in the laboratory as well as $M$. brunneum establishment and persistence under field conditions were conducted to ensure treatment performance in the four field soil types tested. Experimental set up and procedures are described in detail in chapter 3 and will be discussed briefly with modifications below.

\section{$\mathrm{CO}_{2}$ production}

$\mathrm{CO}_{2}$ measurements were setup for all field soils with four replicates on the $29^{\text {th }}$ April 2015 and corresponding AK treatments to each field trial (Table S2). Ordinary round plastic pots (height: $14 \mathrm{~cm}$, diameter: $15 \mathrm{~cm}$ ) were filled with $1.5 \mathrm{~kg}$ soil from the respective field site and treated centrally with the same amount of beads as applied per tuber in a spot treatment $(9.0 \mathrm{~g} \mathrm{AK-wet,} 3.7 \mathrm{~g} \mathrm{AK-dry} \mathrm{and}$ $18.5 \mathrm{~g} \mathrm{AK-CO}$ ) in $8 \mathrm{~cm}$ depth. The untreated control ("Control') consisted of field soil only. A standard disposable $3 \mathrm{ml}$ pipette (Carl Roth $\mathrm{GmbH}+\mathrm{Co}$. Kg, Karlsruhe, Germany), was shortened to $10 \mathrm{~cm}$ length by cutting off half the built-in pipet bulb and inserted directly above the beads in the soil, leaving the first $2 \mathrm{~cm}$ of the tip above the soil surface. The tips of the modified disposable pipettes were sealed between $\mathrm{CO}_{2}$ emission measurements using tape (tesa SE, Norderstedt, Germany). This set up allowed $\mathrm{CO}_{2}$ to be measured at the same spot. $\mathrm{CO}_{2}$ emission measurements were taken weekly for eight weeks inserting the probe (length: $10 \mathrm{~cm}$ ) of the hand-held $\mathrm{CO}_{2}$ meter (CARBOCAP® $\mathrm{BM} 70$, Vaisala, Helsinki, Finland) into the modified pipette with each measurement lasting for 6 min. The mean $\mathrm{CO}_{2}$ emission was calculated from the maximum and a minimum recorded $\mathrm{CO}_{2}$ value. Pots were stored in an open greenhouse at outdoor temperatures and irrigated twice per week to maintain soil moisture between 15 30 vol\% water content, measured with an absolute humidity reader in $6 \mathrm{~cm}$ soil depth (TML 3 ThetaProbe, Delta-T devices, Cambridge, England). 
Metarhizium brunneum viability, virulence and persistence

M. brunneum viability was assessed for each bead type (AK-wet, AK-dry and $A K-c o$ ( $=$ Kill bead only)) by placing a single bead on water agar with $0.05 \%$ chloramphenicol (AppliChem GmbH, Darmstadt, Germany) centrally in a Petri dish (diameter: $9 \mathrm{~cm} ; 7$ replicates / treatment) (Sarstedt AG \& Co., Nümbrecht, Germany). Petri dishes were stored in a dark climatic cabinet (Mytron $\mathrm{GmbH}$, Heiligenstadt, Germany) at $25^{\circ} \mathrm{C}$ for two weeks and M. brunneum growth and sporulation was qualitatively assessed for $A K$-wet, AK-dry and Kill bead types using light microscopy (500X magnification, BH2-HLSH, Olympus Corporation, Tokyo, Japan) in all replicates, except of a single mold contamination of an $A K$-wet bead.

M. brunneum virulence tests were conducted in $50 \mathrm{ml}$ Falcon tubes between $29^{\text {th }}$ April and $9^{\text {th }}$ September. Each Falcon tube was filled with $40 \mathrm{ml}$ soil of the respective field site and treated with $5.0 \times 10^{7}$ conidia $(=4.0 \pm 0.1 \mathrm{~g} \mathrm{AK}$-co

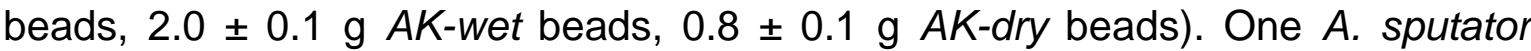
wireworm (length: $1.2-1.7 \mathrm{~cm}$ ), collected from a wireworm rearing, was placed on the soil surface shortly after bead application. A carrot (Daucus carota L. subsp. sativus (Hoffm.) Schübl. \& G. Martens) slice was added to provide a food source for wireworms and exchanged monthly with a fresh slice. Falcon tubes were sealed with a lid, half enclosed to ensure aerial exchange, and stored in a dark climatic cabinet (Mytron $\mathrm{GmbH}$, Heiligenstadt, Germany) at $25^{\circ} \mathrm{C}$. Soil was moistened with $1-3 \mathrm{ml}$ tap water and hereafter if needed. Wireworm vitality was assessed weekly until all wireworms have died or until the first week of September, when field trials were terminated. Dead wireworms showing no symptoms of mycosis were surface sterilized according to Lacey \& Solter (2012), and placed into a Petri dish (diameter: $5 \mathrm{~cm}$; Sarstedt AG \& Co., Nümbrecht, Germany) moist chamber to promote fungal growth. Seven replicates ( 7 falcon tubes) of each corresponding treatment of a field trial including an untreated control (= bare field soil only ("Control')) were set up.

M. brunneum establishment and persistence in the field was studied by analyzing the number of colony forming units (cfu) per gram of soil. Four soil samples were taken with a cylindrical soil core sampler (diameter: $1.8 \mathrm{~cm}$ ) in 20 $\mathrm{cm}$ depth of the center of a potato row diagonally across a plot from four replicates 
of an untreated Control and each AK treatment. The soil samples of each plot were pooled in a Zip-lock ${ }^{\mathrm{TM}}$ plastic bag and stored at $6^{\circ} \mathrm{C}$ in a dark cooling room before further processing. Sampling was done on the day of field trial setup $(\mathrm{BBCH}$ 01; Hack et al., 2001) in April and potato harvesting in August / September (BBCH 99; Hack et al., 2001) (Table S2). Metarhizium spp. isolation was done within 2 - 3 weeks after sampling following a protocol by Dr. Jürg Enkerli (personal communication, 2014, ISS Agroscope, Zürich, Switzerland) (compare chapter 3). Metarhizium spp. identification was done by light microscopy (500X magnification, BH2-HLSH, Olympus Corporation, Tokyo, Japan) based on morphological criteria ((i) conidiogenesis in dense hymenia, (ii) branching conidiophores, (iii) clavate / cylindrical conidia, (iiii) conidia chains) relevant for the genus level (Humber, 2012).

Assessment of wireworm tuber damage

Potatoes were harvested at $\mathrm{BBCH} 99$ (Hack et al., 2001). The two core potato rows of each plot were opened with a hand-operated rotovator (Honda Motor Europe Ltd., Berkshire, England) to lift potatoes onto the soil surface. 50 tubers were collected from each row (= 100 tubers / plot) within $6 \mathrm{~m}$ of a row leaving $0.5 \mathrm{~m}$ to bordering plots on each end of a row. Tubers were stored in the dark at $4{ }^{\circ} \mathrm{C}$ for up to ten days and washed before assessment. Damage was categorized according to EPPO guidelines PP1/46 (Anonymous, 2005) by differentiating damage severity by classes based on the number of holes from wireworm feeding per tuber (class 1: $1-2$, class 2: $3-5$ and class 3 : > 5). Wireworm feeding was defined by $a \geq 5 \mathrm{~mm}$ wireworm tunneling in the tuber flesh (Keiser et al., 2012) and additionally differentiated into wireworm holes only (WW) and wireworm holes with Drycore (Rhizoctonia solani Kühn) symptoms (WW+DC).

\section{Statistical analysis}

\section{Verification of materials' performance}

The time-series data on $\mathrm{CO}_{2}$ emission was pooled across field sites for each treatment and analyzed with untransformed data using linear mixed-effects models (R package nlme, function Ime; Pinheiro et al., 2013, Crawley, 2013) with treatment as a fixed effect and week as a continuous random effect. Differences 
between treatments were compared with posteriori Tukey contrasts ( $R$ package multcomp, function glht; Hothorn et al., 2008). Data pooling across field sites was done due to a non-significance of time-series data on $\mathrm{ppm} \mathrm{CO}_{2}$ emission in the untreated Control $\left(\mathrm{F}_{3,12}=0.85, \mathrm{p}=0.49\right)$.

M. brunneum virulence data were analyzed across all field soils using a Cox's proportional hazard model to investigate the relative risk of wireworm dying until trial termination expressed as the hazard ratio (HR) (Spruance et al., 2004), with treatment and field site as covariates ( $R$ package survival, function coxph; Cox, 1972, Therneau, 2013). Dead wireworms were referred to as an event; alive wireworms in the experiment were censored $(=n)$. The saturated model was simplified by an automated step-wise exclusion of variables with non-significant effects to explore the most parsimonious model using Akaike's information criterion (AIC) (Crawley, 2013). The model assumption of proportional hazards of covariates was given by chi-square tests with $p>0.05$ (Ngandu, 1997).

Metarhizium spp. establishment and persistence was compared between treatments of each field with the non-parametric Kruskal-Wallis test $(\alpha=0.05)$. A multiple comparison test on ranks between treatments was applied when $\alpha<0.05$ (R package pgirmess, function kruskalmc; Giraudoux, 2015).

\section{Wireworm tuber damage}

Tuber damage was analyzed with a one-way ANOVA by comparing the proportion of tubers with at least one cavity caused by wireworm feeding (\% wireworm damage) between treatments of each field site. A split-plot analysis was applied to account for spatial autocorrelation in the randomized complete block design with blocks referred to as the error term (Crawley, 2013). If a dataset was unbalanced from the elimination of outliers, visually identified in boxplots, a linear mixed effects model was applied with treatment as a fixed effect and blocks as a categorical random effect (R package nlme, function Ime; Crawley, 2013).

Treatment efficacies were calculated as the reduction (or increase) in wireworm damage relative to the untreated Control ([Wireworm damage in untreated Control - Wireworm damage in treatment] / Wireworm damage in untreated Control] x 100) (Abbott, 1987). They were analyzed with a linear mixed effect model due to an unbalanced data set. The efficacy of each application type ("spot" and "band") was pooled as they did not differ between fields (spot: Fields 1 
- 2: $F_{1,21}=3.78, p=0.07$; band: Fields $\left.3-4: F_{1,23}=0.42, p=0.52\right)$ and the efficacy of treatment and application type compared with posteriori Tukey contrasts (Hothorn et al., 2008). Variance homogeneity and normality of data were analyzed performing Fligner-Killen tests and $Q-Q$ plots, respectively.

The type and severity of tuber damage in each treatment (= damage pattern) was summed up across all replicates, arranged in a 3-way contingency table, and analyzed for each field to test for associations between the explanatory variables treatment, damage type (wireworm $(=\mathrm{WW})$ / wireworm and Drycore $(=$ $W W+D C)$ ) and damage severity (damage classes $1-3$ ) by a generalized linear model using Poisson errors (function glm; Crawley, 2013). The saturated model, including three-way and two-way interactions between all the explanatory variables, was simplified by comparing generalized linear models with and without interactions using a chi-square test with ANOVA following Crawley (2013). Effects of explanatory variables in the parsimonious model, referring to ratios between treatments, damage type and damage severity were tested with chi-square test on contingency tables and inspected applying posteriori Tukey contrasts (Hothorn et al., 2008). In all analyses, overdispersion did not occur with roughly equal scaled residual deviance and residual degrees of freedom (Crawley, 2013). All sums of tuber damage are additionally given as a percentage on treatments, damage type and damage severity.

All analyses were done with R, version 3.0.2 (R Development Core Team, 2013). Figures were created using SigmaPlot, version 11.0 (Analytical Software, Tallahasee, $\mathrm{FI}, \mathrm{USA}$ ). All shown values refer to the mean \pm standard error.

\section{Results}

Verification of materials' performance

CO2 production

$\mathrm{CO}_{2}$ levels in soil treated with $A K$-wet, $A K$-dry and $A K$-co beads increased significantly compared to bare soil of the Control $(\sim 600 \mathrm{ppm}$ throughout the experimental run) $\left(F_{3,12}=12.69, p<0.001\right)$. No differences in $\mathrm{CO}_{2}$ levels were observed between the bead treatments. $\mathrm{CO}_{2}$ emission across all bead treatments lasted between $4-6$ weeks and peaked after one and three weeks with an 
application of $A K$-dry beads $(1917.50 \pm 224.41 \mathrm{ppm})$ and $A K$-wet (1553.10 \pm $116.37 \mathrm{ppm}) / \mathrm{AK}-\mathrm{co}(2063.13 \pm 333.62 \mathrm{ppm})$ beads, respectively. Thereafter a steady $\mathrm{CO}_{2}$ decline was observed from week four onwards across all treatments (Fig.1).

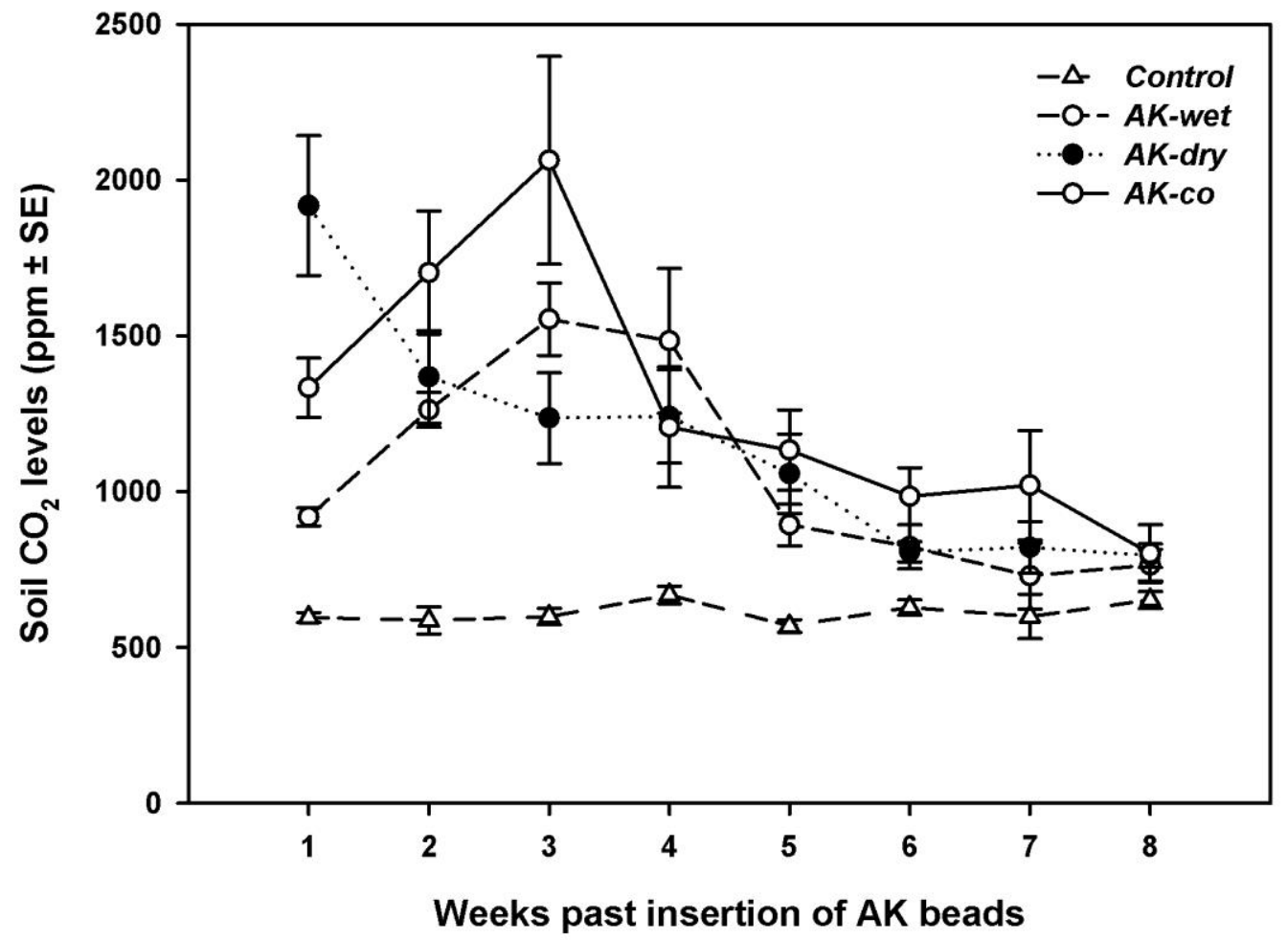

Fig. 1: $\mathrm{CO}_{2}$ levels in parts per million [ppm] (mean \pm standard error (SE)) averaged across four field soils treated with attract-and-kill beads ( $A K$-wet, $A K$-dry: Co-formulated wet and dry beads; AK-co: Combined wet Attract beads and Kill beads) and a Control (= bare field soil). Data were pooled across four tested field soils and tested with a linear mixed-effects model.

Metarhizium brunneum viability, virulence and persistence

Out of the 91 wireworms used for $M$. brunneum virulence tests $\left(=N_{\text {total }}\right) 47$ died and $44(=n)$ outlived the experiment. The HR increased in all AK treatments at a range between 1.9 (AK-wet) - 7.7 (AK-co), but was only significant for the latter (Table 1). Mycosed wireworms were found in all treatments including the Control (58\% in AK-co, $54 \%$ in AK-wet, $36 \%$ in AK-dry and $38 \%$ in Control of dead wireworms). 
Table 1: Cox's Proportional Hazard Model analysis of the risk of death (HR) of $91(\mathrm{~N})$ wireworms (Agriotes sputator) at $95 \%$ upper and lower confidence intervals $(\mathrm{Cl})$ in field soil treated with attract-and-kill beads ( $A K$-wet, $A K$-dry, $A K-c o)$ compared to the Control (= bare field soil). The asterisk $\left({ }^{*}\right)$ indicates a significant difference between the control and the AK treatment $(\alpha=0.05)$.

\begin{tabular}{|c|c|c|c|c|c|c|}
\hline \multirow[b]{2}{*}{ Treatment } & \multirow[b]{2}{*}{$\mathbf{N}(\mathbf{n})$} & \multicolumn{5}{|c|}{ Univariate } \\
\hline & & HR & lower \% $95 \mathrm{Cl}$ & upper $\% 95 \mathrm{Cl}$ & $p$-value & \\
\hline Control & $28(20)$ & 1 & & & & \\
\hline AK-wet & $28(15)$ & 1.88 & 0.78 & 4.54 & 0.16 & \\
\hline$A K-d r y$ & $21(10)$ & 2.24 & 0.90 & 5.58 & 0.08 & \\
\hline$A K-c o$ & 14 (2) & 7.68 & 3.10 & 19.02 & $<0.001$ & $*$ \\
\hline
\end{tabular}

$\mathrm{n}$ : number wireworms censored (= number of alive wireworms)

Metarhizium spp. abundance at harvest was significantly higher with a spot application of $A K$-co beads (up to $1131 \mathrm{cfu} / \mathrm{g}$ soil) compared to the untreated Control as well as an $A K$-wet and $A K$-dry treatment (up to $125 \mathrm{cfu} / \mathrm{g}$ soil) (field 3: Kruskal-Wallis chi-squared $(3)=9.39, p<0.05$ and field 4 : Kruskal-Wallis chisquared $(2)=10.46, p<0.01)$. Metarhizium spp. abundance did not significantly differ between treatments with a band application in field 1 (Kruskal-Wallis chisquared $(2)=0.71, p=0.70$ ) but was significantly higher with a band application of $A K$-dry beads compared to the untreated control in field 2 (Kruskal-Wallis chisquared $(2)=8.64, p<0.05)$. Metarhizium spp. was isolated from the soil at planting in fields $1-3$, but did not significantly differ between treated plots (field 1 : Kruskal-Wallis chi-squared $(2)=2.22, p=0.33$; field 2: Kruskal-Wallis chi-squared $(2)=4.79, p=0.09$; field 3: Kruskal-Wallis chi-squared $(3)=2.27, p=0.52$ ) (Table 2). 


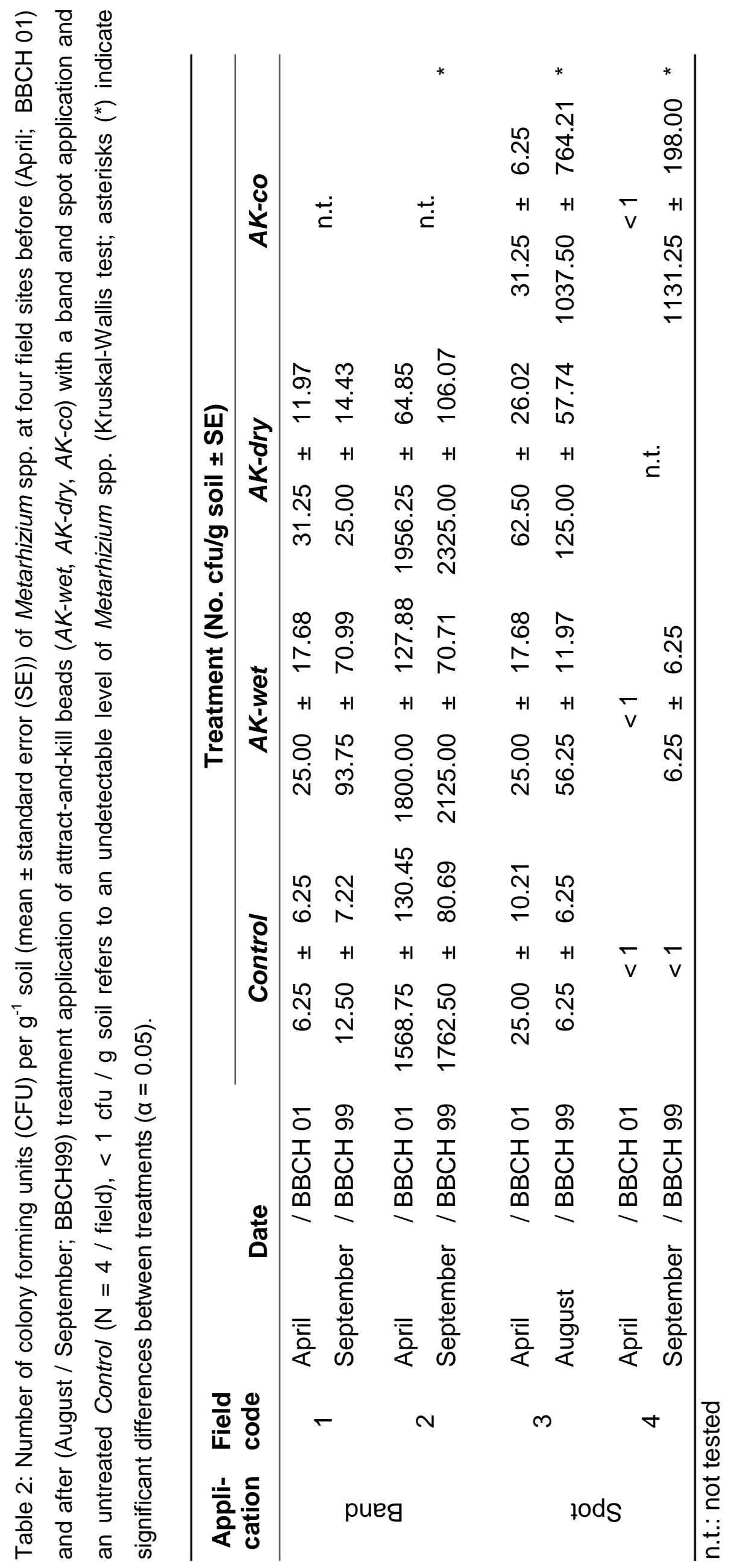




\section{Wireworm tuber damage}

Wireworm tuber damage in the untreated Control varied between 5 (field 4) $26 \%$ (field 3) across all field sites (Fig. 2a - 2d). Highest and lowest tuber damage rates in the Control was recorded in fields with a spot application (Fig. $2 c+2 d$ ), whereas intermediate damage was recorded in fields with a band applications (Fig. 2a $+2 \mathrm{~b}$; field 1: $17 \%$; field 2: $11 \%$ ). A band application of $A K$-wet beads resulted in a lower percentage of damaged potato tubers than AK-dry beads, but could not be significantly reduced compared to the Control (field 1: $F_{2,14}=1.77, p=0.21$; field 2: $\mathrm{F}_{2,14}=1.32, \mathrm{p}=0.30$ ) (Fig. $2 \mathrm{a}+2 \mathrm{~b}$ ). A spot application reduced wireworm tuber damage in all $A K$ treatments, but a significant reduction was only measured in field 4 $\left(F_{2,9}=5.16, p<0.05\right)$ and not in field $3\left(F_{3,20}=2.72, p=0.07\right)(F i g .2 c+2 d)$.
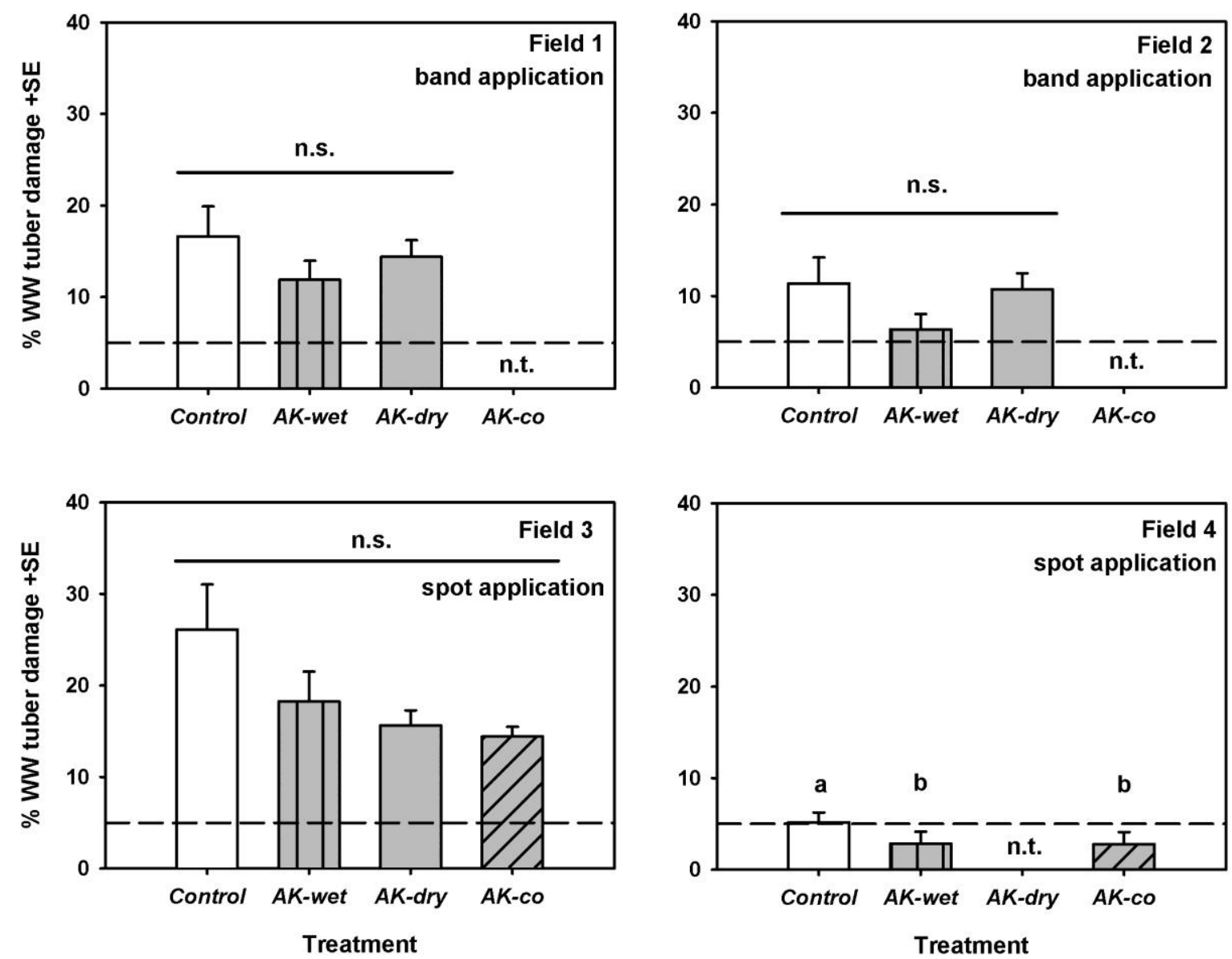

Fig. 2: Wireworm (WW) potato tuber damage in \% (mean \pm standard error (SE)) at four field sites $(1-4)$ with treatments applied at a band / spot underneath seed potatoes. Control: Untreated potato rows; AK-wet: Co-formulated wet attract-and-kill beads; $A K$-dry: Coformulated dry attract-and-kill beads; AK-co: Co-applied wet Attract and Kill beads. Dashed line $(----)=5 \%$ economic threshold level; n.t. not tested. (One-way ANOVA; different lower case letters indicate significant difference after Tukey HSD test $(\alpha=0.05)$ ). 
Treatment efficacy did not significantly differ between treatments $\left(F_{1,43}=2.56\right.$, $p=0.12)$, application type $\left(F_{1,43}=1.49, p=0.23\right)$ and with an interaction of both $\left(F_{1,43}\right.$ $=1.99, p=0.17)$. A higher efficacy could be reached with a spot than a band application with $A K$-co beads resulting in better control than AK-wet / AK-dry beads (Table 3).

Table 3: Treatment efficacies (mean \pm standard error (SE)) as the percentage reduction of wireworm damaged potato tubers compared to the untreated Control ( $A K$-wet: Co-formulated wet attract-and-kill beads; AK-dry: Co-formulated dry attract-and-kill beads; AK-co: Coapplied wet attract and kill-beads) with a spot or band application underneath seed potatoes.

\begin{tabular}{|c|c|c|}
\hline Treatment & Spot application & Band application \\
\hline AK-wet & $37.65 \pm 18.80$ & $36.26 \pm 13.60$ \\
\hline AK-dry & $40.19 \pm 6.35$ & $9.51 \pm 13.05$ \\
\hline$A K-c O$ & $45.29 \pm 8.85$ & n.t. \\
\hline
\end{tabular}

n.t. not tested

The tuber damage pattern in field 1 was depended on a three-way interaction of treatment, damage type (WW / WW+DC) and damage severity (damage class) (chi-square test: Residual (Resid.) degrees of freedom (df) $=0$, Resid. deviance $($ dev. $)=0, p<0.001)$. In field 2 the damage pattern depended on an interaction between treatment and damage type only (chi-square test: Resid. $\mathrm{df}=10$, resid. dev. $=9.83, p<0.05$ ). In field 3 (treatment $x$ damage class: chi-square test: Resid. $d f=8$, resid. dev. $=5.83, p=0.59$; treatment $x$ damage type: Resid. $d f=9$, resid. dev. $=$ 9.45, $p=0.20$; treatment type $x$ treatment class: Resid. $d f=12$, resid. dev. $=15.19, p$ $=0.11$ ) and field 4 (treatment $x$ damage class: chi-square test: Resid. $d f=8$, resid. dev. $=4.86, p=0.53$; treatment $x$ damage type: Resid. $d f=6$, resid. dev. $=3.26, p=$ 0.45 ; treatment type $x$ treatment class: Resid. $d f=6$, resid. dev. $=1.77, p=0.96$ ), no interaction dependencies were observed (Table 4).

The total \% of damaged tubers were significantly affected by treatments in field 1 (chi-square $=6.04, p<0.05$ ), field 2 (chi-square $=14.93, p<0.001$ ) and field 3 (chi-square $=26.23, p<0.001$ ), but not in field 4 (chi-square $=4.02, p=0.13$ ) at a 
range of $34-45 \% / 22-29 \% / 20-38 \% / 23-30 \%$ in the untreated Control / AKwet / AK-dry / AK-co treatments, not taking damage type and damage severity into account. The ratios of \% damaged tubers with wireworm holes to wireworm holes with Drycore symptoms (WW / WW+DC) were highest and significantly biased in field $3(77 \% / 33 \%$; chi-square $=191.91, p<0.001)$ and field $1(62 \% / 38 \%$; chi-square $=$ 21.37, $\mathrm{p}<0.001)$, when damage severity and treatments were not taken into account. In field 2 (47\% / 53\%; chi-square $=0.82, p=0.37)$ and field $4(51 \% / 49 \%$; chi-square $=0.015, p=0.90$ ) equal ratios were observed. The tuber damage severity ratios in \% differed significantly across all fields (field 1: chi-square $=440.69, p<$ 0.001 ; field 2: chi-square $=14.94, p<0.001$; field 3: chi-square $=26.23, p<0.001$; field 4 : chi-square $=122.71, p<0.001$ ) by a decreasing abundance of wireworm damage occurrences when damage classes increase; thus ranges of $85-96 \%$ / 4 $11 \%$ / $0-5 \%$ in class 1 / class 2 / class 3 , when treatment and damage type are not taken into account, were observed (Table 4). 
Table 4: Contingency tables with the number of wireworm holes in potato tubers differentiated by damage type (wireworm holes only (WW); wireworm holes including Drycore symptoms $(\mathrm{WW}+\mathrm{DC})$ and damage severity (class 1: $1-2$ holes; class 2: $3-5$ holes; class 3: $>5$ holes) with AK treatments ( $A K$-wet: Co-formulated wet attract-and-kill beads; $A K-d r y$ : Co-formulated dry attract-and-kill beads; $A K$-co: Combined wet Attract beads and Kill beads) and an untreated Control at four field sites $(1-4)$.

\begin{tabular}{|c|c|c|c|c|c|c|c|c|}
\hline \multirow[t]{2}{*}{ Field 1} & & \multicolumn{3}{|l|}{ WW } & \multicolumn{3}{|c|}{$W W+D C$} & \multirow[b]{2}{*}{ Sum } \\
\hline & & Class 1 & Class 2 & Class 3 & Class 1 & Class 2 & Class 3 & \\
\hline \multirow[t]{4}{*}{ Treatment } & Control & 90 & 6 & 1 & 41 & 5 & 0 & 143 \\
\hline & $A K-w e t$ & 53 & 1 & 4 & 33 & 13 & 1 & 105 \\
\hline & $A K-d r y$ & 57 & 13 & 2 & 38 & 4 & 4 & 118 \\
\hline & Sum & 200 & 20 & 7 & 112 & 22 & 5 & 366 \\
\hline \multirow[t]{2}{*}{ Field 2} & & \multicolumn{3}{|l|}{ WW } & \multicolumn{3}{|c|}{$W W+D C$} & \\
\hline & & Class 1 & Class 2 & Class 3 & Class 1 & Class 2 & Class 3 & Sum \\
\hline \multirow[t]{4}{*}{ Treatment } & Control & 34 & 5 & 4 & 45 & 8 & 1 & 97 \\
\hline & $A K$-wet & 15 & 1 & 2 & 30 & 3 & 2 & 53 \\
\hline & AK-dry & 44 & 6 & 2 & 35 & 3 & 0 & 90 \\
\hline & Sum & 93 & 12 & 8 & 110 & 14 & 3 & 240 \\
\hline
\end{tabular}

\begin{tabular}{|c|c|c|c|c|c|c|c|c|}
\hline \multirow[t]{2}{*}{ Field 3} & & \multicolumn{3}{|l|}{ WW } & \multicolumn{3}{|c|}{$W W+D C$} & \multirow[b]{2}{*}{ Sum } \\
\hline & & Class 1 & Class 2 & Class 3 & Class 1 & Class 2 & Class 3 & \\
\hline \multirow[t]{5}{*}{ Treatment } & Control & 137 & 16 & 0 & 52 & 6 & 0 & 211 \\
\hline & $A K$-wet & 111 & 11 & 2 & 27 & 0 & 0 & 151 \\
\hline & $A K-d r y$ & 90 & 4 & 0 & 28 & 1 & 0 & 123 \\
\hline & $A K-c O$ & 105 & 7 & 0 & 28 & 3 & 0 & 143 \\
\hline & Sum & 443 & 38 & 2 & 135 & 10 & 0 & 628 \\
\hline
\end{tabular}

\begin{tabular}{|c|c|c|c|c|c|c|c|c|}
\hline \multirow[t]{2}{*}{ Field 4} & & \multicolumn{3}{|l|}{ wW } & \multicolumn{3}{|c|}{$W W+D C$} & \multirow[b]{2}{*}{ Sum } \\
\hline & & Class 1 & Class 2 & Class 3 & Class 1 & Class 2 & Class 3 & \\
\hline \multirow[t]{4}{*}{ Treatment } & Control & 13 & 1 & 0 & 16 & 0 & 0 & 30 \\
\hline & $A K$-wet & 10 & 1 & 0 & 5 & 1 & 0 & 17 \\
\hline & $A K-c o$ & 9 & 0 & 0 & 11 & 0 & 0 & 20 \\
\hline & Sum & 32 & 2 & 0 & 32 & 1 & 0 & 67 \\
\hline
\end{tabular}




\section{Discussion}

The study built upon an attract-and-kill (AK) approach against wireworms (Agriotes spp.) in potatoes (compare chapter 3) aiming to develop a technical AK formulation. The AK components consisted of encapsulated EPF M. brunneum (strain: ART2825) conidia with an artificial $\mathrm{CO}_{2}$ source (= baker's yeast) co-applied as two separate wet beads or co-formulated in a single bead as a wet and dry formulation. Performance of both agents differed according to the type of formulation and application in the field. The most technical advanced dry co-formulation performed better with a spot than a band application underneath seed potatoes. AK treatment performance ranged from $10-45 \%$ and could therefore not reach an efficacy of up to $81 \%$ measured in other AK approaches (Vernon et al., 2015).

\section{Verification of materials' performance}

$\mathrm{CO}_{2}$ production

An application of $\mathrm{AK}$ beads increased $\mathrm{CO}_{2}$ levels up to 3.4-fold $(A K-c O)$ with $\mathrm{CO}_{2}$-levels peaking one and three weeks after bead application with a dry (AK-dry) and wet (AK-wet / $A K-c o)$ formulation, respectively. $\mathrm{A} \mathrm{CO}_{2}$ level elevation over a period of up to six weeks can be regarded as sufficient to attract wireworms residing in the upper soil layer after their upward vertical movement from deeper soil layers in spring (Traugott et al., 2015). Soil $\mathrm{CO}_{2}$ levels in an $\mathrm{AK}$ bead treatment results from the conversion of sugar molecules into $\mathrm{CO}_{2}$ molecules through the baker's yeast; in advance soil microorganisms producing exoenzymes with amylase activity degraded starch molecules into convertible sugar molecules (Vemmer et al., 2016). In addition $\mathrm{CO}_{2}$ molecules are produced in bare soil (612 ppm; Fig. 1) from soil respiration through microbial activity (Turpin, 1920, Lundegardh, 1927).

$\mathrm{CO}_{2}$ emission of wet AK beads peaked three weeks after application (Fig. 1), a comparable time interval measured with encapsulated baker's yeast only (Schumann et al., 2014). $\mathrm{CO}_{2}$ emission of co-formulated Beauveria bassiana (Bals.) Vuillemin wet beads peaked after as early as seven days under controlled laboratory conditions (Vemmer et al., 2016) and could therefore be affected by EPF species and abiotic factors (e.g. soil temperature). The higher peak $\mathrm{CO}_{2}$ level (2063 ppm) measured in the $A K$-co treatment is most likely based on the higher bead application rate ( $A K$-co beads: $18.5 \mathrm{~g})$ compared to the $A K$-dry $(=3.7 \mathrm{~g}=9 \mathrm{~g}$ after re-swelling as 
wet formulation; $1917.50 \mathrm{ppm}$ ) and $A K$-wet (= $9.0 \mathrm{~g} ; 1553 \mathrm{ppm}$ ) beads (Fig 1). EPF beads alone could also produce $\mathrm{CO}_{2}$ through microbial respiration (Brandl, M., pers. observation) in addition to the $\mathrm{CO}_{2}$ beads resulting in higher $\mathrm{CO}_{2}$ emission, as it was also observed with $\mathrm{CO}_{2}$ dose response tests (Schumann et al., 2014).

A delayed two week $\mathrm{CO}_{2}$ peaking of wet compared to dry AK beads (Fig. 1) was measured, despite the fact that dry beads need time to re-swell to reach an $a_{w}$ value between $0.61-0.85$ (Beuchat, 1983) for an activation of baker's yeast. Initial re-swelling of dry beads may have caused a preferential water flow towards the dry beads accumulating larger parts of the soil matrix (Simunek et al., 2003), and concurrently soil microorganisms, all displaced by carrier particles such as clay $(<2$ $\mu \mathrm{m})$ (McGechan \& Lewis, 2002). These changes in water flow activity led to a preceded $\mathrm{CO}_{2}$ production from the accumulation of microorganisms around the beads.

Metarhizium brunneum viability, virulence and persistence

M. brunneum strain ART2825 virulence towards wireworms (A. sputator) could be verified in all treatments after 18 weeks with a mortality ranging between 46 ( $A K$ $d r y)-86 \%(A K-C O)$. This extended time period is necessary to kill $A$. sputator wireworms (Eckard et al., 2014). The relative risk of wireworms dying (HR) increased with an application of AK beads (Table 1), but was only significant for an application of $A K-c o$ beads. Wireworm death could not always be related to an M. brunneum infection with the proportion of mycosis ranging from $36-58 \%$ of dead wireworms. Furthermore, mycosed wireworms were found within the untreated Control ( 38\%) due a natural Metarhizium spp. colonization in the tested field soils (Table 2). Differences in co-formulated $A K$-wet and $A K$-dry bead performance was not observed, verifying a successful re-swelling of $A K$-dry beads to create a favorable environment (e.g. > 93\% relative humidity) (Gillespie \& Claydon, 1989) for $M$. brunneum outgrowth and maintain $M$. brunneum virulence. The lower infection potential of co-formulated ( $A K$-wet, $A K$-dry) than co-applied ( $A K$-co) beads (Table 1) could be due to an earlier growth of baker's yeast than $M$. brunneum out of the beads. This was observed on selective medium and may prevent (or delay) conidial outgrowth in the soil. Such a competition did not occur with $A K$-co beads as both yeast and $M$. brunneum were applied in separate beads. The interaction between coformulated contents may therefore require more research as baker's yeast was 
meant to function as a nutrition source and concurrently a virulence enhancer for $M$. brunneum (Shah et al., 2005).

Natural Metarhizium spp. abundance at planting time was found at low densities in fields 1 - 3 with a high silt content $(39.4-81.1 \% ;<1-63 \mathrm{cfu} / \mathrm{g}$ soil) and a high density in field 2 with a low silt content (13.4\%; 1,774 cfu / g soil) (Table 2). These results are in contrast to Clifton et al. (2015) who suggested a positive correlation of Metarhizium spp. abundance and the percentage of silt in the soil and reflect the complexity of Metarhizium spp. abundance in arable land (e.g. Keller et al., 2003, Mietkiewski et al., 1997, Bidochka et al., 1998).

A spot application of $A K$-co beads (fields 3,4) increased Metarhizium spp. abundance in soil, giving a good $M$. brunneum establishment and persistence as measured in previous years (compare chapter 3). The low Metarhizium spp. establishment of co-formulated AK-wet beads may be related back to a delayed / reduced $M$. brunneum growth as previously discussed. The establishment failure of AK-dry beads (field 1, 3 and 4) results from a seasonal drought period from May to August (Brandl, M., pers. observation), limiting the re-swelling of $A K$-dry beads and subsequent $M$. brunneum outgrowth. Irrigation as done in field 1 and field 2 may consequently favor re-swelling of dry beads and can be regarded as an important pre-requisite for wireworm control with a dry M. brunneum formulation.

\section{Wireworm tuber damage}

Tuber damage in the untreated Control varied from $5-26 \%$ across all four field sites. Harvest dates may have influenced damage levels as wireworm pressure increases with a longer vegetation period (Neuhoff et al., 2007). Additional factors such as the wireworm density, cropping history, land management, soil type, weed density and cultivar (Fox, 1961, Hermann et al., 2013, Johnson et al., 2008, Parker \& Howard, 2001) also contribute to such a variation in pest pressure.

Tuber damage was reduced with an application of AK beads across all fields. The efficacy of the reduction in tuber damage varied between the type of application (spot vs. band) and AK bead formulation (Fig. 2, Table 3). The application of AK beads underneath seed potatoes within potato rows aimed to enhance attraction towards wireworms and subsequently increase $M$. brunneum contact as wireworms rarely disperse between crops once they encountered a sufficient food supply (Schallhart et al., 2011). Besides, this AK bead placement carries the advantage of 
easily incorporating product material into existing planting machineries, thus mentioned by Vernon et al. (2015) who approached a similar AK strategy against wireworms in potatoes with attendant insecticide treated (Phenyl Pyrazole, Fipronil) wheat (Triticum aestivum L.) seeds.

A spot application of AK beads resulted in a higher $M$. brunneum efficacy compared to a band application, reflecting previous results with $A K$-co beads only (compare chapter 3). The spatial arrangement of AK beads impact on the number of spores wireworms come into contact with. In a spot treatment wireworms enter a "cloud" of conidia with sufficient conidial titers, an important pre-requisite to cause an EPF infection (Jaronski, 2010). Moreover, a conidial "cloud" may also maintain the required conidia concentration needed to kill wireworms for a longer time as fungal persistence in the soil can last from a few weeks only to more than 40 (Jaronski, 2010).

The performance of an $A K-c 0$ spot application was lower (38\%) than measured in previous field trial studies (75\%, compare chapter 3 ). A higher pest pressure $(16 \%(2015)$ vs. $11 \%(2013+2014)$ tuber damage $)$ may have lowered treatment performance, indicating that AK efficacy is dependent on wireworm density in the field, a common mechanism in behavioral-control methods (Gut et al., 2004). An $A K-c o$ band application, on the other hand, reached a similar efficacy (37\%, compare chapter 3 ) than an $A K$-wet band application (36\%). This subsequently excludes a negative impact on treatment performance from the separation of $A K$ beads, originally hypothesized for an AK-co band application (compare chapter 3). A reduction of tuber damage below the $5 \%$ damage threshold level (Vernon \& van Herk, 2013) was rarely recorded (field 4 only, Fig. 2d), even at the here used high application rates of the AK components ( $150 \mathrm{~kg}$ dry beads / ha). For an economically feasible use, lower application rates as used for conventional products (e.g. 10 kg / ha GoldorBait®; Bundesamt für Ernährungssicherheit, 2016), should be aimed for and requires future field trials (e.g. dose response with AK beads) to enable their practical use.

Damage severity was mainly categorized as "class 1 " in both damage types (WW / WW+DC; Table 4) with one wireworm feeding hole per tuber and was independent of the tuber damage level in a field. Taking the tuber damage level as a measure of wireworm density in the field (Horton, 2006), it indicates that damage severity may not directly correlate to wireworm density in the field (Vernon \& van 
Herk, 2013). It is possible that higher wireworm densities triggered horizontal migration (Sonnemann et al., 2014), resulting in a further spread of wireworms towards other tubers and a less clumped distribution around single tubers. This density behavior could reflect the damage severity measured in the field trials (Table 4). Wireworm density was not measured in this study, e.g. through post-harvest sampling using bait traps (Vernon et al., 2015), but could be integrated in further studies to give a better insight into these wireworm population dynamics.

\section{Conclusion}

An AK approach offers promising potential for wireworm control in potatoes, but its efficacy depends on an AK formulation and type of application. A technical AKdry formulation could only perform well at a spot application but not as a practical more feasible band application. The interaction between $\mathrm{CO}_{2}$ producing compounds such as the here used baker's yeast and $M$. brunneum conidia need to be taken into consideration to improve an AK formulation. Furthermore, the spatial arrangement and $A K$ bead application rates need to be evaluated more thoroughly to optimize its practical use in the field.

\section{Acknowledgements}

These studies were funded by means of the $7^{\text {th }}$ Framework Programme of the European Union 282767 as a part of the project INBIOSOIL (http://inbiosoil.unigoettingen.de). We would like to thank Bianca Tappe for her technical assistance, numerous students for their contribution, and Dr. Christian Ahl (Georg-AugustUniversität, Göttingen) for conducting the soil analysis. Furthermore we would like to thank Wilfried Dreyer (Ökoring AG, Visselhövede, Germany) for his professional support and Agroscope (Reckenholz, Switzerland) for the provision of M. brunneum strain ART2825. Finally we would like to thank all farmers for providing field sites. 


\section{References}

Abbott, W. S. (1987) Abbotts formula - a method of computing the effectiveness of an insecticide. Journal of the American Mosquito Control Association, 3, 302303.

Anonymous (2005) Wireworms. Bulletin OEPP/EPPO Bulletin, 35, 179-182.

Anonymous (2012) Design and analysis of efficacy evaluation trials. Bulletin OEPP/EPPO Bulletin, 42, 367-381.

Beuchat, L. R. (1983) Influence of water activity on growth, metabolic-activities and survival of yeasts and molds. Journal of Food Protection, 46, 135-141.

Bidochka, M. J., Kasperski, J. E. \& Wild, G. a. M. (1998) Occurrence of the entomopathogenic fungi Metarhizium anisopliae and Beauveria bassiana in soils from temperate and near-northern habitats. Canadian Journal of BotanyRevue Canadienne De Botanique, 76, 1198-1204.

Bischoff, J. F., Rehner, S. A. \& Humber, R. A. (2009) A multilocus phylogeny of the Metarhizium anisopliae lineage. Mycologia, 101, 512-530.

Bmelv, R. (2010) Gute fachliche Praxis im Pflanzenschutz. Gute fachliche Praxis im Pflanzenschutz, Grundsätze für die Durchführung. Bonn, Germany: Bundesministerium für Ernährung, Landwirtschaft und Verbraucherschutz.

Bundesamt Für Ernährungssicherheit (2016) Plant protection product register. http://pmg.ages.at/export/PMG/PMG/web/reg/3588_0_e.html, 03. March 2016.

Clifton, E. H., Jaronski, S. T., Hodgson, E. W. \& Gassmann, A. J. (2015) Abundance of soil-borne entomopathogenic fungi in organic and conventional fields in the Midwestern USA with an emphasis on the effect of herbicides and fungicides on fungal persistence. Plos One, 10, 1-17.

Cox, D. R. (1972) Regression models and life-tables. Journal of the Royal Statistical Society Series B-Statistical Methodology, 34, 187-220.

Crawley, M. J. (2013) The R Book - second edition, London, UK, John Wiley \& Sons, Ltd.

De Faria, M. R. \& Wraight, S. P. (2007) Mycoinsecticides and mycoacaricides: A comprehensive list with worldwide coverage and international classification of formulation types. Biological Control, 43, 237-256.

Doane, J. F., Lee, Y. W., Klingler, J. \& Westcott, N. D. (1975) Orientation response of Ctenicera destructor and other wireworms (Coleoptera: Elateridae) to 
germinating grain and to carbon-dioxide. Canadian Entomologist, 107, 12331252.

Eckard, S., Ansari, M. A., Bacher, S., Butt, T. M., Enkerli, J. \& Grabenweger, G. (2014) Virulence of in vivo and in vitro produced conidia of Metarhizium brunneum strains for control of wireworms. Crop Protection, 64, 137-142.

Eilenberg, J., Hajek, A. \& Lomer, C. (2001) Suggestions for unifying the terminology in biological control. Biocontrol, 46, 387-400.

El-Sayed, A. M., Suckling, D. M., Byers, J. A., Jang, E. B. \& Wearing, C. H. (2009) Potential of "Lure and Kill" in long-term pest management and eradication of invasive species. Journal of Economic Entomology, 102, 815-835.

Ericsson, J. D., Kabaluk, J. T., Goettel, M. S. \& Myers, J. H. (2007) Spinosad interacts synergistically with the insect pathogen Metarhizium anisopliae against the exotic wireworms Agriotes lineatus and Agriotes obscurus (Coleoptera: Elateridae). Journal of Economic Entomology, 100, 31-38.

European Parliament and the Council of the European Union (2009a) Directive 2009/128/EC of the European Parliament and of the Council of 21 October 2009 establishing a framework for Community action to achieve the sustainable use of pesticides. Official Journal of the European Union, 52, 7186.

European Parliament and the Council of the European Union (2009b) Regulation (EC) No 1107/2009 of the European Parliament and of the Council of 21 October 2009 concerning the placing of plant protection products on the market and repealing Council Directives 79/117/EEC and 91/414/EEC. Official Journal of the European Union, 52, 1-50.

Fox, C. J. S. (1961) The distribution and abundance of wireworms in the Annapolis Valley of Nova Scotia. Canadian Entomologist, 93, 276-279.

Gillespie, A. T. \& Claydon, N. (1989) The use of entomogenous fungi for pest-control and the role of toxins in pathogenesis. Pesticide Science, 27, 203-215.

Giraudoux, P. (2015) Data analysis in ecology. R package version 1.6.2.

Gut, L. J., Stelinski, L. L., Thomson, D. R. \& Miller, J. R. (2004) Behaviour-modifyiing chemicals: Prospects and constraints in IPM. In: Koul, O., Dhaliwal, G. S. \& Cuperus, G. W. (eds.) Integrated pest management: Potential, constraints and challenges. Wallingford, UK: CABI Publishing. 
Hack, H., Gall, H., Klemke, T., Klose, R., Meier, U., Stauss, R. \& Witzen-Berger, A. (2001) Potato. In: Meier, U. (ed.) Growth stages of mono-and dicotyledonous plants. Germany: Federal Biological Research Centre for Agriculture and Forestry.

Hajek, A. E., Mcmanus, M. L. \& Delalibera, I. (2007) A review of introductions of pathogens and nematodes for classical biological control of insects and mites. Biological Control, 41, 1-13.

Heitefuß, R. (1987) Pflanzenschutz - Grundlagen der praktischen Phytomedizin, Stuttgart, Thieme.

Hermann, A., Brunner, N., Hann, P., Wrbka, T. \& Kromp, B. (2013) Correlations between wireworm damages in potato fields and landscape structure at different scales. Journal of Pest Science, 86, 41-51.

Horton, D. R. (2006) Quantitative relationship between potato tuber damage and counts of Pacific coast wireworm (Coleoptera: Elateridae) in baits: seasonal effects. Journal of the Entomological Society of British Columbia, 103, 37-48.

Hothorn, T., Bretz, F. \& Westfall, P. (2008) Simultaneous inference in general parametric models. Biometrical Journal, 50, 346-363.

Howarth, F. G. (1991) Environmental impacts of classical biological-control. Annual Review of Entomology, 36, 485-509.

Humber, R. A. (2012) Identification of entomopathogenic fungi. In: Lacey, L. A. (ed.) Manual of Techniques in Invertebrate Pathology London, UK: Academic Press.

Hyslop, J. A. (1915) Wireworms attacking cereal and forage crops. Bulletin of the U.S. Department of Agriculture, 156, 1-34.

Jackson, M. A., Dunlap, C. A. \& Jaronski, S. T. (2010) Ecological considerations in producing and formulating fungal entomopathogens for use in insect biocontrol. Biocontrol, 55, 129-145.

Jaronski, S. T. (2010) Ecological factors in the inundative use of fungal entomopathogens. Biocontrol, 55, 159-185.

Johnson, S. N., Anderson, E. A., Dawson, G. \& Griffiths, D. W. (2008) Varietal susceptibility of potatoes to wireworm herbivory. Agricultural and Forest Entomology, 10, 167-174.

Johnson, S. N. \& Gregory, P. J. (2006) Chemically-mediated host-plant location and selection by root-feeding insects. Physiological Entomology, 31, 1-13. 
Johnson, S. N. \& Nielsen, U. N. (2012) Foraging in the dark - chemically mediated host plant location by belowground insect herbivores. Journal of Chemical Ecology, 38, 604-614.

Kabaluk, J. T., Goettel, M. S., Erlandson, M., Ericsson, J. D., Duke, G. \& Vernon, R. S. (2005) Metarhizium anisopliae as a biological control for wireworms and a report of some other naturally-occuring parasites. IOBC/wprs Bulletin, 28, 109-115.

Kabaluk, J. T., Vernon, R. S. \& Goettel, M. S. (2007) Mortality and infection of wireworm, Agriotes obscurus [Coleoptera : Elateridae], with inundative field applications of Metarhizium anisopliae. Phytoprotection, 88, 51-56.

Keiser, A., Haberli, M. \& Stamp, P. (2012) Drycore appears to result from an interaction between Rhizoctonia solani and wireworm (Agriotes ssp.) evidence from a 3-year field survey. Potato Research, 55, 59-67.

Keller, S., Kessler, P. \& Schweizer, C. (2003) Distribution of insect pathogenic soil fungi in Switzerland with special reference to Beauveria brongniartii and Metharhizium anisopliae. Biocontrol, 48, 307-319.

Kölliker, U., Biasio, L. \& Jossi, W. (2011) Potential control of swiss wireworms with entomopathogenic fungi. IOBC/wprs Bulletin, 66, 517-520.

Lacey, L. A. \& Solter, L. F. (2012) Initial handling and diagnosis of diseased invertbrates. In: Lacey, L. A. (ed.) Manual of Techniques in Invertebrate Pathology London, UK: Academic Press.

Lundegardh, H. (1927) Carbon dioxide evolution and crop growth. Soil Science, 23, 417-453.

Mcgechan, M. B. \& Lewis, D. R. (2002) Transport of particulate and colloid-sorbed contaminants through soil, part 1: General principles. Biosystems Engineering, 83, 255-273.

Meyling, N. V. \& Eilenberg, J. (2007) Ecology of the entomopathogenic fungi Beauveria bassiana and Metarhizium anisopliae in temperate agroecosystems: Potential for conservation biological control. Biological Control, 43, 145-155.

Mietkiewski, R. T., Pell, J. K. \& Clark, S. J. (1997) Influence of pesticide use on the natural occurrence of entomopathogenic fungi in arable soils in the UK: Field and laboratory comparisons. Biocontrol Science and Technology, 7, 565-575. 
Neuhoff, D., Christen, C., Paffrath, A. \& Schepl, U. (2007) Approaches to wireworm control in organic potato production. IOBC/wprs Bulletin, 30, 65-68.

Ngandu, N. H. (1997) An empirical comparison of statistical tests for assessing the proportional hazards assumption of Cox's model. Statistics in Medicine, 16, 611-626.

Parker, W. E. \& Howard, J. J. (2001) The biology and management of wireworms (Agriotes spp.) on potato with particular reference to the U.K. Agricultural and Forest Entomology, 3, 85-98.

Pinheiro, J., Bates, D., Debroy, S., S., D. \& R Development Core Team (2013) nlme: Linear and nonlinear mixed effects models. $R$ package version 3. 1-111.

R Development Core Team (2013) R: A language and environment for statistical computing. R foundation for statistical computing, http://www.R-project.org/ Vienna, Austria

Schallhart, N., Tusch, M. J., Staudacher, K., Wallinger, C. \& Traugott, M. (2011) Stable isotope analysis reveals whether soil-living elaterid larvae move between agricultural crops. Soil Biology \& Biochemistry, 43, 1612-1614.

Schumann, M., Toepfer, S., Vemmer, M., Patel, A., Kuhlmann, U. \& Vidal, S. (2014) Field evaluation of an attract and kill strategy against western corn rootworm larvae. Journal of Pest Science, 87, 259-271.

Shah, F. A., Wang, C. S. \& Butt, T. M. (2005) Nutrition influences growth and virulence of the insect-pathogenic fungus Metarhizium anisopliae. Fems Microbiology Letters, 251, 259-266.

Simunek, J., Jarvis, N. J., Van Genuchten, M. T. \& Gardenas, A. (2003) Review and comparison of models for describing non-equilibrium and preferential flow and transport in the vadose zone. Journal of Hydrology, 272, 14-35.

Sonnemann, I., Grunz, S. \& Wurst, S. (2014) Horizontal migration of click beetle (Agriotes spp.) larvae depends on food availability. Entomologia Experimentalis Et Applicata, 150, 174-178.

Spruance, S. L., Reid, J. E., Grace, M. \& Samore, M. (2004) Hazard ratio in clinical trials. Antimicrobial Agents and Chemotherapy, 48, 2787-2792.

Therneau, T. M. (2013) A Package for Survival Analysis in S. R package version 2.37 $-4$ 
Thomas, C. A. (1940) The biology and control ow wireworms: A review of the literature. The Pennsylvania State College, School of Agriculture and Experiment Station, State College, Pennsylvania, US, Bulletin 392.

Toepfer, S., Ellsbury, M. M., Eschen, R. \& Kuhlmann, U. (2007) Spatial clustering of Diabrotica virgifera virgifera and Agriotes ustulatus in small-scale maize fields without topographic relief drift. Entomologia Experimentalis Et Applicata, 124, $61-75$.

Traugott, M., Benefer, C. M., Blackshaw, R. P., Van Herk, W. G. \& Vernon, R. S. (2015) Biology, ecology, and control of elaterid beetles in agricultural land. Annual Review of Entomology, Vol 60, 60, 313-334.

Turpin, H. W. (1920) The carbon dioxide of the soil air. Cornell University Agr. Exp. Sta., Memoir, 32, 315-362.

Vemmer, M., Schumann, M., Beitzen-Heineke, W., French, B. W., Vidal, S. \& Patel, A. (2016) Development of a $\mathrm{CO}_{2}$ releasing co-formulation based on starch, Saccharomyces cerevisiae and Beauveria bassiana attractive towards western corn rootworm larvae. Pest Management Science.

Vernon, R. S. \& Van Herk, W. G. (2013) Wireworms as pests of potato. In: Giordanengo, P., Vincent, C. \& Alyokhin, A. (eds.) Insect Pests of Potato. Oxford, UK: Academic Press.

Vernon, R. S., Van Herk, W. G., Clodius, M. \& Tolman, J. (2015) Companion planting attract-and-kill method for wireworm management in potatoes. Journal of Pest Science, 1-15. 


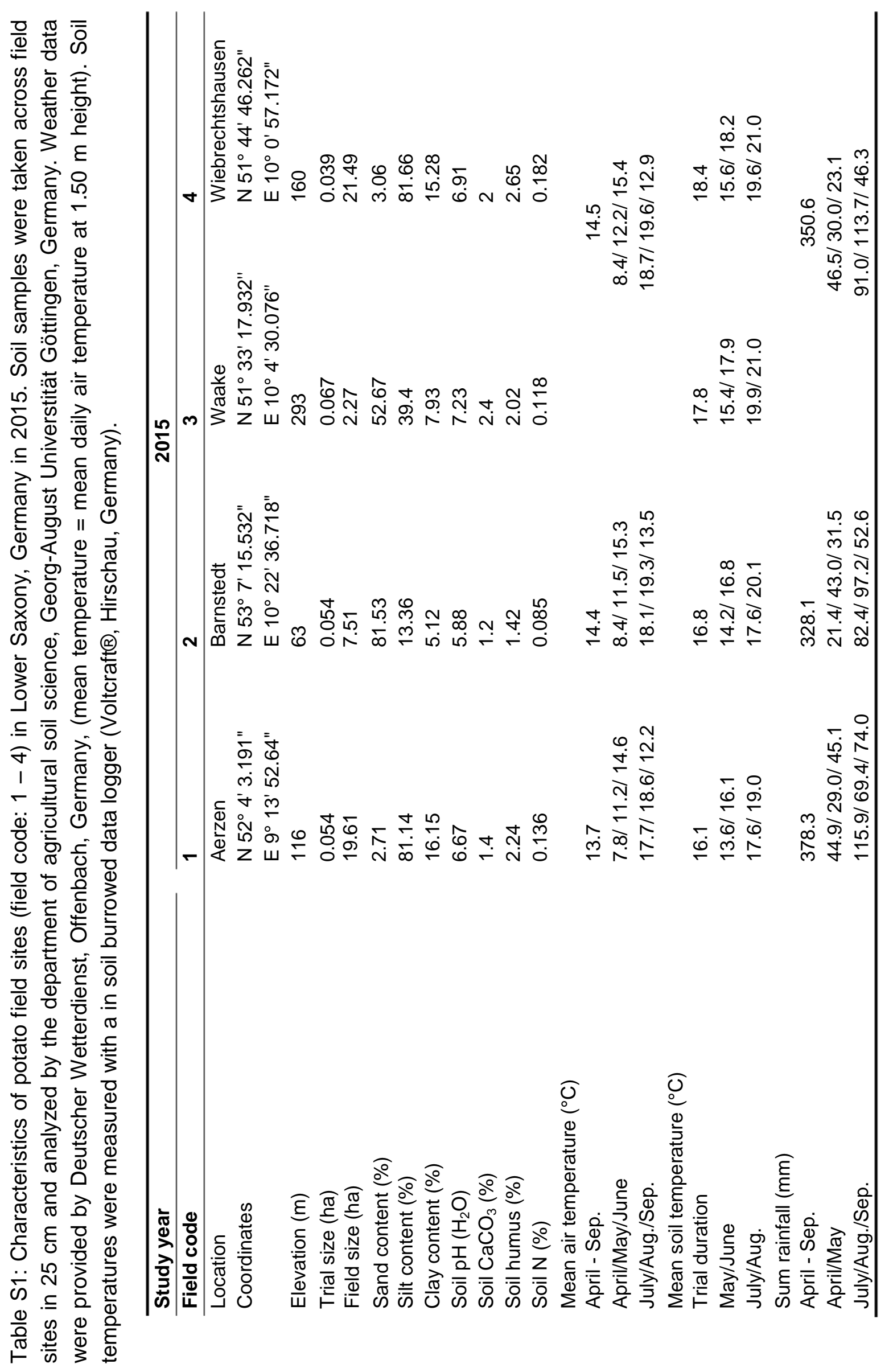


Chapter 4: Technical attract-and-kill formulations for wireworm control

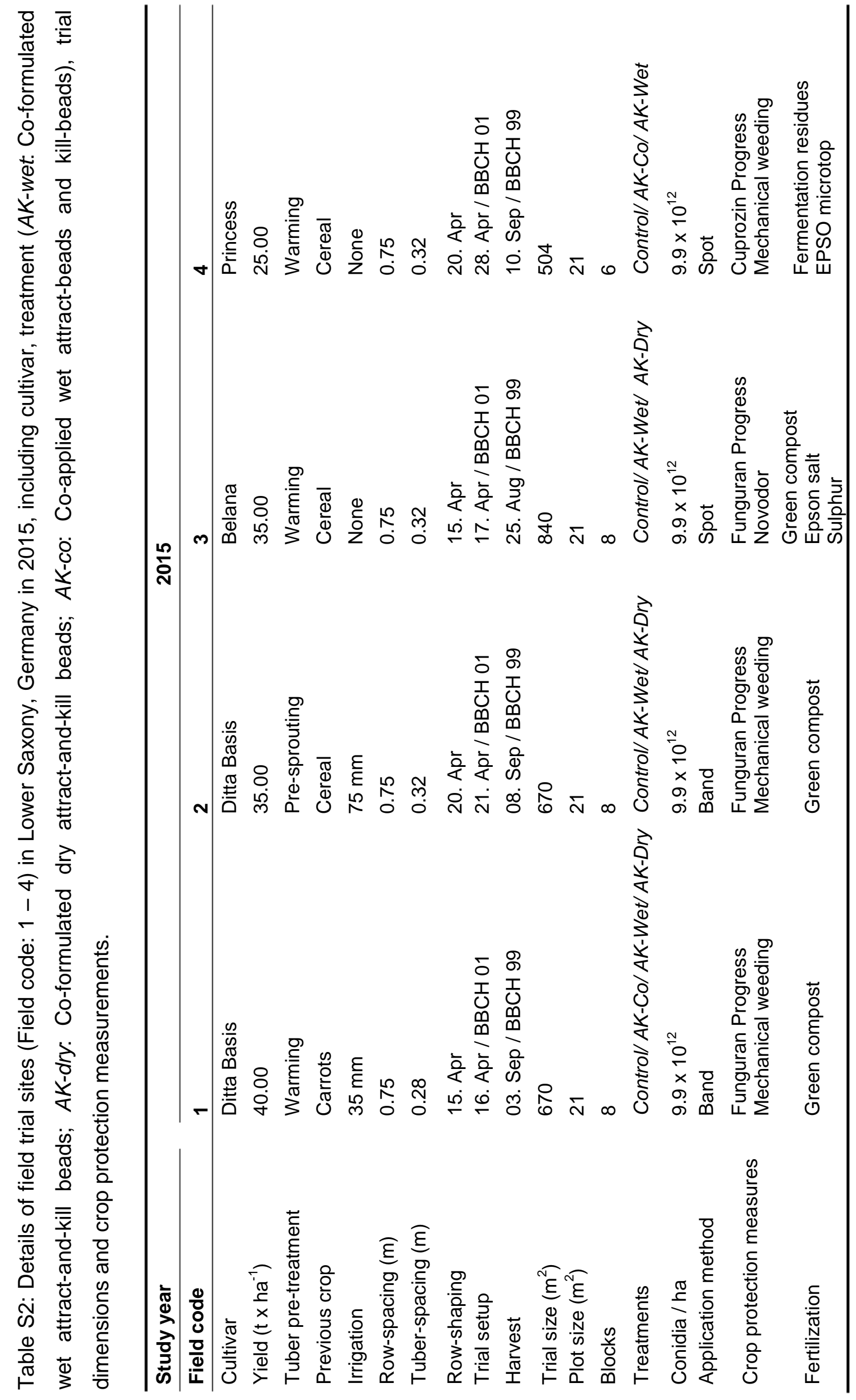




\section{General discussion}

Root-feeding insect control is of major concern to maintain qualitative and high yielding crops. Taking account societal concerns of chemical applications in insect control reflected by the (EC) No regulation 1107/2009 (European Parliament and the Council of the European Union, 2009b) and Directive 2009/128/EC (European Parliament and the Council of the European Union, 2009a) biological control agents (BCAs) are given priority. In this respect, understanding root-feeding insect ecology might be of great value to assess alternative control strategies implemented in the integrated pest management approach to enhance BCAs efficacies. However, rootfeeding ecology research was hitherto hindered due to the cryptic root-feeding behavior but is nowadays intensively studied to tackle knowledge gaps (Johnson \& Rasmann, 2015).

A major achievement in this respect was the conceptual model draft by Johnson \& Gregory (2006), which describes host-location behavior as a cascade of chemical signals. Regarding this, Hiltpold \& Turlings (2012) postulated manipulation feasibilities in any host-location step to enhance on the one hand insect pest control and on the other hand to improve crop yield. This postulate has already been proven in the control of western corn rootworm larvae (WCR) Diabrotica virgifera virgifera LeConte (Coleoptera: Chrysomelidae) (WCR) and wireworms Agriotes spp. Eschscholtz (Coleoptera: Elateridae) by combining the disruption of host-location behavior with an attendant insecticide (Schumann et al., 2014a, Vernon et al., 2015). Furthermore, the same authors argue that such combinations allow drastic reductions of insecticidal inputs, due to synergistic effects, obtaining similar insect pest control as through conventional insecticidal inputs. This is of particular interest as the required chemical input for root-feeding insects is excessively higher than that of shoot-feeding insects (Blackshaw \& Kerry, 2008).

\section{Stress-and-kill}

The implementation of a "stress-and-kill" (SK) approach through a combination of turmeric (Curcuma longa L.) and the entomopathogenic fungus (EPF) Metarhizium brunneum (Metschnikoff) Sorokin (strain: BIPESCO5) encapsulated within sodium (Na)-alginate beads did not significantly control WCR, thus making this approach not feasible for the control of WCR larvae using these agents. 
Screening of repellent extracts (chapter 1)

The present study investigated the potential repellence of garlic (Allium sativum L.), pepper (Capsicum sp. L.), cape aloe (Aloe ferox Miller), neem (Azadirachta indica A. Juss) and turmeric (Curcuma longa L.) derived extracts against WCR larvae in a no-choice bioassay conducted in peat-soil filled Petri dishes. Repellence was examined by WCR larvae leaving a treated soil section before or after its initial contact exhibiting a directional avoidance reaction (Dethier et al., 1960, Lockwood et al., 1984). Regarding this, garlic and turmeric were evaluated as the most promising compounds. Cape aloe, neem and pepper extracts did not cause significant behavioral effects on WCR larvae, despite their known repellent properties against above-ground insects (e.g. Hedin et al., 1974, Schmutterer, 1990).

Turmeric repellence was further evaluated in a rhizotron experiment, which allowed monitoring larval dispersal over time. Host root dependence (Moeser \& Hibbard, 2005), a typical aggregation behavior for below-ground organisms (Brown \& Gange, 1990) as well as the attractiveness of maize roots (Zea mays L.) was monitored throughout the experiment. The application of turmeric resulted in multiple clustering of the larval distribution after $48 \mathrm{~h}$ of larval insertion, compared to an aggregation in a major cluster in the control treatment. An aggregation around the plant base, commonly observed for second and third instar larvae (Strnad \& Bergman, 1987), was disrupted through turmeric, resulting in larval clusters in deeper soil layers within the roots system. Furthermore, larval behavior was altered through turmeric with significantly more larvae moving through the soil and subsequently less larvae feeding. Such a behavioral alteration is known to occur for WCR larvae (Monke et al., 1985) and wireworms (Agriotes obscurus L.) (van Herk \& Vernon, 2013) when exposed to insecticides ex situ, but was never observed in situ. WCR larvae were observed at a $5 \mathrm{~cm}$ distance from a turmeric application point. Thus, turmeric induces repellence upon taxis (= directional avoiding reaction) and orthokinesis (= undirected increased activity) (Dethier, 1956).

\section{Turmeric and Metarhizium brunneum (chapter 2)}

A displacement of WCR larvae through repellence could be observed across all exclusive dose-response turmeric variants in the Petri dish and in the small container two choice tests with larvae being pushed into an untreated-half. Thus, WCR larval host-plant location behavior was subsequently disrupted and WCR 
larvae were repelled by turmeric for at least five weeks. This period would be sufficient to be used in WCR control. A maximum repellency period as reported for the lesser grain borer up to eight weeks (Jilani \& Saxena, 1990) could not be measured given the conducted setup. A decrease in turmeric repellency after two weeks, observed for the lesser grain borer (Jilani \& Saxena, 1990) as well as for the red flour beetle (Tribolium castaneum Herbst) (Jilani et al., 1988), may have triggered an immigration of WCR larvae during larval development.

There was a low and non-significant reduction in larval densities comparable to past studies (e.g. Pilz et al., 2009, Rudeen et al., 2013), despite the fact that $M$. brunneum was able to outgrow $\mathrm{Na}$-alginate barrier and infect $T$. molitor larvae in a quality control. The use of EPF-beads, was meant to increase $M$. brunneum establishment, persistence and viability performance by offering favorable conditions (e.g. > $93 \%$ relative humidity), for a successful conidial germination (Gillespie \& Claydon, 1989). However, its use might have decreased M. brunneum conidia distribution in soil as compared to an application of conidia in a suspension given the size of the released inoculum (EPF-bead: Diameter: $2.7 \pm 0.2 \mathrm{~mm}$; conidia: length: $5.0-7.0 \mu \mathrm{m}$, width: $2.0-3.5 \mu \mathrm{m}$ (Bischoff et al., 2009)) and subsequently decreased WCR larval infection chances.

A combined application of turmeric and EPF-beads could not enhance the reduction of larval densities or increase plant biomass compared to a single application of either treatment. Turmeric did not affect $M$. brunneum growth despite its known antifungal properties (Damalas, 2011). The SK failure reasons are unknown and in contrast to the postulate given by Ansari et al. (2008) that, where one agent (e.g. turmeric) stresses or alters the insect behavior, increases the susceptibility to another agent (e.g. M. brunneum). A potential decrease in turmeric repellency, as aforementioned, could be reasoning.

\section{Attract-and-kill}

The implementation of an "attract-and-kill" (AK) strategy through a combination of baker's yeast (Saccharomyces cerevisiae Meyen ex Hansen) and M. brunneum (Metschnikoff) Sorokin (strain: ART2825) encapsulated within Na-alginate beads reduced wireworm tuber damage significantly making this approach feasible for wireworm control in potatoes. 
Verification of material's performance - laboratory

The application of $\mathrm{AK}$ beads in bare soil increased $\mathrm{CO}_{2}$ soil levels significantly, depending on bead type (Attract, AK-co, AK-wet, AK-dry), soil type and application dates. $\mathrm{CO}_{2}$ emission in the soil lasted for at least four weeks, comparable to time spans with beads used by Schumann et al. (2014b), and can be regarded as long enough to coincide with wireworm activity in spring (Traugott et al., 2015).

Mycosed wireworms were found in all M. brunneum treatments and soil types up to 18 weeks after application. These extended time periods are necessary to kill some wireworms Agriotes spp. (Eckard et al., 2014). A low infection potential of coformulated beads ( $A K$-wet, $A K$-dry) could be related to an earlier growth of baker's yeast than $M$. brunneum out of the beads. This was observed on selective medium and may prevent (or delay) conidial outgrowth in the soil. Such competition did not occur with a co-application of beads $(A K-c O)$ as both baker's yeast and M. brunneum conidia were applied in separate beads. Differences in co-formulated AK-wet and $A K$-dry bead performance was not observed, verifying a successful re-swelling of $A K$ dry beads to create a favorable environment (e.g. $>93 \%$ relative humidity) for $M$. brunneum outgrowth (Gillespie \& Claydon, 1989) and maintain M. brunneum virulence.

Verification of material's performance - field

Natural Metarhizium spp. abundance at planting time was found on more than $50 \%$ of the eleven tested field sites (2013 - 2015). An AK-co application increased Metarhizium spp. abundance in the soil with both a spot and band application, indicating an establishment and persistence within the potato growing period, required for the effectiveness of Metarhizium spp. (Inyang et al., 2000). The low Metarhizium spp. establishment of co-formulated AK-wet beads may be related back to a delayed / reduced growth as previously discussed. Because verification of Metarhizium spp. abundance in the tested fields via morphological characteristics (Humber, 2012) was performed by light microscopy, differentiation between natural and artificially introduced Metarhizium spp. was not possible. New diagnostic tools, using microsatellite markers, allowing identifying and comparing the introduced EPF strain with those present in the field may have provided a better understanding of the fate of the introduced EPF strain in these soils. 


\section{Wireworm tuber damage}

Tuber damage in the untreated control varied from $5-35 \%$ across all eleven field sites due to their differences in cropping history, soil type, weed density, and geographical features (Fox, 1961, Furlan, 2004, Cherry \& Stansly, 2008, Hermann et al., 2013). Harvest dates may have additionally influenced tuber damage with late dates (early September) increasing the potential of tuber damages simply by a prolonged phase of tubers exposed to wireworms as compared to early dates (late August) (Neuhoff et al., 2007).

Tuber damage reductions through an application of AK beads were demonstrated across all fields, whereas tuber damage reduction efficacies varied between the type of application (spot vs. band) and AK bead formulation used. An early application during potato planting in April resulted in better control than during daughter tuber formation in June - August. This is most likely due to wireworms' tendency to reside in the upper soil layers at these times as they exhibit strong seasonal activity in spring and autumn through a vertical movement in the soil profile (Traugott et al., 2015), driven by suitable soil moisture and temperature (Parker \& Howard, 2001, Lafrance, 1968, Traugott et al., 2015). The time until M. brunneum infection of wireworms takes between three weeks to three months; this period might be too long to prevent wireworms from feeding on daughter tubers with a later application during the vegetation period.

A spot application of AK beads resulted in higher $M$. brunneum efficacy as compared to a band application (up to $75 \%$ ), which is comparable to insecticidal control measures (Vernon et al., 2013, Vernon et al., 2015). This was also true for the most technical advanced dry co-formulated beads (AK-dry). The spatial arrangement of AK beads impacts on the number of conidia wireworms come into contact with. In a spot treatment wireworms enter a "cloud" of conidia with sufficient conidial titers to kill them more effectively. This is of particular importance as they need to require a sufficient amount of conidia attached to their cuticle for an infection (Jaronski, 2010). The spot underneath treatment may also benefit by the attraction through the seed potato itself, increasing the probability of infection. This circumstance may not be true for a band application of AK beads, which might be the reason for a lower treatment efficacy. 


\section{Conclusion}

The postulate given by Hiltpold \& Turlings (2012) regarding the possibility to manipulate host-plant location behavior was confirmed by an application of turmeric oil (= stress) and $\mathrm{CO}_{2}$ emitting beads (= attract) in the soil for WCR larvae and wireworms, respectively. The concurrent application of $M$. brunneum conidia encapsulated in single beads (= Kill) or in combination with $\mathrm{CO}_{2}$ emitting beads $(=$ $A K$-co, AK-wet, AK-dry) resulted in the control of wireworms, but not for WCR larvae. The studied AK strategy points the way of future wireworm (Agriotes spp.) management measurements in potatoes (compare Vernon et al., 2015), whereas the studied SK strategy for WCR larval control in maize currently does not. A major drawback within the SK strategy refers most probably to the killing agent. The exchange of $M$. brunneum with entomopathogenic nematodes, for example, may result in better or even synergistic control options of WCR larvae as these antagonists are known to have great potential for larval control (Toepfer et al., 2010). Beyond, a formulation of turmeric might be a further approach to maintain repellence over a prolonged period. In contrast, although an AK strategy for wireworm control seems to be feasible, formulations have to be improved to enhance M. brunneum efficacy. This is due the reasonable assumption that baker's yeast growth competes with $M$. brunneum growth in a technical co-formulated AK bead. Further studies are consequently needed to approach this problem by an assessment of the minimum proportion of baker's yeast possible, simultaneously maintaining sufficient $\mathrm{CO}_{2}$ gradients in the soil. Moreover, dose response tests and different AK application techniques should be studied to make an AK approach marketable for farmers use. 


\section{References: General introduction and general discussion}

Ansari, M. A., Shah, F. A. \& Butt, T. M. (2008) Combined use of entomopathogenic nematodes and Metarhizium anisopliae as a new approach for black vine weevil, Otiorhynchus sulcatus, control. Entomologia Experimentalis Et Applicata, 129, 340-347.

Barnett, K. \& Johnson, S. N. (2013) Living in the soil matrix: Abiotic factors affecting root herbivores, United Kingdom, Elsevier Ltd., Academic Press.

Bernklau, E. J., Fromm, E. A. \& Bjostad, L. B. (2004) Disruption of host location of western corn rootworm larvae (Coleoptera: Chrysomelidae) with carbon dioxide. Journal of Economic Entomology, 97, 330-339.

Bischoff, J. F., Rehner, S. A. \& Humber, R. A. (2009) A multilocus phylogeny of the Metarhizium anisopliae lineage. Mycologia, 101, 512-530.

Bjostad, L. B. \& Hibbard, B. E. (1992) 6-Methoxy-2-Benzoxazolinone - a semiochemical for host location by western corn-rootworm Larvae. Journal of Chemical Ecology, 18, 931-944.

Blackshaw, R. P. \& Kerry, B. R. (2008) Root herbivory in agricultural ecosystems. In: Johnson, S. N. \& Murray, P. J. (eds.) Root feeders - an ecosystem perspective. Wallingford, UK: CABI.

Blot, Y., Brunel, E. \& Courbon, R. (1999) Survey on the infection of wheat and maize by larvae of wireworms of Agriotes and Athous genera (Coleoptera: Elateridae) in some areas of West France. Annales De La Societe Entomologique De France, 35, 453-457.

Branson, T. F. \& Ortman, E. E. (1969) Feeding behavior of larvae of western corn rootworm - normal larvae and larvae maxillectomized with laser radiation Annals of the Entomological Society of America, 62, 808-812.

Brown, V. K. \& Gange, A. C. (1990) Insect herbivory below ground. Advances in Ecological Research, 1-58.

Butt, T. M. (2002) Use of entomogenous fungi for the control of insect pests. In: Esser, K. \& Bennett, R. (eds.) The Mycota. Berlin: Springer.

Cherry, R. \& Stansly, P. (2008) Abundance and spatial distribution of wireworms (Coleoptera: Elateridae) in Florida sugarcane fields on muck versus sandy soils. Florida Entomologist, 91, 383-387. 
Chiang, H. C., French, L. K. \& Rasmussen, D. E. (1980) Quantitative relationship between western corn-rootworm population and corn yield. Journal of Economic Entomology, 73, 665-666.

Damalas, C. A. (2011) Potential uses of turmeric (Curcuma longa) products as alternative means of pest management in crop production. Plant Omics, 4, 136-141.

De Faria, M. R. \& Wraight, S. P. (2007) Mycoinsecticides and mycoacaricides: A comprehensive list with worldwide coverage and international classification of formulation types. Biological Control, 43, 237-256.

Dethier, V. G. (1956) Repellents. Annual Review of Entomology, 1, 181-202.

Dethier, V. G., Browne, L. B. \& Smith, C. N. (1960) The designation of chemicals in terms of the responses they elicit from insects. Journal of Economic Entomology, 53, 134-136.

Doane, J. F., Lee, Y. W., Klingler, J. \& Westcott, N. D. (1975) Orientation response of Ctenicera destructor and other wireworms (Coleoptera: Elateridae) to germinating grain and to carbon-dioxide. Canadian Entomologist, 107, 12331252.

Eckard, S., Ansari, M. A., Bacher, S., Butt, T. M., Enkerli, J. \& Grabenweger, G. (2014) Virulence of in vivo and in vitro produced conidia of Metarhizium brunneum strains for control of wireworms. Crop Protection, 64, 137-142.

El-Sayed, A. M., Suckling, D. M., Byers, J. A., Jang, E. B. \& Wearing, C. H. (2009) Potential of "Lure and Kill" in long-term pest management and eradication of invasive species. Journal of Economic Entomology, 102, 815-835.

Ericsson, J. D., Kabaluk, J. T., Goettel, M. S. \& Myers, J. H. (2007) Spinosad interacts synergistically with the insect pathogen Metarhizium anisopliae against the exotic wireworms Agriotes lineatus and Agriotes obscurus (Coleoptera: Elateridae). Journal of Economic Entomology, 100, 31-38.

European Parliament and the Council of the European Union (2009a) Directive 2009/128/EC of the European Parliament and of the Council of 21 October 2009 establishing a framework for Community action to achieve the sustainable use of pesticides. Official Journal of the European Union, 52, 7186. 
European Parliament and the Council of the European Union (2009b) Regulation (EC) No 1107/2009 of the European Parliament and of the Council of 21 October 2009 concerning the placing of plant protection products on the market and repealing Council Directives 79/117/EEC and 91/414/EEC. Official Journal of the European Union, 52, 1-50.

Fox, C. J. S. (1961) The distribution and abundance of wireworms in the Annapolis Valley of Nova Scotia. Canadian Entomologist, 93, 276-279.

Furlan, L. (2004) The biology of Agriotes sordidus Illiger (Col., Elateridae). Journal of Applied Entomology, 128, 696-706.

Gillespie, A. T. \& Claydon, N. (1989) The use of entomogenous fungi for pest-control and the role of toxins in tathogenesis. Pesticide Science, 27, 203-215.

Gray, M. E., Sappington, T. W., Miller, N. J., Moeser, J. \& Bohn, M. O. (2009) Adaptation and invasiveness of western corn rootworm: Intensifying research on a worsening pest. Annual Review of Entomology, 54, 303-321.

Hajek, A. E. \& St. Leger, R. J. (1994) Interactions between fungal pathogens and insect hosts. Annual Review of Entomology, 39, 293-322.

Hedin, P. A., Maxwell, F. G. \& Jenkins, J. N. (1974) Insect plant attractans, feeding stimulants, repellents, deterrents, and other related factors affecting insect behavior. In: Maxwell, F. G. \& Harris, F. A. (eds.) Proceedings of the summer institute on biological control of plant and insects and diseases. Mississippi, United States of America: The University Press of Mississippi

Hermann, A., Brunner, N., Hann, P., Wrbka, T. \& Kromp, B. (2013) Correlations between wireworm damages in potato fields and landscape structure at different scales. Journal of Pest Science, 86, 41-51.

Hibbard, B. E. \& Bjostad, L. B. (1989) Corn semiochemicals and their effects on insecticide efficacy and insecticide repellency toward western corn rootworm larvae (Coleoptera: Chrysomelidae). Journal of Economic Entomology, 82, 773-781.

Hibbard, B. E. \& Bjostad, L. B. (1990) Isolation of corn semiochemicals attractive and repellent to western corn rootworm larvae. Journal of Chemical Ecology, 16, 3425-3439.

Hiltpold, I. \& Turlings, T. C. J. (2012) Manipulation of chemically mediated interactions in agricultural soils to enhance the control of crop pests and to improve crop yield. Journal of Chemical Ecology, 38, 641-650. 
Humber, R. A. (2012) Identification of entomopathogenic fungi. In: Lacey, L. A. (ed.) Manual of Techniques in Invertebrate Pathology London: Academic Press.

Inyang, E. N., Mccartney, H. A., Oyejola, B., Ibrahim, L., Pye, B. J., Archer, S. A. \& Butt, T. M. (2000) Effect of formulation, application and rain on the persistence of the entomogenous fungus Metarhizium anisopliae on oilseed rape. Mycological Research, 104, 653-661.

Isman, M. B. (2006) Botanical insecticides, deterrents, and repellents in modern agriculture and an increasingly regulated world. Annual Review of Entomology, 51, 45-66.

Jackson, M. A., Dunlap, C. A. \& Jaronski, S. T. (2010) Ecological considerations in producing and formulating fungal entomopathogens for use in insect biocontrol. Biocontrol, 55, 129-145.

Jaronski, S. T. (2010) Ecological factors in the inundative use of fungal entomopathogens. Biocontrol, 55, 159-185.

Jilani, G. \& Saxena, R. C. (1990) Repellent and feeding deterrent effects of turmeric oil, sweetflag oil, neem oil, and a neem-based insecticide against lesser grain borer (Coleoptera: Bostrychidae). Journal of Economic Entomology, 83, 629634.

Jilani, G., Saxena, R. C. \& Rueda, B. P. (1988) Repellent and growth-inhibiting effects of turmeric oil, sweetflag oil, neem oil, and "margosan-o" on red flour beetle (Coleoptera: Tenebrionidae). Journal of Economic Entomology, 81, $1226-1230$.

Johnson, S. N., Anderson, E. A., Dawson, G. \& Griffiths, D. W. (2008) Varietal susceptibility of potatoes to wireworm herbivory. Agricultural and Forest Entomology, 10, 167-174.

Johnson, S. N. \& Gregory, P. J. (2006) Chemically-mediated host-plant location and selection by root-feeding insects. Physiological Entomology, 31, 1-13.

Johnson, S. N. \& Nielsen, U. N. (2012) Foraging in the dark - chemically mediated host plant location by belowground insect herbivores. Journal of Chemical Ecology, 38, 604-614.

Johnson, S. N. \& Rasmann, S. (2015) Root-feeding insects and their interactions with organisms in the rhizosphere. Annual Review of Entomology, 60, 517-535.

Jones, O. T. \& Coaker, T. H. (1978) A basis for host plant finding in phytophagous larvae. Entomologia Experimentalis Et Applicata, 24, 272-284. 
Kabaluk, J. T., Goettel, M. S., Erlandson, M., Ericsson, J. D., Duke, G. \& Vernon, R. S. (2005) Metarhizium anisopliae as a biological control for wireworms and a report of some other naturally-occuring parasites. IOBC/wprs Bulletin, 28, $109-115$.

Kahler, A. L., Olness, A. E., Sutter, G. R., Dybing, C. D. \& Devine, O. J. (1985) Root damage by western corn rootworm and nutrient content in maize. Agronomy Journal, 77, 769-774.

Klingler, J. (1957) Über die Bedeutung des Kohlendioxyds fur die Orientierung der Larven von Otiorrhynchus sulcatus F., Melolontha und Agriotes (Col.) im Boden (Vorlaufige Mitteilung). Mitteilungen der Schweizerischen Entomologischen Gesellschaft, 30, 317-322.

Lafrance, J. (1968) The seasonal movements of wireworms (Coleoptera: Elateridae) in relation to soil moisture and temperature in the organic soils of southwestern Quebec. The Canadian Entomologist, 100, 801-807.

Lockwood, J. A., Sparks, T. C. \& Story, R. N. (1984) Evolution of insect resistance to insecticides: A reevaluation of the roles of physiology and behavior. Bulletin of the Entomological Society of America, 30, 41-51.

Lundegardh, H. (1927) Carbon dioxide evolution and crop growth. Soil Science, 23, 417-453.

Meyling, N. V. \& Eilenberg, J. (2007) Ecology of the entomopathogenic fungi Beauveria bassiana and Metarhizium anisopliae in temperate agroecosystems: Potential for conservation biological control. Biological Control, 43, 145-155.

Moeser, J. \& Hibbard, B. E. (2005) A synopsis of the nutritional ecology of larvae and adults of Diabrotica virgifera virgifera (LeConte) in the New and Old world nouvelle cuisine for the invasive maize pest Diabrotica virgifera virgifera in europe. In: Vidal, S., Kuhlmann, U. \& Edwards, C. R. (eds.) Western corn rootworm ecology and management. London: CABI.

Monke, B. J., Mayo, Z. B. \& Ball, H. J. (1985) Bioassay rating system for predicting mortality of moribund corn-rootworm (Coleoptera: Chrysomelidae) larvae following exposure to insecticide-treated soil. Journal of Economic Entomology, 78, 467-470.

Moore, D., Robson, G. D. \& Trinci, A. P. J. (2011) 21st century guidebook to fungi. United States of America: Cambridge University Press, New York. 
Neuhoff, D., Christen, C., Paffrath, A. \& Schepl, U. (2007) Approaches to wireworm control in organic potato production. IOBC/wprs Bulletin, 30, 65-68.

Parker, W. E. \& Howard, J. J. (2001) The biology and management of wireworms (Agriotes spp.) on potato with particular reference to the U.K. Agricultural and Forest Entomology, 3, 85-98.

Pilz, C., Keller, S., Kuhlmann, U. \& Toepfer, S. (2009) Comparative efficacy assessment of fungi, nematodes and insecticides to control western corn rootworm larvae in maize. Biocontrol, 54, 671-684.

Pilz, C., Wegensteiner, R. \& Keller, S. (2007) Selection of entomopathogenic fungi for the control of the western corn rootworm Diabrotica virgifera virgifera. Journal of Applied Entomology, 131, 426-431.

Pline, M. \& Dusenbery, D. B. (1987) Responses of plant-parasitic nematode Meloidogyne incognita to carbon dioxide determined by video cameracomputer tracking. Journal of Chemical Ecology, 13, 873-888.

Rudeen, M. L., Jaronski, S. T., Petzold-Maxwell, J. L. \& Gassmann, A. J. (2013) Entomopathogenic fungi in cornfields and their potential to manage larval western corn rootworm Diabrotica virgifera virgifera. Journal of Invertebrate Pathology, 114, 329-332.

Schmutterer, H. (1990) Properties and potential of natural pesticides from the neem tree, Azadirachta indica. Annual Review of Entomology, 35, 271-297.

Schumann, M., Patel, A. \& Vidal, S. (2013) Evaluation of an attract and kill strategy for western corn rootworm larvae. Applied Soil Ecology, 64, 178-189.

Schumann, M., Patel, A. \& Vidal, S. (2014) Soil application of an encapsulated $\mathrm{CO}_{2}$ source and its potential for management of western corn rootworm larvae. Journal of Economic Entomology, 107, 230-239.

Spike, B. P. \& Tollefson, J. J. (1989) Relationship of plant phenology to corn yield loss resulting from western corn rootworm (Coleoptera: Chrysomelidae) larval ilnjury, nitrogen deficiency, and high plant-density. Journal of Economic Entomology, 82, 226-231.

Spike, B. P. \& Tollefson, J. J. (1991) Yield response of corn subjected to western corn rootworm (Coleoptera: Chrysomelidae) infestation and lodging. Journal of Economic Entomology, 84, 1585-1590. 
Strnad, S. P. \& Bergman, M. K. (1987) Distribution and orientation of western corn rootworm (Coleoptera: Chrysomelidae) larvae in corn roots. Environmental Entomology, 16, 1193-1198.

Thomas, C. A. (1940) The biology and control ow wireworms: A review of the literature. The Pennsylvania State College, School of Agriculture and Experiment Station, State College, Pennsylvania,, Bulletin 392.

Thorpe, W. H., Crombie, A. C., Hill, R. \& Darrah, J. H. (1947) The behaviour of wireworms in response to chemical stimulation. Journal of Experimental Biology, 23, 234-267.

Toepfer, S., Burger, R., Ehlers, R. U., Peters, A. \& Kuhlmann, U. (2010) Controlling western corn rootworm larvae with entomopathogenic nematodes: Effect of application techniques on plant-scale efficacy. Journal of Applied Entomology, 134, 467-480.

Toepfer, S. \& Kuhlmann, U. (2006) Constructing life-tables for the invasive maize pest Diabrotica virgifera virgifera (Coleoptera: Chrysomelidae) in Europe. Journal of Applied Entomology, 130, 193-205.

Traugott, M., Benefer, C. M., Blackshaw, R. P., Van Herk, W. G. \& Vernon, R. S. (2015) Biology, ecology, and control of elaterid beetles in agricultural land. Annual Review of Entomology, Vol 60, 60, 313-334.

Turlings, T. C. J., Hiltpold, I. \& Rasmann, S. (2012) The importance of root-produced volatiles as foraging cues for entomopathogenic nematodes. Plant and Soil, $358,47-56$.

Van Herk, W. G. \& Vernon, R. S. (2013) Categorization and numerical assessment of wireworm mobility over time following exposure to bifenthrin. Journal of Pest Science, 86, 115-123.

Vernon, R. S. \& Van Herk, W. G. (2013) Wireworms as pests of potato. In: Giordanengo, P., Vincent, C. \& Alyokhin, A. (eds.) Insect Pests of Potato. Oxford, UK: Academic Press.

Vernon, R. S., Van Herk, W. G., Clodius, M. \& Harding, C. (2009) Wireworm management I: Stand protection versus wireworm mortality with wheat seed treatments. Journal of Economic Entomology, 102, 2126-2136.

Vernon, R. S., Van Herk, W. G., Clodius, M. \& Harding, C. (2013) Further studies on wireworm management in Canada: Damage protection versus wireworm mortality in potatoes. Journal of Economic Entomology, 106, 786-799. 
Vernon, R. S., Van Herk, W. G., Clodius, M. \& Tolman, J. (2015) Companion planting attract-and-kill method for wireworm management in potatoes. Journal of Pest Science, 1-15.

Villani, M. G. \& Wright, R. J. (1990) Environmental-influences on soil macroarthropod behavior in agricultural systems. Annual Review of Entomology, 35, 249-269.

Wenke, K., Kai, M. \& Piechulla, B. (2010) Belowground volatiles facilitate interactions between plant roots and soil organisms. Planta, 231, 499-506. 


\section{Publications}

Brandl, M. A., Schumann, M., Przyklenk, M., Vemmer, M., Patel, A., Vidal, S. (2014) Effects of novel fungal formulations (Metarhizium brunneum) to control wireworm (Agriotes spp.) damage in potato fields. J Plant Dis Protect 2, 98.

Mävers, F. \& Brandl M. (2016): Erst anlocken, dann abtöten; Drahtwürmer in Kartoffeln - Attract-and-Kill. Kartoffelbau 4 / 2016 (67. Jg.), 28-30.

Brandl, M. A., Schumann M, French B. W., Vidal S (2016) Screening of botanical extracts for repellence against western corn rootworm larvae. J. Insect Behav 29:395-414

\section{Presentations at conferences and workshops}

Brandl, M. A., Schumann, M., Vidal, S. (2013) Exploring synergistic effects of semiochemicals, entomopathogenic fungi and nematodes against rootherbivores. IOBC-WPRS Bulletin 90, 37.

Brandl, M. A., Schumann, Vidal, S. (2014) Modification of western corn rootworm larval behavior with botanical based extracts. 25th IWGO Conference \& 4th International conference on Diabrotica Genetics, Chicago, USA.

Brandl, M., Schumann, M., Przyklenk, M., Vemmer, M., Patel, A., Vidal, S. (2014) Effects of novel fungal formulations (Metarhizium brunneum) to control wireworm (Agriotes spp.) damage in potato fields. 32. Tagung des AK: "Nutzarthropoden und Entomopathogene Nematoden", Darmstadt, Germany

Brandl, M. A., Schumann, M., Przyklenk, M., Vemmer, M., Patel, A., Vidal, S. (2014) Ein 'Attract \& Kill' - Ansatz zur Drahtwurmregulierung bei Kartoffeln durch Metarhizium brunnem. DPG-Tagung, Freiburg, Germany.

Brandl, M. A., Schumann, M., Vidal, S. (2015) Methodological screening approach for potential repellents against western corn rootworm larvae. DGaaE, Entomologentagung, Frankfurt/ Main, Germany. 


\section{Publications}

Brandl, M. A., Schumann, M., Przyklenk, M., Patel, A., Vidal, S. (2015) An "Attract \& Kill" approach in potato to reduce wireworms tuber damage. 15th Meeting of the IOBC/WPRS WG "Microbial and Nematode Control of Invertebrate Pests", Riga, Lettland.

Brandl, M. A., Schumann, M., Przyklenk, M., Patel, A., Vidal, S. (2015) An Attractand-Kill approach against wireworms (Agriotes spp.) in potatoes. INBIOSOIL Symposium 2015, "Strategies for a sustainable agriculture in Europe: innovative biological options", Göttingen, Germany.

\section{Posters at conferences}

Brandl, M. A., Schumann, M., Vidal, S. (2013) Screening of repellent substances against western corn rootworm larvae. DGaaE, Entomologentagung, Göttingen, Germany.

Brandl, M. A., Schumann, M., Przyklenk, M., Vemmer, M, Patel, A., Vidal, S. (2014) An „Attact \& Kill“-approach against wireworms (Agriotes spp.) in corn. $25^{\text {th }}$ IWGO Conference \& 4th International conference on Diabrotica Genetics, Chicago, USA.

Brandl, M. A., Schumann, M., Przyklenk, M., Patel, A., Vidal, S. (2014) Screening unterschiedlicher Pilzformulierungen (Metarhizium brunneum) zur Bekämpfung der Larven des westlichen Maiswurzerlbohrers (Diabrotica virgifera virgifera). DPG-Tagung, Freiburg, Germany.

Brandl, M. A., Claus, H., Schumann, M., Przyklenk, Peters, A., M., Patel, A., Vidal, S. (2015) Attract-and-Kill formulations against wireworms (Agriotes spp.) in maize. INBIOSOIL Symposium 2015, "Strategies for a sustainable agriculture in Europe: innovative biological options”, Göttingen, Germany. 


\section{Acknowledgements / Danksagung}

Herrn Prof. Dr. Stefan Vidal danke ich für die Vergabe dieses interessanten und praxisnahen Themas, Freiraum für eigene Ideen, wertvolle Gedanken, Möglichkeit an Konferenzen teilzunehmen sowie Durchsicht der Manuskripte.

Herrn Dr. Mario Schumann danke ich für die gute und wertvolle Zusammenarbeit, die vielen anregenden Diskussionen im Büro, Ideen und Hilfestellungen, die Geduld bei der Korrekturlesung, und das 'Schwitzen' auf dem Acker.

Dank gilt dem gesamten Bielefelder Team für die gute Zusammenarbeit. Ich danke im Besonderen Herrn Michael Przyklenk für die Produktion der Pilz- und $\mathrm{CO}_{2}$ Kapseln 'on time', die belebenden Diskussionen und Konferenzzeiten. Herrn Prof. Dr. Anant Patel möchte ich zudem für die bereitwillige Übernahme des Korreferats danken.

Herrn Prof. Dr. Stefan Schütz danke ich für die Mitgliedschaft im Prüfungskomitee.

Mein Dank gilt der Bodenschädlingstruppe mit Frau Frauke Mävers und Frau Bianca Tappe. Frau Bianca Tappe möchte ich außerdem für Ihre unermüdliche Hilfe, Gespräche und ihre auflockernde Art danken.

Ich danke allen Auszubildenden, die mir bei den Versuchsanstellungen geholfen haben - Martina, Marie, Magdalena und Marian; sowie allen Hiwis - Bernhard Liese, Florian Diekers, Christian Bödeker und im Besonderen Thies Fellenberg (für drei Versuchsjahre in Folge - Respekt).

Herrn Wilfried Dreyer danke ich für die gute Zusammenarbeit bei der Durchführung der Feldversuche.

Ich danke allen Landwirten die Ihre Flächen zur Verfügung gestellt haben.

Ich danke Herrn Dr. Christian Ahl für die Durchführung der Bodenanalysen.

Meinen Kollegen der Agrarentomologie danke ich für die gute und freundliche Zusammenarbeit, sowie den vielen Stunden bei (zu starkem) Kaffee.

Ein herzlicher Dank gilt dem Technikerteam: Frank Gremmes, Mark Fiebrich, Hubertus Reintke und Maik Knobel.

Ich danke meiner Familie und Freunden, besonders meiner wunderbaren Ehefrau, die mich stets unterstützt und bei Bedarf motiviert hat! Danke! 


\section{E r k I ärunge n}

1. Hiermit erkläre ich, dass diese Arbeit weder in gleicher noch in ähnlicher Form bereits anderen Prüfungsbehörden vorgelegen hat.

Weiter erkläre ich, dass ich mich an keiner anderen Hochschule um einen Doktorgrad beworben habe.

Göttingen, den

(Unterschrift)

2. Hiermit erkläre ich eidesstattlich, dass diese Dissertation selbständig und ohne unerlaubte Hilfe angefertigt wurde.

Göttingen, den

(Unterschrift) 